RD/RA Guidance

Rev. 1

$10 / 13 / 93$

\title{
REMEDIAL DESIGN AND REMEDIAL ACTION GUIDANCE FOR THE IDAHO NATIONAL ENGINEERING LABORATORY
}

\section{DISCLAIMER}

This report was prepared as an account of work sponsored by an agency of the United States Government. Neither the United States Government nor any agency thereof, nor any of their employees, makes any warranty, express or implied, or assumes any legal liability or responsibility for the accuracy, completeness, or usefulness of any information, apparatus, product, or process disclosed, or represents that its use would not infringe privately owned rights. Reference herein to any specific commercial product, process, or service by trade name, trademark, manufacturer, or otherwise does not necessarily constitute or imply its endorsement, recommendation, or favoring by the United States Government or any agency thereof. The views and opinions of authors expressed herein do not necessarily state or reflect those of the United States Government or any agency thereof.

\section{Developed By}

RUST Geotech Inc.

Morrison Knudsen-Ferguson of Idaho Company

U.S. Department of Energy, Idaho Operations Office

U.S. Environmental Protection Agency Region X and

State of Idaho, Department of Health and Welfare

Under DOE Contract Numbers:

RUST Geotech Inc., DE-AC04-86ID12584

MK-FIC, DE-AC07-89ID12721

DSTRIUUTION OF THIS DOCUNENT IS UNUMTED WN 


\section{DISCLAMMIER}

Portions of this document may be illegible in electronic image produets. Images are produced from the best available original document. 
RD/RA Guidance

Rev. 1

$10 / 13 / 93$

\section{CONTENTS}

Acronyms $\mathrm{v}$

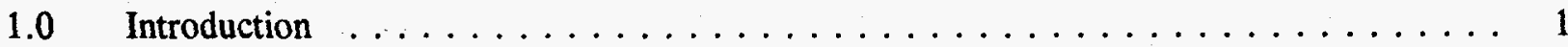

$1.1 \quad$ Purpose and Scope of Guidance $\ldots \ldots \ldots \ldots \ldots \ldots \ldots \ldots$

1.2 Definition of Terms . . . . . . . . . . . . . . . . . . . . 1

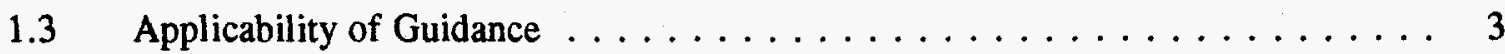

$2.0 \quad$ Remedial Design/Remedial Action Strategy $\ldots \ldots \ldots \ldots \ldots \ldots \ldots \ldots \ldots$

2.1 Introduction . . . . . . . . . . . . . . . . . . . . 4

2.2 Remedial Design/Remedial Action Process . . . . . . . . . . . . . 4

2.3 Waste Area Group Manager Roles and Responsibilities . . . . . . . . . . . . 7

$2.4 \quad$ Project Scoping . . . . . . . . . . . . . . . . . . . . 7

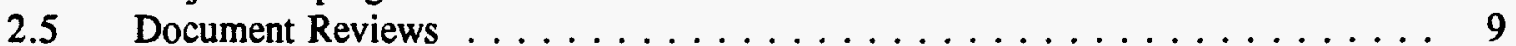

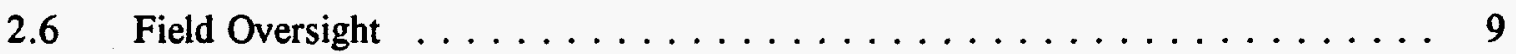

2.7 Disposition of Changed Conditions $\ldots \ldots \ldots \ldots \ldots \ldots \ldots$

3.0 Remedial Design/Remedial Action Scope of Work and Remedial

Design Work Plan . . . . . . . . . . . . . . . . . . . . . . . 12

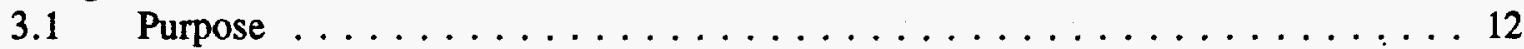

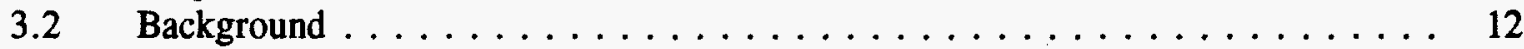

3.3 Elements of Remedial Design/Remedial Action Scope of Work . . . . . . . . . 12

3.3.1 Strategy for RD/RA and Rationale for Remedial Work Element

Breakout ........................... 13

3.3.2 Critical Path Method Schedule . . . . . . . . . . . . . . . 13

3.3.3 Plans to Expedite RD/RA . . . . . . . . . . . . . . . . . 13

3.3.4 Unresolved Significant Issues $\ldots \ldots \ldots \ldots \ldots \ldots \ldots \ldots$

3.3.5 RD/RA Elements of the Community Relations Plan $\ldots \ldots \ldots \ldots \ldots 14$

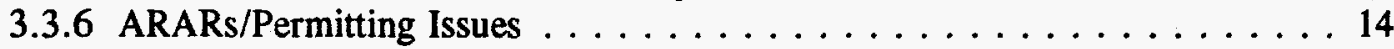

3.3.7 Identify Scope and Schedule for Deliverable Documents . . . . . . . . 15

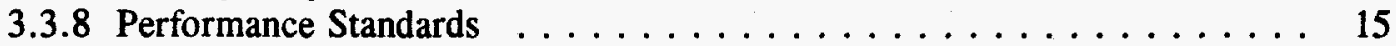

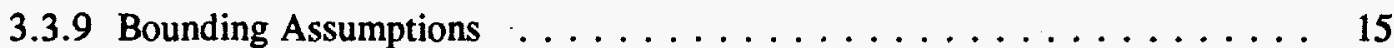

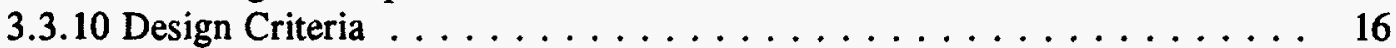

3.3.11 Plans for Disposition of Changed Conditions . . . . . . . . . . . 16

3.4.12 RD Cost Estimate . . . . . . . . . . . . . . . . . . 16

3.4.13 Correlations Between Plans and Specifications . . . . . . . . . . 16

3.4.14 Design Approval Procedures and Requirements . . . . . . . . . . 17

3.4 Elements of Remedial Design Work Plan . . . . . . . . . . . . . 17 
RD/RA Guidance

Rev. 1

$10 / 13 / 93$

Contents (continued)

Page

3.5 Remedial Design/Remedial Action Scope of Work and Remedial Design Work

Plan Process . . . . . . . . . . . . . . . . . . . . 17

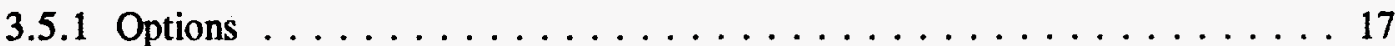

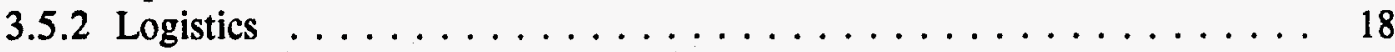

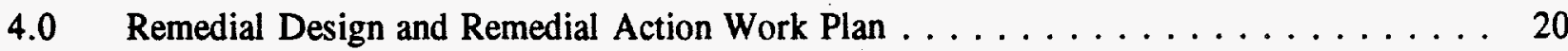

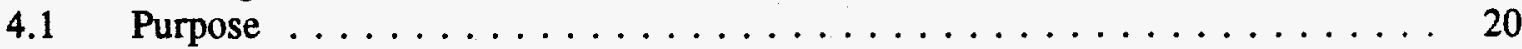

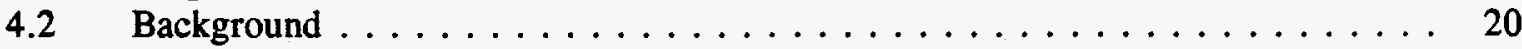

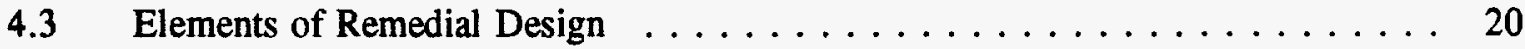

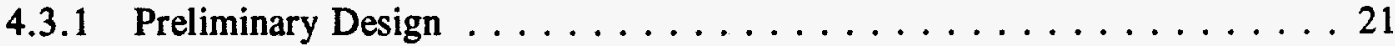

4.3.2 Draft Remedial Design . . . . . . . . . . . . . . . . . 21

4.4 Elements of Remedial Action Work Plan . . . . . . . . . . . . . . . 23

4.5 Remedial Design and Remedial Action Work Plan Process . . . . . . . . . . 23

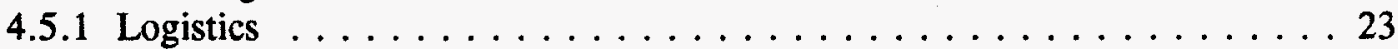

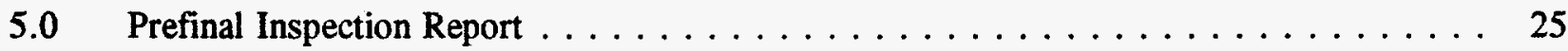

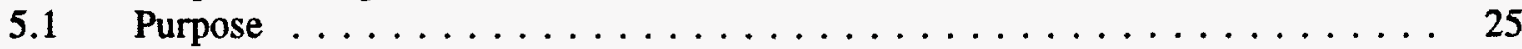

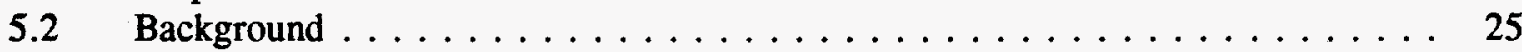

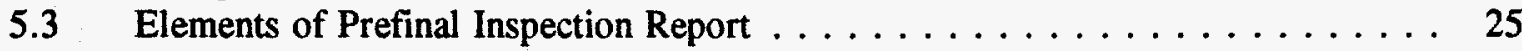

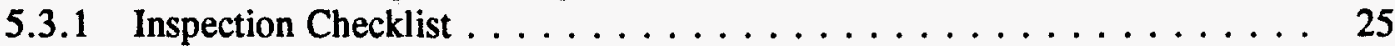

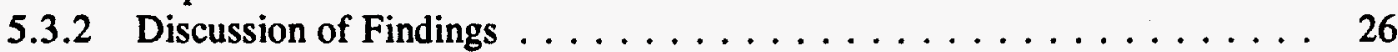

5.3 .3 Corrective Action Plans . . . . . . . . . . . . . . . . . 26

5.3.4 Operation and Maintenance Plan Update . . . . . . . . . . . . 26

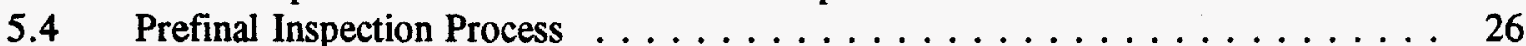

5.4 .1 Logistics ........................... 26

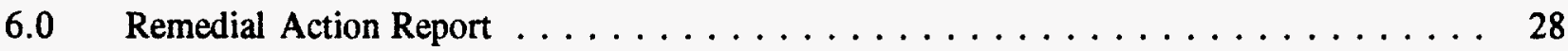

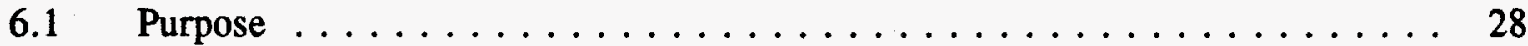

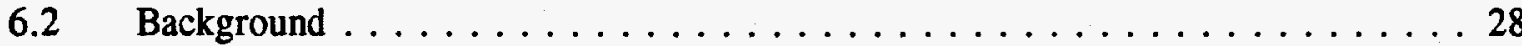

$6.3 \quad$ Elements of Remedial Action Report $\ldots \ldots \ldots \ldots \ldots \ldots$

6.3 .1 Outstanding Items . . . . . . . . . . . . . . . . 28

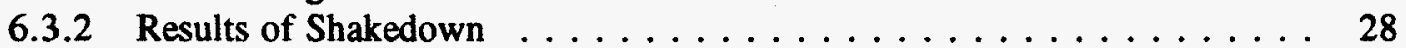

6.3.3 Certification that Remedy is Operational and Functional . . . . . . . . 28

6.3 .4 Operation and Maintenance Update . . . . . . . . . . . . . . 29

6.3 .5 Results of Final Inspection . . . . . . . . . . . . . . 29

6.3.6 Decontamination \& Decommissioning (D\&D) Plan . . . . . . . . . 29

6.3 .7 Deletion From the NPL . . . . . . . . . . . . . . . 29

6.3 .8 Five-Year Review Process . . . . . . . . . . . . . . . . . . . . 29

$6.4 \quad$ Remedial Action Report Process . . . . . . . . . . . . . . . . . . . . 29

6.4 .1 Logistics . . . . . . . . . . . . . . . . . . . . . . . 29 
RD/RA Guidance

Rev. 1

$10 / 13 / 93$

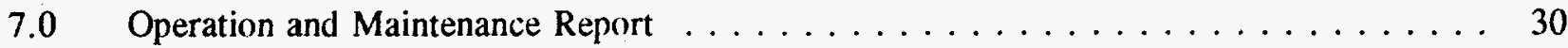

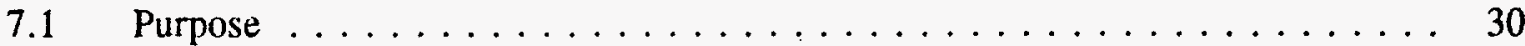

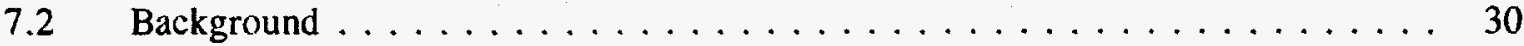

$7.3 \quad$ Elements of Operation and Maintenance Report $\ldots \ldots \ldots \ldots \ldots \ldots$

7.3.1 Description of Operation and Maintenance . . . . . . . . . . . . 30

7.3 .2 Site Monitoring ....................... 30

7.3.3 Verification that Remedy Meets Performance Criteria . . . . . . . . . 31

7.3 .4 Future O\&M Requirements . . . . . . . . . . . . . . . 31

7.4 Operation and Maintenance Report Process $\ldots \ldots \ldots \ldots \ldots \ldots \ldots \ldots$

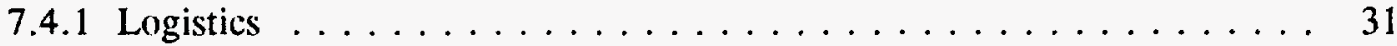

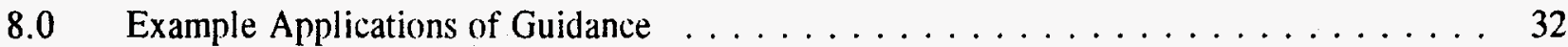

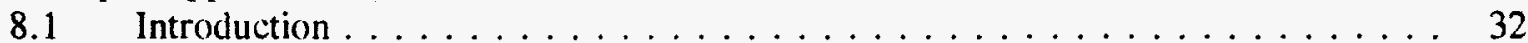

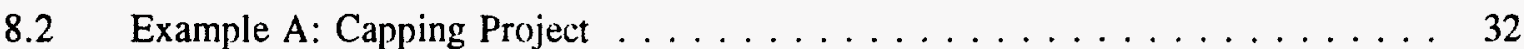

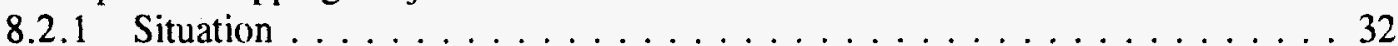

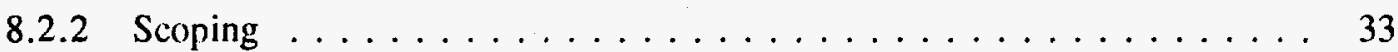

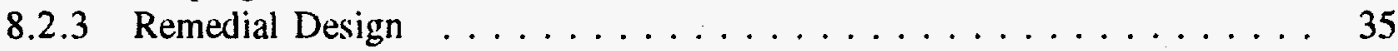

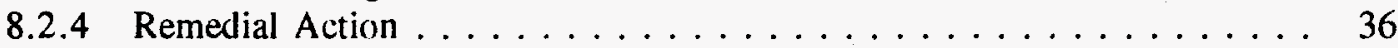

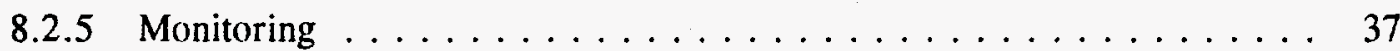

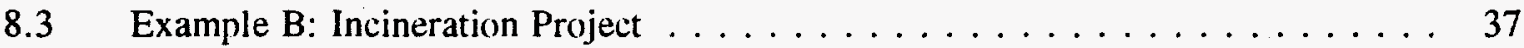

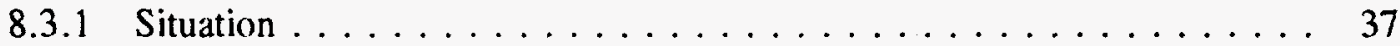

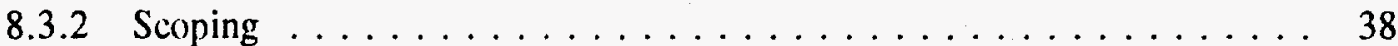

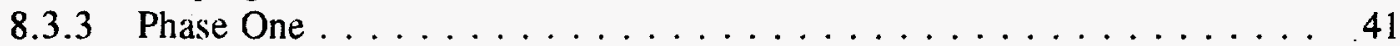

8.3 .4 Phase Two ....................... 43

8.3.5 Operation and Maintenance ................... 44

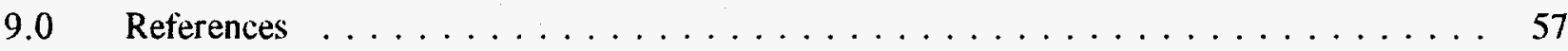

Appendix A

Excerpts from the Idaho National Engineering Laboratory . . . . . . . . . . . 58

Federal Facility Agreement and Consent Order Action Plan Relevant

to the Remedial Design/Remedial Action Process

Appendix B

List of Applicable U.S. Department of Energy Orders . . . . . . . . . . . . . . 62

Appendix C

EPA Engineering Issue, "Data Gaps in Remedial Design" . . . . . . . . . . . . . . 64

Appendix D

RD/RA Guidance Comments and Comment Resolution 


\section{FIGURES}

Figure 2-1

Figure 8-1

Figure 8-2
Remedial Design/Remedial Action Flow Chart $\ldots \ldots \ldots \ldots$

Critical Path Schedule for Capping Project $\ldots \ldots \ldots 45$

Critical Path Schedule for Incineration Project $\ldots \ldots \ldots$. . . . . . . 49 


\section{Acronyms}

ARAR

ASA

BDAT

BRA

CERCLA

CPM

CRP

CX

D\&D

DOE

DOE-ID

DRC

EA

EPA

ERWM

ESD

FFA/CO

FSAR

FS

HEPA

H\&S

HIPT

IDAPA

IDHW

IH

INEL

M\&O

MS\&QM

MK-FIC

NCP

NEC

NEPA

NPL

O\&M

OMP

OSHA

OSWER

OU

POHC

PSAR

QAPjP

QPP
Applicable or Relevant and Appropriate Requirement

Auditable Safety Analysis

Best Demonstrated Available Technology

Baseline Risk Assessment

Comprehensive Environmental Response, Compensation, and Liability Act

Critical Path Method

Community Relations Plan

Categorical Exclusion

Decontamination and Decommissioning

U.S. Department of Energy

U.S. Department of Energy, Idaho Operations Office

Dispute Resolution Committee

Environmental Assessment

U.S. Environmental Protection Agency, Region X

Environmental Restoration Waste Management

Explanation of Significant Differences

Federal Facility Agreement and Consent Order

Final Safety Analysis Report

Feasibility Study

High Efficiency Particulate Air

Health and Safety

Health Physics Technician

Idaho Administrative Procedures Act

Idaho Department of Health and Welfare

Industrial Hygienist

Idaho National Engineering Laboratory

Maintenance and Operation

Managing for Safety and Quality Manual

Morrison Knudsen-Ferguson of Idaho Company

National Contingency Plan

National Electric Code

National Environmental Policy Act

National Priority List

Operation and Maintenance

Occupational Medical Program

Occupational Safety and Health Administration

Office of Solid Waste and Emergency Response

Operable Unit

Principal Organic Hazardous Constituent

Preliminary Safety Analysis Report

Quality Assurance Project Plan

Quality Program Plan 
Acronyms (continued)

$\begin{array}{ll}\text { RA } & \text { Remedial Action } \\ \text { RAO } & \text { Remedial Action Objective } \\ \text { RAWP } & \text { Remedial Action Work Plan } \\ \text { RCRA } & \text { Resource Conservation and Recovery Act } \\ \text { RD } & \text { Remedial Design } \\ \text { RD/RA } & \text { Remedial Design/Remedial Action } \\ \text { RFP } & \text { Request for Proposal } \\ \text { RI } & \text { Remedial Investigation } \\ \text { RIFS } & \text { Remedial Investigation/Feasibility Study } \\ \text { ROD } & \text { Record of Decision } \\ \text { SACM } & \text { Superfund Accelerate Cleanup Model } \\ \text { SAFER } & \text { Streamlined Approach for Environmental Restoration } \\ \text { SAP } & \text { Sampling and Analysis Plan } \\ \text { SAR } & \text { Safety Analysis Report } \\ \text { SEB } & \text { Source Evaluation Board } \\ \text { SOW } & \text { Scope of Work } \\ \text { TBC } & \text { To Be Considered } \\ \text { TS } & \text { Treatability Study } \\ \text { UMTRA } & \text { Uranium Mill Tailings Remedial Action } \\ \text { WAG } & \text { Waste Area Group }\end{array}$




\subsection{Introduction}

\subsection{Purpose and Scope of Guidance}

The U.S. Department of Energy, Idaho Operations Office (DOE-ID), the U.S. Environmental Protection Agency, Region X (EPA), and the Idaho Department of Health and Welfare (IDHW) have developed this guidance on the remedial design and remedial action (RD/RA) process. This guidance is applicable to activities conducted under the Idaho National Engineering Laboratory (INEL) Federal Facility Agreement and Consent Order (FFA/CO) and Action Plan. The INEL FFA/CO and Action Plan provides the framework for performing environmental restoration according to the Comprehensive Environmental Response, Compensation, and Liability Act (CERCLA). The guidance is intended for use by the DOE-ID, the EPA, and the IDHW Waste Area Group (WAG) managers and others involved in the planning and implementation of CERCLA environmental restoration activities.

The scope of the guidance includes the RD/RA strategy for INEL environmental restoration projects and the approach to development and review of RD/RA documentation. Chapter 2 discusses the general process, roles and responsibilities, and other elements that define the RD/RA strategy. Chapters 3 through 7 describe the RD/RA documents identified in the FFA/CO and Action Plan. Chapter 8 provides examples of how this guidance can be applied to restoration projects. Appendices are included that provide excerpts from the FFA/CO pertinent to RD/RA (Appendix A), a list of applicable U.S. Department of Energy (DOE) orders (Appendix B), and an EPA Engineering Issue, "Data Gaps in Remedial Design" (Appendix C).

\subsection{Definition of Terms}

For the purpose of this guidance, the following terms are defined:

Baseline - A quantitative expression of projected technical, schedule and cost base, or standard for measurement during the performance of an effort; the established plan against which the status of resources and the objectives of a project can be measured.

Bounding assumptions - Assumed conditions that define and constrain the range of possible outcomes of the project. Examples of bounding assumptions include contaminant concentration ranges, design input values, equipment operation ranges, and worker safety bases.

Conceptual design - Those efforts to develop a project scope, schedule, and cost to satisfy the program needs, ensure project feasibility, and attain performance standards. This includes the development of project criteria and design parameters and the identification of requirements necessary to describe the project.

Design criteria - Design standards and requirements established from laws, codes, guidance, and best management practices. Examples of design criteria include building codes, DOE orders, and industry standards. 
Inspection - Examination or measurement to verify whether an item or activity conforms to specified requirements.

Operation and maintenance (O\&M) - The period of the project between remedial action and project closeout.

Performance standard - Standards based on remedial action objectives (RAOs) identified in the Record of Decision (ROD), such as cleanup criteria.

Project - A unique major effort within a program that has firmly scheduled beginning, intermediate, and ending date milestones. For RD/RA, it is the remedy described in the ROD for a site or operable unit (OU) identified in the FFA/CO.

Remedial action (RA) - The construction activities required to remove or reduce the contamination hazard from sites contaminated with radioactive, hazardous, or mixed wastes. RA will be the period between remedial design (RD) and O\&M, which includes construction and the demonstration of system capabilities.

Remedial design - The period between the signature of the ROD and commencement of RA activities, during which project engineering design and planning are completed and approved.

Remedial work element - A portion of a project that has been broken out through phasing. This may be a separate contract package for procurement of RD work elements or RA work elements.

Shakedown - The period between construction of a work element and operational certification through completion of all required inspections and trial tests. An example is the inspection and "cold" and "hot" testing before acceptance by DOE-ID, EPA, and IDHW for operation of an equipment component or treatment system.

Title I (preliminary design) - Continued design effort that utilizes the conceptual design and project design criteria as a basis for project development. Tasks include preparation of preliminary planning and engineering studies, preliminary drawings and outline specifications, life-cycle cost analysis, preliminary cost estimates, and scheduling for project completion. Preliminary design provides identification of long-lead procurement items and analysis of risks associated with continued project development.

Title II (detailed design) - Continued development of the project that is based on approved preliminary design (Title I). Detailed design includes any revisions required of the Title I effort; preparation of final working drawings, specifications, bidding documents, cost estimates; and development of firm construction and procurement schedules.

Title III (construction inspection) - Those activities required to ensure that the project is constructed in accordance with the plans and specifications and that the quality of the materials and workmanship is consistent with the requirements of the project. 


\subsection{Applicability of Guidance}

This guidance is intended to augment the description of the RD/RA process provided in the FFA/CO and Action Plan. Pertinent sections of the FFA/CO and Action Plan are annexed to the guidance in Appendix A. Users of the guidance should refer to the FFA/CO and Action Plan for specific requirements for $\mathrm{RD} / \mathrm{RA}$ implementation. The guidance is specific to CERCLA remedial actions and does not cover removal actions, emergency response actions, and actions undertaken as normal "housekeeping" by DOE-ID. However, many elements of RD/RA strategies in the guidance are applicable to projects other than remedial actions that may be performed at the INEL.

This guidance provides an approach to project planning and implementation but is not intended to be used as a "cookbook." DOE-ID, EPA, and IDHW recognize that each project is unique and projectspecific strategies must be developed accordingly. It is anticipated that the approach provided in the guidance will form a standard method; however, the strategy for each project will be negotiated among the DOE-ID, the EPA, and the IDHW WAG managers through project scoping. This guidance is not intended to cause the replanning of ongoing projects, but the techniques described in the guidance should be incorporated in future planning or implementation of these projects where feasible. 


\subsection{Remedial Design/Remedial Action Strategy}

\subsection{Introduction}

Development of an effective management strategy is critical to successful implementation of RD/RA projects. Formulation of the RD/RA strategy is based on an understanding of the process and the roles and responsibilities of key participants. In addition, site-specific factors are considered in development of the strategy.

This chapter describes the RD/RA process and roles and responsibilities of the WAG managers for implementing the INEL FFA/CO and Action Plan. In the spirit of the approach identified in the FFA/CO, the WAG managers will develop strategies that emphasize

- Working as a team to implement the objectives of the FFA/CO, e.g., to protect human health and the environment

- Communication, exchange of information, and participation of the three parties in actions

- Expediting cleanup to the extent possible through a "bias for action" position as described in the FFA/CO.

\subsection{Remedial Design/Remedial Action Process}

RD/RA includes the development of the actual design of the selected remedy and implementation of the remedy through construction. A period of O\&M may follow the RA activities. Guidance has been developed and published by the EPA on the RD/RA process (see References, Chapter 9). However, this guidance has limited applicability to implementation of the RD/RA process at Federal facilities and particularly to some of the unique restoration projects that may be implemented at the INEL.

Pertinent sections of the FFA/CO and Action Plan provide the requirements for RD/RA implementation specific to the INEL environmental restoration program. Figure 2-1 provides a flowchart of the RD/RA documentation process. The flow chart is based on the overall contracting strategy employed at the INEL, where the maintenance and operation (M\&O) contractor(s) for the facility perform the pre-ROD investigation, study, and decision phases of the CERCLA process. A separate RD/RA contractor performs the RD/RA phase. Once sites have completed restoration activities, the M\&O contractor(s) completes final closeout documentation for use in the deletion of the site from the National Priority List (NPL). Appropriate levels of involvement by contractors in phases other than those for which they are in charge is necessary to ensure smooth transition periods between contractors. A description of the major phases in the RD/RA process follows:

1. RD/RA Scoping - The scoping phase should begin during the remedial investigation/feasibility study (RI/FS) or the planning stage of an interim action. This scoping differs from scoping associated with development of RI/FS or interim action documentation (such as the RI/FS Report, Proposed Plan, and ROD). The purpose of RD/RA scoping is to achieve a smooth transition from pre-ROD completion activities to post-ROD activities and to ensure that RD/RA aspects of the project have been considered before the ROD and adequately planned for in pre- 
ROD documentation. The first step of RD/RA scoping is involvement of the RD/RA contractor during the RI/FS or interim action. Typically this involvement would occur through informal interaction between contractors and the document review and comment process associated with the RI/FS. The RD/RA contractor provides input on design data needs, treatability study needs, cost estimates, and the implementability and short-term effectiveness of remedies under consideration. RD/RA scoping is performed in parallel with the pre-ROD completion activities and concludes with the development of the RD/RA Scope of Work (SOW) and, if applicable, the RD Work Plan. These documents define the plan for the remedial design phase. Scoping is described further in Section 2.4.

2. Remedial Design - The RD phase includes development of the design documents, procurement documents, and project management documents for the project. RD includes drawings, specifications, and procedures for construction and operation of the remedy. The Remedial Action Work Plan (RAWP) provides the management plan including the schedule and cost estimate for RA. The primary objective of the RD phase is to establish the plan for the RA phase.

3. Remedial Action - The RA phase includes construction and start-up/shakedown of the facilities and systems needed to implement the remedy. For simple remedies or those requiring only a short time period to implement, RA also may include all actions needed to implement the remedy. Major documents developed from this phase include the Prefinal Inspection Report and RA Report. The Prefinal Inspection Report documents the prefinal inspection of facility and systems construction. The RA Report documents activities performed during RA.

4. Operation and Maintenance - For those projects that require a separate O\&M phase, O\&M will include operation and maintenance of facilities and systems constructed to implement the remedy. O\&M scoping should be performed to achieve a smooth transition from RD/RA activities to O\&M activities, which typically would involve a change of contractor. Where appropriate, at completion of O\&M, the O\&M Report is prepared to document activities performed during remedy implementation.

5. Closeout - During this phase, documentation developed during the action is archived for use in notices of completion, 5-year reviews, subsequent actions, and ultimately deletion of the site from the NPL. 


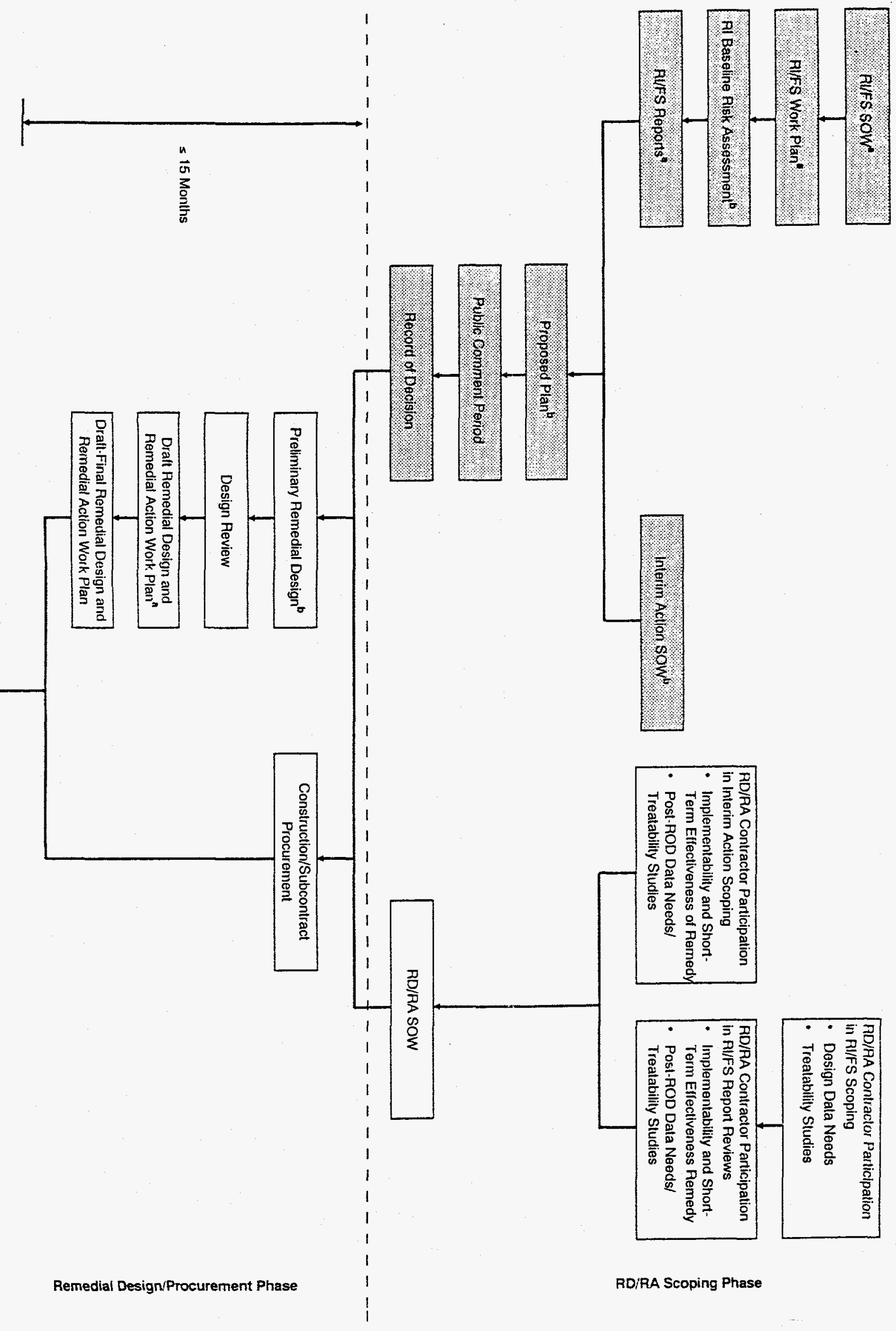



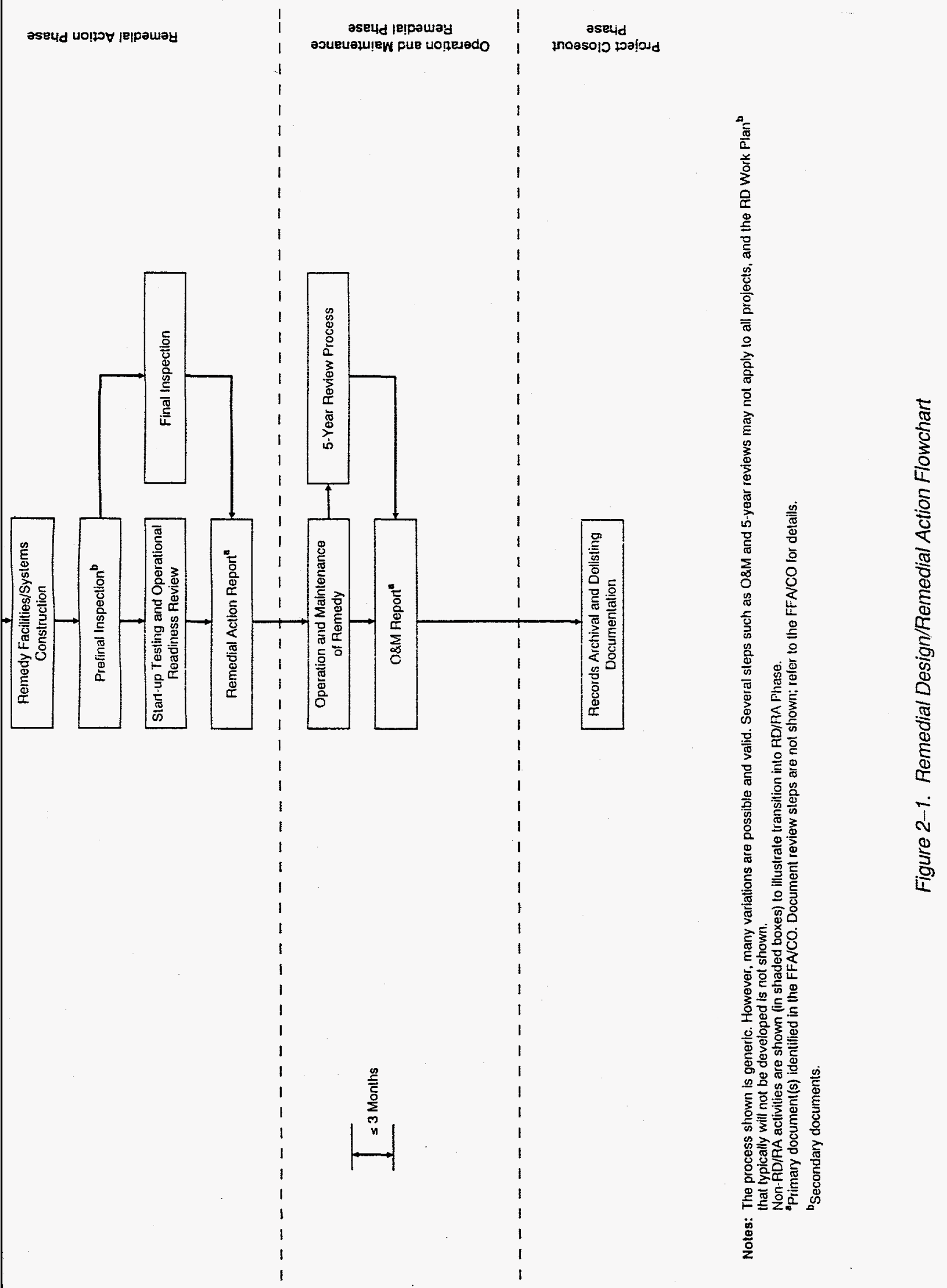


\subsection{Waste Area Group Manager Roles and Responsibilities}

This section provides a general description of the roles and responsibilities of the DOE-ID, the EPA, and the IDHW WAG managers related to RD/RA implementation. The key to success of the RD/RA process is early and continuous involvement by the DOE-ID, the EPA and the IDHW WAG managers, using a team approach.

The DOE-ID WAG manager has primary responsibility for the project implementation including management of contractors and all activities associated with execution of the project. The DOE-ID WAG manager has responsibility for meeting the requirements of the FFA/CO, project-specific RODs, and DOE-ID orders, policies, and procedures.

The EPA and the IDHW WAG managers have the responsibility to provide oversight of the project including review, comment, and consultation to ensure DOE-ID compliance with the FFA/CO and requirements of the ROD for each project.

\subsection{Project Scoping}

Involvement by the WAG managers in the RD/RA process begins during the pre-ROD completion activities (e.g., RI/FS, Proposed Plan, and ROD development). The level of involvement and effort expended in RD/RA scoping grows as the project continues and culminates with development of the RD/RA SOW. Elements of RD/RA that should be considered in scoping include

1. Feasibility Study (FS) content - The content of the FS should be reviewed from the RD/RA implementation perspective. CERCLA FSs often lack adequate consideration of remedy constructibility or implementability, design data needs, RD/RA cost estimates, and impacts based on definition of RAOs. Presumptive remedies for sites with similar characteristics should be included as part of the FS.

2. Record of Decision (ROD) content - The content of the ROD should be reviewed from the RD/RA perspective. The RAOs set forth in the ROD ultimately will determine whether the remedial action is successful, so they need to be realistic and implementable. Also, costs identified in the ROD need to include RD/RA and be an accurate assessment of costs incurred for work at a Federal facility.

3. RD/RA planning - RD/RA planning includes work element definition, identification of RD/RA documents, contracting approach, phasing, and other factors that affect the overall RD/RA management strategy. Phasing, fast-tracking, and contracting strategies are discussed in EPA guidance (EPA 1990b).

4. RD/RA data needs - A distinction must be made between data gaps and data needs. Data gaps contribute to the uncertainty of the project. Data needs are data gaps that are critical inputs to the process that must be addressed by characterization, treatability studies, or other means to successfully implement the project.

5. Performance standards - The performance standards, based on the RAOs identified in the ROD, such as cleanup criteria and compliance with applicable or relevant and appropriate requirements (ARARs), must be reviewed to identify how they will be measured and accomplished. It is critical to reach agreement among DOE-ID, EPA, and IDHW to the extent 
possible on exactly what will constitute success or failure of performance standards. Issues of concern include

- Will design criteria or performance standards be used (i.e., technology driven vs. risk based or performance standards)?

- What measurements will be used to gauge compliance with substantive requirements of ARARs?

- Will a specific contaminant concentration or range of values be used?

- What media will be measured?

- What will be the point of compliance (i.e., where will measurements be taken)?

- What is the frequency of measurement?

- What contingency plans are developed in case of noncompliance?

The WAG managers will strive to resolve these issues before the ROD and before completion of the $\mathrm{RD} / \mathrm{RA}$ SOW. However, all of these issues may not be resolvable before RD is initiated. In that case, planning for the resolution and consideration of the uncertainty associated with unresolved issues should be documented in the RD/RA SOW (see Section 3.3.4).

Document-specific scoping is also recommended at the beginning of each major RD/RA document (i.e., RD/RA SOW, RD, etc.). Document scoping is focused on reaching a consensus among the WAG managers on the scope, content, and format of each document before it is written. A suggested approach to facilitate scoping is to develop an annotated outline of the document. The outline is reviewed by the WAG managers prior to scoping meetings. During the scoping meetings, comments on the outline are resolved, providing a common understanding of the planned effort and clear guidance to the contractor on the expectations of the final product.

In addition to primary and secondary documents, the technical memorandum, or tech memo, provides interim data or information to the WAG managers between significant deliverables. The intent of a tech memo is solely to provide additional information, and it cannot be used for resolving issues. Tech memos will be used only when there is too much information or the information is too complex to handle through informal communication by the WAG managers. In some cases, tech memos can minimize the number of primary or secondary documents and ultimately reduce the project duration by minimizing review cycles.

Tech memos have no formal content requirements as identified in the FFA/CO because they are designed to be specific to the project and information being provided. The requirements for a tech memo will be established by the WAG managers in the planning document in which it is identified. 


\subsection{Document Reviews}

Each document developed in the RD/RA process establishes the foundation for subsequent planning and documentation. Document reviews also provide the primary method for EPA and IDHW oversight of the RD/RA process. As such, it is important to plan for the document review process for each project. The WAG managers must focus reviews of RD/RA documents to manage limited resources, optimize "value added" to documents, and accomplish RD/RA in a timely and cost, effective manner. To accomplish focused reviews without diminishing the quality of documentation, the following points should be considered in formulating the document review strategy for each project:

- Agency time constraints and limited resource availability do not allow for special interest area reviews on RD/RA documents. The level of review will be commensurate with the complexity of the project and should focus on factors that affect the design and implementation of a remedy. Reviewers should not expend resources commenting on differences in interpretation or presentation that do not affect the integrity of the RD/RA process.

- The DOE-ID, EPA, and IDHW WAG managers will be involved in the formulation of design criteria during scoping of the project. Preliminary meetings will help focus the WAG managers on what is important to review.

- In accordance with EPA guidance, reviewers will focus on whether the document meets the requirements of the ROD goals (EPA 1990a). This determination will be based on the following:

- Is the remedy protective of human health and the environment?

- Will the remedy comply with the ARARs identified in the ROD?

- Is the remedy consistent with RAOs?

- Reviews should verify continuity in the RA process from start to finish. Have assumptions been monitored, critical data needs resolved, objectives and performance measurements considered? Have we traded one problem for another?

- Reviews should verify consistency with the FFA/CO requirements and this guidance. Deviations from this guidance are anticipated to meet project-specific needs. However, justification should be provided and resolved between the WAG managers before changes are made.

\subsection{Field Oversight}

The DOE-ID, EPA, and IDHW WAG managers will provide field oversight during RA action projects. The level-of-effort of field oversight will be commensurate with the project complexity and, except in emergency situations, only DOE-ID shall give directions to their contractors.

Field oversight should focus on critical issues and may consist of observing sampling, obtaining splits of samples, visiting the construction site, observing start-up testing, conducting preliminary 
inspections in support of the Prefinal Inspection, and performing other activities as deemed necessary to monitor the progress of the remedy. Utilization of checklists that are jointly developed by DOE-ID, EPA, the IDHW in advance are recommended for field inspections.

The RAWP will identify the protocol and coordination requirements for site visits. EPA or IDHW field oversight of RD/RA activities should be coordinated in advance with the DOE-ID WAG manager. Issues identified during these site visits shall be raised to the DOE-ID field representative and WAG manager as soon as possible.

\subsection{Disposition of Changed Conditions}

Changes from planned conditions inevitably will occur during the execution of RD/RA. Identification and rapid disposition of significant changes is critical to successful project implementation. The WAG managers will develop plans for addressing changed conditions as part of the RD/RA strategy. Considerations in planning for changed conditions are described below:

1. Utilize planning elements of uncertainty management - Several uncertainty management models have been developed and applied to environmental restoration projects. These include the "Observation Approach" developed by the field of geotechnical engineering, the "Streamlined Approach For Environmental Restoration" (SAFER) developed by DOE-ID, and the "Superfund Accelerated Cleanup Model" (SACM) developed by the U.S. Environmental Protection Agency. These models share common elements including explicit recognition and management of uncertainty, streamlined data collection and directly linking it to decisionmaking, early convergence on a remedy, and assurance of participation and consensus of key stakeholders. Specific applications may include identification of the project hypothesis (i.e., most likely outcome of project and assumptions used to predict the outcome), contingency planning for uncertainties, monitoring for changed conditions, and implementing contingency plans if changes are encountered. Planning elements of these management approaches are applicable to most environmental restoration projects and are recommended to be considerations in developing a strategy to identify and respond to changed conditions.

2. Develop approaches to respond rapidly to change - Regardless of the type of remedy selected, rapid disposition of changes is critical to controlling costs and schedule performance of the project. Planning is recommended to minimize the number of concurrences and other actions required to resolve changed conditions when they occur. Communication methods should be established for the WAG managers to quickly resolve changed conditions and minimize project downtime.

3. Establish protocol for notification and concurrence requirements - When changed conditions are discovered by DOE-ID, EPA, or IDHW, a predetermined protocol should be followed for notification of the other agencies and, if applicable, concurrence on response actions. The protocol should identify what changed conditions require notification and when concurrence will be required. Concurrence normally will be required only for those changes that are considered significant. Changes that typically would be considered significant include

- Changes that affect RAOs of the ROD,

- Cost changes that may cause the project cost estimate provided in the ROD to increase by 50 percent or decrease by 30 percent, 
RD/RA Guidance

Rev. 1

$10 / 13 / 93$

- Changes that require modifications to documents, and

- Changes that significantly affect project schedules (i.e., impact project milestones).

4. Plan for response to discovery of dangerous/emergency conditions - Special consideration is given to the disposition of dangerous or emergency conditions. Planning for emergency events will be consistent with the facility emergency response plan and will be documented in the RAWP or O\&M Plan. If a dangerous/emergency condition is discovered that may pose "imminent and substantial endangerment to people or the environment," DOE-ID, EPA, or IDHW have the authority to stop work per FFA/CO Section 29. The following applies to work stoppage:

- Stop work notification, concurrence, and documentation requirements of FFA/CO Section 29 apply only to dangerous/emergency condition that occur pursuant to activities conducted under the FFA/CO. Other work stoppages such as the RD/RA contractor ordering a subcontractor to stop work because of nondangerous/emergency conditions normally would not require notification or concurrence unless the action constitutes a significant change as discussed in No. 3 above.

5. Follow EPA guidance for changes that affect the ROD - EPA guidance is available on the disposition of changes that affect the ROD (EPA 1989). This guidance differentiates between nonsignificant, significant, and fundamental changes. Associated responses range from

- No action

- Issuance of an Explanation of Significant Differences (ESD). (For typical changes, an ESD without public comment would be issued. For complex changes, e.g., a treatability variance, an ESD would be issued in draft form with opportunities for informal public meetings.)

- Reopening the ROD through a ROD amendment.

Examples of nonsignificant, significant, and fundamental changes are provided in the referenced guidance.

6. Consider non-CERCLA and project-specific factors - The effect of changes on nonCERCLA factors (i.e., DOE orders, National Environmental Policy Act [NEPA] compliance, etc.) must be expeditiously identified, and their potential to impact CERCLA activities adversely must be considered by DOE-ID. These factors may be the most difficult to address under changed conditions because of lengthy procedural requirements and document review cycles. Contingency planning must consider the impact of compliance with these factors. Projectspecific factors such as site conditions, operating facility requirements, and remediation subcontractor contract provisions also can limit options to respond to changed conditions and, therefore, are factored into planning.

The planning for disposition of changed conditions will be included in RD/RA documents. The RD/RA SOW will address changes that may occur during the design phase of the project. The RAWP will include planning for changes that occur during the RA phase. Activities most likely to change should be addressed in the assumptions sections of these documents. Discussion of how these elements can be incorporated in RD/RA planning documents is provided in subsequent chapters of this guidance. 


\subsection{Remedial Design/Remedial Action Scope of Work and Remedial Design Work Plan}

\subsection{Purpose}

The RD/RA SOW initiates the RD/RA process and establishes the overall strategy for managing the remedial design process through commencement of RA work elements. This document is designed to confirm any previous scoping efforts, define associated planning, and establish enforceable deadlines and target dates for RD. Additionally, the RD/RA SOW will identify design data needs that continue to exist at the post-ROD stage and the planned method and schedule for obtaining the required data.

Typically, the RD Work Plan will not be necessary. The required information, if available, will be incorporated into the RD/RA SOW. In the event that all of the design phase planning cannot be completed and presented in the RD/RA SOW, an RD Work Plan will be produced and submitted as a separate document or perhaps submitted as part of the conceptual design document.

Part 12.2 of the FFA/CO states that DOE-ID will, within 21 days of issuance of the ROD, propose target dates and deadlines for completion of post-ROD documents. This requirement will be met for the RD phase through the submittal of the RD/RA SOW by DOE-ID to EPA and IDHW.

\subsection{Background}

- General guidance is identified in the FFA/CO Action Plan Section 2.11, "RD/RA Scoping Process," and Section 2.12, "Remedial Design Process."

- EPA guidance is available for many elements of the RD/RA SOW and RD Work Plan (EPA 1986 and EPA 1990a). However, this guidance has limited applicability to Federal facilities remediation projects.

- The FFA/CO Action Plan does not define the RD/RA SOW as either a primary or secondary document, however, it is required and is subject to dispute resolution. The RD Work Plan is identified as a secondary document.

\subsection{Elements of Remedial Design/Remedial Action Scope of Work}

The FFA/CO Action Plan identifies the minimum elements for the RD/RA SOW. Because this guidance advocates the elimination of the RD Work Plan for most projects, significant elements identified in the FFA/CO Action Plan for the RD Work Plan (see Appendix A) have been incorporated into the elements identified in this guidance as sections of the RD/RA SOW.

The emphasis placed on elements of the RD/RA SOW identified in this section will vary based on the specifics of the project. For example, the RD/RA SOW for a simple, straight forward project may contain little or no discussion of some of the elements identified. In contrast a complex project may warrant detailed discussion of each element in turn. 


\subsubsection{Strategy for Remedial Design and Remedial Action and Rationale for Remedial Work Element Breakout}

The RD/RA strategy will include a systematic analysis of the major management considerations required to achieve the goals of the ROD in a timely manner. The consideration of any remaining design data needs and plans to fill these needs will be a part of the strategy.

Scoping of work elements that constitute the RD and RA is an integral part of the strategy. One of the first items to be evaluated in the strategy is the potential and rationale for phasing the project (EPA 1990b). Any plans for phasing of the project should be defined in this section of the RD/RA SOW.

Typically, the introductory section of the RD/RA SOW includes a description of the planned action. This is an appropriate place to include a summary of the RD/RA strategy and work element breakout.

\subsubsection{Critical Path Method Schedule and Milestone List}

The Critical Path Method (CPM) schedule, based on enforceable milestones, will identify all work elements through RA commencement and show dependencies which define the critical path.

Significant to this effort is an agreement on what constitutes meeting the statutory requirement to commence substantial continuous physical on-site remedial action within 15 months of issuance of a ROD.

An enforceable milestone list also should be provided as part of this task. The milestone list will include only those deliverables, such as submittal of primary documents, for which the agencies agree will be enforceable and subject to dispute resolution pursuant to the provisions of the FFA/CO.

\subsubsection{Plans to Expedite Remedial Design and Remedial Action}

Most projects can be streamlined to expedite their schedules. If time is a constraint, schedules should be reviewed to determine what standard tasks can be eliminated or shortened. This section of the RD/RA SOW will discuss the methods planned to expedite RD/RA, including documentation development, contracting strategy, phasing, or other methods employed. Where appropriate, the WAG managers should consider alternate review cycles for RD/RA documents as a means to expedite the schedule.

A working schedule should be provided as part of this task. This schedule is based on the threeagency commitment to review time reductions according to their resource availability. A working schedule is expected for all projects in accordance with the FFA/CO "bias for action" philosophy and the desire to avoid working against the enforceable schedule with greater risk of dispute/stipulated penalties.

\subsubsection{Unresolved Significant Issues}

Significant issues that remain to be resolved or that require further analysis should be identified and descirbed. A plan to resolve these issues, which includes significance of issue, actions planned to resolve issues, schedule for actions, and uncertainty management approach as discussed in Section 2.7 , should be an integral part of the RD/RA SOW. 


\subsubsection{Remedial Design and Remedial Action Elements of the Community Relations Plan}

The requirements for RD/RA elements of the Community Relations Plan (CRP) are found in Part 300.435 (c) of the National Contingency Plan (NCP).

Prior to the initiation of RD, the CRP shall be reviewed to determine the need for updating to address any new community concerns anticipated to arise during $R D$ and $R A$.

After the completion of the final engineering design, the DOE-ID shall issue a fact sheet and provide, as appropriate, a public briefing prior to the initiation of the RA. An article in the INEL Reporter could serve this purpose, however, in some cases a more detailed presentation in a fact sheet dedicated to the project may be warranted.

\subsubsection{Applicable or Relevant and Appropriate Requirements/ To Be Considereds/Permitting Issues}

This section provides a preliminary identification of how compliance will be achieved with the ARARs, to be considered (TBCs), and substantive permit requirements with for the project. This section includes

- ARARs/TBCs established in the ROD. This should be a reiteration of the ARARs/TBCs specified in the Statutory Determinations section of the ROD. Include any helpful explanation from the Selected Remedy section if necessary.

- What will constitute compliance with ARARs. Parameters that will demonstrate compliance with ARARs should be defined as explicitly as possible in the RD/RA SOW. It should be recognized, however, that these parameters will be refined as the design progresses.

- Identification of any permits that would otherwise be required for on-site remedial actions together with a description of the standards, requirements, criterias, or limitations that would have had to have been met to obtain such permits and how the response action will meet these standards (as required by Section 7.7 of the FFA/CO). A table may be appropriate to list these permits and describe associated substantive requirements.

- Identification of any permits that will be required to the extent the remedy involves off-site actions (e.g., treatment, storage, or disposal), the anticipated requirements of such permits, the schedule for obtaining such permits, the permitting agency, etc.

- Identification of RD/RA changes that trigger new or different ARARs/TBCs (see discussion below).

Because ARARs are "frozen" at the time that the ROD is signed, in the absence of significant design changes, RD/RA activities do not need to accommodate newly promulgated ARARs. However, because the 5-year review process involves an evaluation as to whether the selected remedy remains "protective," in light of new standards, DOE-ID will evaluate, on a case-by-case basis, significant new requirements to ensure that the selected remedy does in fact, remain protective. 
RD/RA Guidance

Rev. 1

$10 / 13 / 93$

Post-ROD changes in RD/RA activities will be handled in accordance with EPA's Guidance on

Preparing Superfund Decision Documents, OSWER Directive 9355.3.02, July 1989. Throughout the $\mathrm{RD} / \mathrm{RA}$ process, additional comments or information may be submitted from regulatory agencies or the general public or be generated by DOE through the value engineering process, additional site investigations, or sampling activity. Such comments or information may be relevant to ARARs, TBCs, and permitting issues. These comments or additional information will be analyzed in accordance with the EPA guidance referenced above to determine whether they should be "considered" and formally addressed. There is a four-part standard for determining whether additional comments or information should be "considered": The comments or additional information (1) are "significant," (2) are not contained elsewhere in the administrative record file, (3) could not have been submitted during official public comment period, and (4) support the need to significantly alter the response action. DOE's analysis will focus on whether the comments or additional information generated during RD/RA would cause the agencies to initiate a change to the remedy. Such a change may be (1) nonsignificant (documented in the post-decision document file but not the administrative record file), (2) significant (documented in an ESD that is placed in the administrative record and is distributed for public notice, or (3) fundamental (requires a revised proposed plan for public comment and a ROD amendment).

Particularly during the RD/RA engineering process, nonsignificant (i.e., minor) changes often occur as a result of conducting the value engineering process, which may cause modifications to functional specifications of the remedy to optimize performance and minimize costs. This could affect the type of materials, equipment, facilities, services, and supplies used to implement the remedy. It could also result in refinements to cost and time estimates for implementing the remedy or an expansion to the original boundaries of a site to address the extent of contamination. As long as these changes do not significantly affect the scope, performance, or cost of a remedy, they are considered to be minor, or nonsignificant, and do not require preparation of an ESD or a ROD amendment. They will, however, be documented in the post-decision document file (equivalent to the RD/RA case file) but not in the administrative record file for the ROD. DOE also may choose to prepare an RD Fact Sheet to document nonsignificant changes for public dissemination.

\subsubsection{Identification of Scope and Schedule for Deliverable Documents}

Identification of the content and deadlines for primary documents, secondary documents, and tech memos will be part of the scoping process. Two primary documents are required by Section 8.5 of the FFA/CO: the RD and the RA Work Plan (or a combination, see Section 4.0 of Guidance). It is not possible to define a single set of secondary documents or tech memos that will be applicable to all projects. This section will be used to establish those documents/memorandums associated with the $\mathrm{RD}$ phase and to target schedules for each.

\subsubsection{Performance Standards}

The cleanup criteria (action levels and cleanup standards) and measurement methods for meeting RAOs established in the ROD (see Section 2.4) should be identified. The measurement methods will be identified as precisely as possible, but given the early stage of projects, it may only be possible to identify them conceptually.

\subsubsection{Bounding Assumptions}

The limiting factors and conditions under which the RD/RA activities will be performed should be identified, these may include but are not limited to 
- Location and/or space limitations

- Weather

- Contaminant types and concentration ranges

- Available service limitations such as electrical power

- Waste volume estimates

- Worker safety basis and requirements

- Bounding requirements of non-CERCLA factors (i.e., bounding NEPA and Safety Analysis Report (SAR) criteria)

- Limitations of adjacent operating facilities or waste sites.

\subsubsection{Design Criteria}

Development of the general design criteria that will support the achievement of the cleanup standards established in the ROD should begin at the time the preferred remediation alternative is identified. The basis of the criteria is the functional and operational parameters, as identified in the ROD, that the alternative must meet. These functional and operational criteria are further developed, validated, and expanded during the design phase.

\subsubsection{Plans for Disposition of Changed Conditions}

Plans should be established to respond to changed conditions that may occur during RD as described in Section 2.7. These plans should be developed by considering and discussing likely or potential deviations from the expected conditions during RD/RA and identifying means for communicating and addressing those deviations. A variety of "what if" scenarios should be considered. Consensus should be developed on how to communicate and deal with those types of scenarios if they occur.

\subsubsection{Remedial Design Cost Estimate}

The development of an accurate cost estimate is essential to provide adequate funding. The cost estimate should be prepared to the same standards as the plans and specifications for the project. The project cost estimate will become more refined as the design progresses from the ROD to the preliminary design to the prefinal/final design.

The requirement for the identification of funding needs and funding availability for RD/RA is satisfied by including a statement of funding needs and that DOE has adequate funding in existing budget plans in this section.

\subsubsection{Correlations Between Plans and Specifications}

This section will state that correlation between plans and specifications for consistency will occur, how it will be accomplished and by whom, and project-specific correlation needs. It also will discuss the process for checking revisions, and reviews/approvals for changes subsequent to final approval and signature. 


\subsubsection{Design Approval Procedures and Requirements}

The procedures and requirements for obtaining approval of the design documents will follow those outlined in the FFA/CO. DOE-ID shall have the authority to approve and accept design with concurrence from EPA and IDHW.

A discussion of review, comment resolution, approval approach, meetings, and interfaces will be provided. This information can be combined with discussion of scope and schedule of documents (see Section 3.3.7).

\subsection{Elements of Remedial Design Work Plan}

Typically, a separate RD Work Plan, as described in the FFA/CO Action Plan, will not be necessary. The contents of the RD Work Plan described in the FFA/CO Action Plan will be incorporated into the RD/RA SOW.

An RD Work Plan will be developed only for projects with extremely complex or unique design requirements that will require deviation from standard engineering practice or projects where all of the design phase planning cannot be completed before submittal of the RD/RA SOW. In this case, an RD Work Plan would be developed and submitted as a separate document or perhaps in conjunction with the conceptual design. If an RD Work Plan is deemed necessary, the content requirements contained in Section 2.12 of the FFA/CO Action Plan shall be provided as a minimum.

\subsection{Remedial Design/Remedial Action Scope of Work and Remedial Design Work Plan Process}

\subsubsection{Options}

The scoping approach is dependent on the type of project and whether any post-ROD treatability studies (TSs) will be performed or contingent remedies identified. The following subsections identify unique situations that would impact the RD/RA SOW. Note that the phased approach discussed also may be used, if warranted, in situations where there are no TSs or contingent remedies.

Depending on the complexity and the rationale behind the planning, the RD/RA SOW may be phased. Through phasing, a project is divided into separate remedial work elements that can be implemented on different schedules resulting in acceleration of the RD and RA. It allows certain elements of a project to be started ahead of others to lessen the hazards present at the site and to complete simple work elements ahead of more complex and hazardous work elements. Phasing decisions are based on many criteria, including availability of existing information, type of waste, type of media, technology requirements, and funding availability. Examples of projects amenable to a phased approach include but are not limited to

- Information for part of a site is already sufficient to begin design

- $\quad$ TSs affecting remediation decisions are performed after the ROD 
- The engineering required for certain components of a project is more conventional and may lend itself readily to accelerated schedules

- Different media types can be phased into discrete remedial work elements to expedite the start of RA

- Remedial actions that encompass varying degrees of technology requirements (e.g., simple vs. detailed equipment design and fabrication) that allow each element to be implemented as it is finalized without waiting for completion of the design for another element.

By phasing, the RD/RA is broken down into smaller, discrete work elements that are more manageable and cost efficient and less subject to changes or cost increases. Improvement of a project's critical path schedule may be achieved by overlapping work element starts and concurrent actions in design and construction, providing these elements are on the critical path. Once the decision to phase is made, fast-tracking of individual phases should be considered.

\subsubsection{Contingent Remedy}

An RD/RA SOW for a contingent remedy should not be written until the need to implement the contingent remedy has been identified and agreed upon by all parties. This approach is based on the assumption that no ESD would be needed to implement the contingent action because the contingent action is identified in the ROD. It is important that explicit criteria be established (preferably in the ROD) for how the contingent action would be triggered.

While an RD/RA SOW will not be prepared for a contingent action until after the contingent remedy has been triggered, some considerations and planning should be given to the conceptual framework of the contingent RD/RA SOW. This consideration will aid in the efficiency of the development of the SOW in the event that it becomes necessary.

\subsubsection{Non-Critical Path, Post-ROD Treatability Study}

This type of project would involve small-scale TSs, such as bench-scale solidification formula tests that can be accomplished concurrent with initial phases of RD, and feed information into RD. Planning for the TS is incorporated into the RD/RA SOW as a concurrent activity with RD and does not necessarily trigger any unique critical path phasing of work elements. Contingency planning may be required if the results of the study are significant to the design.

\subsubsection{Critical Path, Post-ROD Treatability Study}

This type of project typically involves large-scale TSs usually associated with high uncertainty and contingent RODs. In this case it is certain that the project will be phased to meet the 15 -month criteria. The phasing will be employed with additional planning for the TS and evaluation of the TS in the first phase.

\subsubsection{Logistics}

Scoping of RD/RA begins during the RI/FS or the planning stages of the interim action process. At this point the RD/RA contractor should begin to provide input on design data needs, RD/RA costs, treatability concerns, and implementability. This input typically is in the form of document review and comments. 
The RD/RA strategy is developed by the RD/RA contractor in accordance with the baseline and then scoped by all three agencies in an RD/RA SOW kick-off meeting. This meeting is recommended to coincide with the completion of the RI/FS and Draft Proposed Plan (see Figure 2-1). The purpose of this meeting is to initiate SOW activities and lay out a SOW roadmap. The result of this meeting should be an agreed upon approach to obtain the RD/RA objectives established by the WAG managers. This approach will be documented in the RD/RA SOW.

The RD/RA SOW is developed in parallel with the ROD. For planning purposes, the goal should be to complete the RD/RA SOW at the time the ROD is signed. The FFA/CO requires that the RD/RA SOW be issued within 21 days of issuance of the ROD. Experience has shown that by planning ahead, the 21 days can be used more effectively to work out the finer points of finalizing the SOW. It should also be recognized that completing the RD/RA SOW as soon as possible will directly reduce the time required for $\mathrm{RD}$ and allow initiation of cleanup sooner. 


\subsection{Remedial Design and Remedial Action Work Plan}

\subsection{Purpose}

The RD establishes the general size, scope, and character of the project. It details and addresses the technical requirements of the RA. RD begins with preliminary design and ends with the completion of a detailed set of engineering plans and specifications. The preliminary design is used to achieve early consensus on the significant aspects of the design approach.

The RAWP is the basis for the approach to the implementation of the designed RA. The RAWP details the management approach including schedules and cost for the construction, or construction and operation, of the remedy.

The RD and RAWP will build upon the planning elements established in the RD/RA SOW and carry them through to completion of planning and initiation of the remedy. For the purpose of this guidance, it is recommended to combine the RD and RAWP to expedite review times and eliminate the need for consistency checks between the two documents; however, site-specific considerations may dictate the need for separate documents. The final decision as to how the RD and RAWP are configured is made by the WAG managers and should be documented in the RD/RA SOW.

\subsection{Background}

- General guidance is identified in the FFA/CO Action Plan Sections 2.12, "Remedial Design Process," and 2.13, "Remedial Action Process."

- $\quad$ EPA guidance is available for many elements of the RD/RAWP (EPA 1986). However, this guidance has limited applicability to Federal facilities remediation projects.

- The FFA/CO defines the preliminary design as a secondary document and the RD and RAWP as primary documents.

- $\quad$ RAWPs may be prepared for discrete work elements and be reviewed as tech memos or secondary documents; however, ultimately they will be combined into one main RAWP, which will be reviewed as a primary document.

- The submittal of the RD and RAWP and their targeted schedules will be identified in the RD/RA SOW.

\subsection{Elements of Remedial Design}

The FFA/CO identifies the elements to be included in the RD. This guidance also identifies those elements recommended for inclusion in the preliminary design and incorporates their revision into the draft RD along with those elements identified in the FFA/CO. For some remedies, not all of the elements of the RD identified in this section are applicable. 


\subsubsection{Preliminary Design}

The RD presents the design, layout, specifications, and overall approach for construction of RA structures, facilities, and appurtenances. The preliminary design submittal may include but is not limited to

- Process flow diagrams

- General arrangements drawings

- Preliminary specifications

- Major equipment identification

- Design criteria

- Volume, flow rate, and quantity estimates

- $\quad$ ARARs, TBCs, and permitting considerations (This discussion should not repeat the items included in Section 3.3.6, rather it should include any updates or revisions to that discussion along with a description of the specific design features that are planned to be used to achieve compliance with the controlling parameters of each ARAR, TBC, or substantive permit standard that would otherwise be required. If off-site actions are planned as part of the remedy, identification of permits, permit schedules, and permit criteria, standards, or limitations should be included, as appropriate, to avoid delays in implementing the remedial action.)

- Status of ROD assumptions

- Design alternatives

- Identification of unresolved data needs

- Identification of RA sampling/verification methods

Typically for simple projects, the preliminary design would involve "off-the-shelf" technology and all of the elements described above would not need to be included at this stage of the design. The amount of information required to be provided in the design is project-specific and should be determined during scoping. The WAG managers shall identify and agree upon the critical components for presentation in the preliminary design meeting and in the preliminary design document. The above list contains items to be considered for incorporation in the preliminary design, but all items are negotiable depending on schedules and complexity of the project.

\subsubsection{Draft Remedial Design}

The draft RD (or prefinal design) represents the complete design for the phase and may include but is not limited to

- Comment resolution from the preliminary design 
- Completed design drawings and specifications

- Cost estimate for RA

- $\quad$ Revised

Process flow diagrams

General arrangements drawings

Major equipment identification

Design criteria

Volume, flow rate, and quantity estimates

ARARs, TBCs, and permitting considerations (See discussion in Section 3.3.6 on comments or additional information that may affect ARARS, TBCs, or permitting considerations. EPA RD/RA Guidance (EPA 1986) requires the prefinal design submittal be reviewed for compliance with all ARARs identified in the ROD, utilization of currently accepted environmental control measures and technology, and consistency with ROD and environmental/public impacts.)

- Operation and Maintenance Plan

A phased approach, e.g., the initial O\&M Plan and any necessary revisions, is recommended to define the $O \& M$ requirements associated with a specific project. For the purposes of this guidance, the initial O\&M Plan will address the period of equipment/facility readiness review and start-up testing prior to completion of the prefinal inspection. When applicable, this O\&M Plan will be updated/revised and submitted with the Prefinal Inspection Report (see Section 5.3.4).

The logic behind the phasing approach to O\&M is based upon the complexity of the project. Simple projects should only require an initial O\&M Plan to cover the entire requirements of O\&M for that project. For the purposes of this guidance, the O\&M Plans will take on the same significance, e.g., primary, secondary, etc., as the document with which it is submitted. For examples of the phased O\&M Plan approach, see the situations contained in Section 8.0 of this guidance.

In the case where the remedy results in complete restoration of the area and no O\&M phase is deemed necessary, an O\&M Plan would not be required.

- $\quad$ Sampling and Analysis Plan (SAP)

- Quality Assurance Project Plan (QAPjP)

- $\quad$ Site Health and Safety (H\&S) Plan

- $\quad$ Results of additional studies, if any (such as results of post-ROD TSs)

- Schedule (if the draft RD and RAWP are not combined).

As in the preliminary design, the WAG managers must identify and agree upon the critical components for presentation in the draft RD. The above list contains items to be considered for incorporation in the draft $\mathrm{RD}$, but all items are negotiable. 


\section{Elements of Remedial Action Work Plan}

The RAWP defines work elements, focuses attention on the components of the elements that are critical to implementation of the ROD, and presents a CPM schedule through initiation of the O\&M phase. The FFA/CO Action Plan identifies the requirements of the RAWP. This guidance recommends the following elements as those needed to generally satisfy the requirements in the FFA/CO. The RAWP may include but is not limited to

- Revised detailed schedule through RA, including construction inspection hold points and targeted schedules for primary and secondary documents

- $\quad$ Revised detailed cost estimate through RA

- Discussion and planning of the RA work elements, including rationale for the various tasks

- Relevant changes in the RD Work Plan (if one was developed) or the RD/RA SOW and any associated changes in ARARs and permitting considerations (see Section 3.3.6)

- Identification of RA inspections, hold points, and reports

- Identification of protocol and coordination of field oversight and preliminary field inspections, where applicable

- Emergency procedures

- Waste management plan

- Decontamination and decommissioning plan, where applicable

- Performance measurement points and rationale for their selection

- Any other procedures relevant to the RA activities.

The WAG managers must identify and agree upon the critical components for presentation in the RAWP. The above list contains items to be considered for incorporation in the RAWP, but all items are negotiable.

The RAWP will also expand upon and update the planning basis for RD/RA identified in the RD/RA SOW. This revised planning should target the elements discussed in Sections 3.3.4, 3.3.5, 3.3.8, 3.3.9, and 3.3.11 of this guidance. Additionally, it should include any planning for the O\&M decision point that would trigger an O\&M Report, where applicable (see Section 7.0).

\subsection{Remedial Design and Remedial Action Work Plan Process}

\subsubsection{Logistics}

Projects may include preliminary, draft, and draft-final design submittal. Complex projects should be phased and it is recommended that only Preliminary and draft design submittal be made for each major phase of the project. It is not necessary (or desirable) to call all preliminary/draft RD 
deliverables secondaries/primaries on a multiphase project. Less significant phases (i.e., site preparation and utilities phase, erection of temporary buildings/facilities phase, etc.) that are standard construction activities or have minimal implication to RAOs, should be downgraded to tech memos or secondary documents. Subsequent primary documents on significant phases of the project will provide opportunities for dispute resolution of previous phases of the project if required. However, WAG managers should resolve issues as identified to avoid proceeding with a project without consensus on approach. For an example of this approach, see Section 8.3.

The preliminary design, a secondary document, will be submitted to all parties to review as early as possible during the design phase. This review will conclude with a tri-party design review meeting to ensure that consensus is maintained on the design and to resolve significant issues. This is the primary opportunity to identify and resolve design issues. If the project proceeds without consensus, there is significant risk of dispute, work stoppage of RD/RA contractors procured concurrent with design finalization, or significant project cost/schedule impacts. The preliminary design will not be revised/resubmitted, however comment resolution will be incorporated in the draft RD.

The draft $\mathrm{RD}$ is the complete design ready to be input to final stages of construction subcontract procurement. The draft-final RD represents the complete RD with comment resolution/incorporation from the draft RD review. 


\subsection{Prefinal Inspection Report}

\subsection{Purpose}

The Prefinal Inspection Report provides a means to document the prefinal inspection performed by the DOE-ID, EPA, and IDHW project managers, or their designees, at completion of construction activities for long-term remedial actions or at completion of remediation for short-term remedial actions. This report will be issued, after which, dependent on the action, will indicate that the objectives of the ROD have been met or that start-up of the remedial action facility operations will commence.

\subsection{Background}

- General guidance is identified in the FFA/CO Action Plan Section 2.13, "Remedial Action Process."

- $\quad$ EPA guidance is available for many elements of the prefinal inspection (EPA 1986). However, this guidance has limited applicability to Federal facilities remediation projects.

- The FFA/CO defines the Prefinal Inspection Report as a secondary document.

- Submittal of the Prefinal Inspection Report and its targeted schedule will be identified in the RAWP.

- The recommended format for the report is an inspection checklist, discussion of findings, and corrective actions plan. Documentation of any preliminary inspections performed will be included as attachments.

- The report may include an update to the O\&M Plan depending on the project (see Section 5.3.4).

\subsection{Elements of Prefinal Inspection Report}

The FFA/CO Action Plan identifies the items to be included in the Prefinal Inspection Report. The elements identified in this section are recommended as the content for the Prefinal Inspection Report and should be applicable to all projects.

\subsubsection{Inspection Checklist}

The checklist should contain specific project systems, components, start-up test procedures, or other areas agreed upon by all parties to be inspected that will constitute acceptance of construction activities. The focus is on RA elements significant to meeting the requirements of the ROD. Backup sheets may be required to describe each item on the checklist and the criteria for acceptance/rejection of each item. 


\subsubsection{Discussion of Findings}

This section provides an area for documentation of inspection findings. All documented findings should tie to appropriate checklist items.

\subsubsection{Corrective Action Plans}

This section will document corrective actions to be taken to correct deficiencies identified in the inspection. The corrective actions should identify the required action, acceptance criteria or standard, planned date of completion, and plan for final inspection.

\subsubsection{Operation and Maintenance Plan Update}

The report may include an update of the O\&M Plan that will address planning for the shakedown phase (see Section 4.3.2). No revision to the O\&M Plan is required for projects where there is no shakedown phase.

\subsection{Prefinal Inspection Process}

\subsubsection{Logistics}

The process for developing the Prefinal Inspection Report is highly dependent on project-specific factors and associated inspection requirements. Many projects will require multiple step start-up activities that may require a series of inspections that culminate with an agreed upon prefinal inspection point. DOE-ID may hold a preliminary inspection, prior to the prefinal inspection, with their contractors for DOE-ID contract purposes.

A typical Prefinal Inspection Report process includes the following:

- Inspection hold points are established in the RAWP detailed CPM

- The DOE-ID WAG manager develops draft prefinal inspection checklist and distributes to other WAG managers for review as identified in the RAWP

- Updated O\&M Plan's submitted with checklist, if applicable

- WAG managers reach consensus on checklist before inspection

- DOE-ID notifies EPA and IDHW of inspection

- Inspection is performed. If issues are identified at inspection, they should be resolved at closeout of inspection or a corrective action plan should be developed. Inspection report is completed at closeout. Date for final inspection is established if needed. For example, if the prefinal inspection did not identify any outstanding items, then there may be no need for a final inspection.

- Prefinal report is not revised/finalized. The subsequent RA Report will document the prefinal inspection process. The completed prefinal inspection checklist may be included as an appendix to the RA Report. 
RD/RA Guidance

Rev. 1

$10 / 13 / 93$

Typically, for simple projects, and in the case where there are no significant findings identified during the prefinal inspection, the prefinal inspection would also serve as the final inspection (see Section 6.3.5). 


\subsection{Remedial Action Report}

\subsection{Purpose}

The purpose of the RA Report is to document that the remedy is operational and functional and, if applicable, to update planning for the O\&M phase.

\subsection{Background}

- General guidance is identified in the FFA/CO Action Plan Section 2.13, "Remedial Action Process."

- The FFA/CO defines the RA Report as a primary document.

- Submittal of an RA Report and its targeted schedule will be identified in the RAWP.

- To the extent possible, RA Reports for individual work elements will be consolidated into a single RA Report.

\subsection{Elements of Remedial Action Report}

The FFA/CO Action Plan identifies elements to be included in the RA Report. The elements identified in this section describe what occurred during RA and provide plans for subsequent O\&M activities and reports, if applicable. Typically, projects that have no O\&M phase will not require an O\&M Plan update (see Section 6.3.4).

\subsubsection{Outstanding Items}

Any outstanding items from the Prefinal Inspection Report should be identified and described. In responding to comments received, the Prefinal Inspection Report will not be revised but, rather, will be finalized in the context of the RA Report.

\subsubsection{Results of Shakedown Phase}

Results of initial shakedown, when applicable, including observations and corrective actions taken should be provided. Also, the results of the initial operation period that occurs after shakedown and prior to report preparation should be described.

\subsubsection{Certification That Remedy Is Operational and Functional}

DOE-ID will provide a statement certifying that the remedy is achieving, or has achieved, the requirements of the ROD as measured by the predetermined performance standards. These performance standards, and measurement thereof, have been formerly negotiated in the RD/RA SOW (see Section 3.3.8) and refined in subsequent RD/RA documents. 


\subsubsection{Operation and Maintenance Plan Update}

If applicable, an updated O\&M Plan is included in the RA Report. This O\&M Plan will be equivalent to any former O\&M Plan plus information obtained from the operating period identified in the RAWP. This will be the final phase in the O\&M Plan cycle. The updated O\&M Plan should outline the long-term operation and maintenance requirements of the remedy, as well as identify any impacts on the initial O\&M Plan from change orders or variations from planned conditions documented on the as-built drawings. Included in this plan are requirements for periodic reporting, identification of endpoints for O\&M, and identification of scope and schedule for the O\&M Report. Where applicable, to ensure a smooth transition to the O\&M phase of the project, the O\&M contractor should be included in the scoping of this plan.

\subsubsection{Results of Final Inspection}

The results of any final inspection will be documented in the RA Report, which will be submitted within 60 days of the final inspection (See FFA/CO Section 12.2). The final inspection is used to follow up prefinal inspection issues. Typically, if there were no significant findings during the prefinal inspection, there is no need to perform an additional final inspection.

\subsubsection{Decontamination and Decommissioning Plan}

The plan for decontamination and decommissioning (D\&D) activities (associated with the remedial action) should be updated at completion of O\&M, as appropriate. Typically, this would not be needed in the situation where the RA equated to the complete cleanup. In this case, D\&D would be implemented prior to the final inspection.

\subsubsection{Deletion From the NPL}

To Be Determined

\subsubsection{Five-Year Review Process}

To Be Determined

\subsection{Remedial Action Report Process}

\subsubsection{Logistics}

Section 12.2 of the FFA/CO requires that the draft of the RA Report be submitted within 60 days of the final inspection.

The RA Report is prepared when the tasks as defined in the RAWP have been completed and agreed upon by all three parties.

The RA Report may be submitted at the completion of simple projects, with a short duration O\&M phase, to document the results of the short period of operation. 


\subsection{Operation and Maintenance Report}

\subsection{Purpose}

The O\&M Report summarizes the results of O\&M activities and establishes any additional O\&M, review, and documentation required for the site. O\&M Reports are only required when a decision that requires a primary document is planned for in the O\&M phase.

\subsection{Background}

- General guidance is identified in the FFA/CO Action Plan Section 2.14, "Operation and Maintenance."

- The FFA/CO defines the O\&M Report as a primary document.

- The preparation of an O\&M Report may not be appropriate for some remedial actions. For example, actions such as capping, where significant decisions would not be made during O\&M, would not generally require an O\&M Report. If an O\&M Report is not required, O\&M data identified in the FFA/CO for submittal to the three agencies will be provided by some predetermined method identified during scoping.

- The identification and submittal of an O\&M Report and its targeted schedule will be identified in the RAWP.

- $\quad$ Planning for the O\&M decision point that would require an O\&M Report should be included in the RAWP and RA Report.

\subsection{Elements of Operation and Maintenance Report}

The FFA/CO Action Plan identifies the elements to be included in the O\&M Report. The elements identified in this section describe what occurred during the major remedy phase, e.g., O\&M.

\subsubsection{Description of Operation and Maintenance}

O\&M performed, operation records, and maintenance frequency should be described. This description also will include any unexpected events.

\subsubsection{Site Monitoring}

The results of monitoring requirements for any established performance standards (from ARARs and permitting requirements) should be identified and described, indicating that the remedy meets the performance criteria. 


\subsubsection{Verification That Remedy Meets Remedial Action Objectives and} Applicable or Relevant and Appropriate Requirements

DOE-ID will document verification of compliance with RAOs and ARARs specified in the ROD. This documentation will be based on the agreed upon performance standards, and measurement thereof, specified in the RD/RA SOW (see Section 3.3.8). Verification should include the approach for determining success, e.g., trend analysis, and should be closely coordinated with long-term O\&M monitoring requirements.

\subsubsection{Future Operation and Maintenance Requirements}

Future monitoring program requirements to be undertaken at the site should be identified. The future monitoring description shall include analytical parameters, sampling locations, contaminant concentrations, monitoring frequency, schedule for review periods, and facility maintenance requirements.

\subsection{Operation and Maintenance Report Process}

Section 12.2 of the FFA/CO requires that the draft of the O\&M Report be submitted within 90 days of the completion of O\&M activities. The timing of submittal also may be planned on the basis of the timing of the major decision point that drove the development of the report.

The O\&M Report would be prepared on the basis of a specified action level or a specified time period. It is the intent that the O\&M Report be completed as soon as possible in the O\&M phase. Action levels or specified time periods would most likely be identified in the ROD for the action.

Periodic reports developed during operation, as required by the O\&M Plan (if applicable), will be evaluated prior to the O\&M Report.

During review of the report, the agencies will use information provided in the report to make a major decision concerning remedy implementation. 


\subsection{Example Applications of Guidance}

\subsection{Introduction}

The following are examples of how this RD/RA guidance can be applied to environmental restoration projects. Any similarity to current or planned remediation activities at the INEL is unintentional. These examples are idealized and designed to show the flexibility of the guidance by demonstrating the applicability or nonapplicability of sections in this document to project-specific situations.

Two scenarios are discussed. The first situation selects capping as the preferred alternative on the basis of the results from an RI/FS. The second selects incineration with a post-ROD TS on the solidification of the ash. Associated with this example is a contingent remedy involving chemical extraction and solidification in the event the TS goals are not met. These examples were selected to represent the range of project complexity from a relatively straight forward case to a complex, innovative, remedial action.

The examples describe the situation and then discuss the planned approach for each of the phases, e.g., scoping, RD, RA, and O\&M. Also included are schedules to illustrate the timing of the projects and milestones.

\subsection{Example A: Capping Project}

\subsubsection{Situation}

This example is designed to illustrate the RD/RA process for a situation in which capping is the preferred alternative. It was assumed that this alternative was selected on the basis of results from an RI/FS. The site in question was assumed to be an infiltration pond contaminated with metals and radionuclides that caused an unacceptable risk through the inhalation/ingestion pathway for the future residential exposure scenario. Specific intricacies addressed by this example that affect RD/RA of this project are listed below:

- Scoping involvement in the RI/FS

- $\quad$ Performing pre-ROD TSs

- Conducting geotechnical and characterization studies of cap material and pond sediments

- Including the conceptual cap design in the RD/RA SOW

- Preparing an ESD to the ROD because of a significant change in the RD/RA costs

- Complying with ARARs

- Being awarded of a fixed unit price, estimated quantity, total estimated price contract to construct the cap

- $\quad$ Preparing a phased O\&M Plan 
- Preparing an RA Report at the conclusion of the remedial action.

\subsubsection{Scoping}

RI/FS Scope of Work - During scoping meetings for the RI/FS, several potential remedial alternatives were identified. Among the most promising of these alternatives were no action, contaminant extraction and concentration, and capping.

Existing groundwater monitoring wells were in place to identify impacts to the groundwater effectively. A sampling plan was devised to collect sediment samples from the bottom of the pond. Data from these samples would be used to quantify risks from the pond and would serve as a basis for evaluating alternatives. No other design data were identified as needed to evaluate the alternatives. The need for a pre-ROD TS was identified to evaluate contaminant extraction and concentration effectively. It was decided that this bench-scale TS would be conducted off-site with real waste.

FS Scoping Involvement - As the RI was nearing an end, a scoping meeting for the FS was held. This meeting was held shortly before the Draft RI Report was submitted for IDHW and EPA review. Scheduling the meeting prior to submission of the RI Report was necessary so that preparation of the FS could begin soon enough to meet FFA/CO enforceable milestones. Participants included DOE-ID, DOE-ID's assessment contractor, the EPA, and IDHW. A member of DOE-ID's RD/RA contractor's staff was also present and contributed to the identification of design data needs and provided insight on "state-of-the-art" capping under way at other DOE facilities.

The purpose of this meeting was to review results from the RI, to identify FS objectives, and to arrive at a list of remedial alternatives for preliminary screening. The IDHW and EPA staff members had a general understanding of the results from the RI because, as identified in the RI/FS Work Plan, a number of interim tech memos had been supplied to them and their DOE-ID counterpart had made an active effort to keep them informed of significant information collected through the RI. Preliminary results of the RI indicated that contaminant levels in the pond sediments were high enough to pose an unacceptable risk to future residents. This unacceptable risk was through the ingestion and inhalation pathway. Bench-scale TSs conducted during the RI indicated that contaminants could be extracted from the sediments. However, ion exchange resins were not very effective in removing the radionuclides present, resulting in a large volume of low-level radioactive waste that had to be stabilized and disposed. Therefore, this remediation technology was disregarded for consideration as a remedy alternative.

The objective of the FS was to identify a preferred remedial alternative for addressing the elevated risk associated with the sediments in the pond. After agreement was reached regarding the approach to the FS, the group continued the scoping effort by identifying a number of potential remedial alternatives. In situ stabilization was identified as a potential remedial alternative, as was capping and the no action alternative. The detailed evaluation of alternatives performed in the FS identified capping as the preferred alternative.

To provide constructibility input into the process at an early stage, the RD/RA contractor participated in the formal review of the Draft RI/FS Report concurrent with the IDHW and EPA. Comments developed by the RD/RA contractor were shared with all parties to facilitate the finalization of the RI/FS and decision process.

The focus of the RD/RA contractor's review was to identify potential problems associated with the implementation of the preferred and other alternatives and to develop a conceptual approach for 
RD/RA for each alternative. During their review, a problem with the implementation of the preferred alternative was identified. Although capping was selected as the preferred alternative, the proposed cap configuration was more restrictive than regulations required, and the suggestion was offered to move towards a more appropriate cap design for the associated waste. In addition, the RD/RA contractor recommended that several characterization tests be performed to assist with the modeling effort for remedial design. These tests were performed before the ROD was issued by the assessment contractor.

Because the conceptual design for the cap was to be included with the RD/RA SOW, treatability work plans had to be implemented immediately to accommodate the schedule requirements. The TSs included evaluating the various liner materials, e.g., clay, biointrusion layer, random fill layer, and vegetative layer, for their characteristics and applicability. These tests included gradations, specific gravity, Atterberg limits, permeability, Standard Proctor, petrographic analysis, freeze-thaw, Los Angeles abrasion, Schmidt hammer, and porosity.

The preferred alternative in the proposed plan presented to the public a capping design similar to the Uranium Mill Tailings Remedial Action (UMTRA) Title II design identified as the preferred alternative. In addition to the cap, groundwater monitoring would be conducted for an initial period of 5-years to assess the success of the cap in preventing migration of metals or radionuclides into the groundwater.

The Categorical Exclusion (CX) to meet NEPA requirements was prepared and reviewed concurrently with the proposed plan. In this manner, the requirements to meet NEPA were fulfilled prior to the signature of the ROD.

RD/RA SOW - After comments on the proposed plan were received from the public and it became evident that the preferred alternative would be the selected alternative, a conceptual framework for conducting RD/RA was developed by the IDHW, EPA, and DOE-ID WAG managers. This framework was developed through a series of conference calls to discuss the RD/RA process. As a result of these conference calls, a preliminary draft RD/RA SOW was developed by DOE-ID and its RD/RA contractor. It was agreed by the three agencies that based on the simplicity of the cap design and the fact that it was off-the-shelf technology, the RD would be expedited by including a conceptual design of the cap in the RD/RA SOW. Because not all of the characterization and treatability tests had been completed for the cap materials, default parameters were used in the cap design models for producing the conceptual design. Because of the default parameters used, the design for the cap was more conservative than anticipated. This preliminary draft of the RD/RA SOW was submitted to IDHW and EPA for formal review.

Development of the RD/RA SOW continued in parallel with the development of the ROD. IDHW and EPA provided informal comments, by teleconference and in writing, on the preliminary draft document at the same time that formal comments on the draft ROD were provided. While comments on the draft ROD were being incorporated, the RD/RA SOW also was revised so that it could be resubmitted, informally, when the draft final ROD was submitted to IDHW and EPA. After IDHW and EPA had reviewed the second informal submittal of the RD/RA SOW, a teleconference was held prior to signature of the ROD to resolve any remaining issues related to the work outlined in the $\mathrm{RD} / \mathrm{RA}$ SOW. As a result of the teleconference, final changes to the SOW were made so that it could be submitted within 21 days after the signature of the ROD.

The RD/RA strategy to implement the remedial action included completing the characterization studies and treatability work to develop the design parameters for the cap design (post-ROD, noncritical path TS), procuring a subcontractor to construct the cap, developing a monitoring program for 
RD/RA Guidance

Rev. 1

$10 / 13 / 93$

the existing groundwater wells in the contaminated site vicinity, and producing one secondary and one primary document to implement the action.

\subsubsection{Remedial Design}

Preliminary Design - As stated earlier, the conceptual design was submitted as part of the RD/RA SOW. The design package included identification of the design criteria, key features of the specifications, a Preliminary Drawing, Preliminary H\&S Plan, Preliminary QAPjP, and a Preliminary Monitoring Plan.

RD and RA Work Plan - The Draft RD and RA Work Plan, submitted as a combined primary document, included the following elements:

Remedial Design

- Construction drawings and technical specifications for inclusion in the bid package to the RA subcontractor

- QAPjP

- H\&S Plan

- O\&M Plan (including groundwater monitoring plan)

- $\quad$ ARARs compliance description

Remedial Action Work Plan

- $\quad$ Cost estimate for RA

- Construction schedule

- Identification of primary and secondary documents; their contents and deliverable dates

Although several other ARARs were identified and complied with, the IDHW fugitive dust regulation, Idaho Administrative Procedures Act (IDAPA) 16.01.01252 and 01252, is cited as a specific example. Compliance with this ARAR included employment of best management practices such as deployment of water trucks for dust mitigation and soil compaction, use of soil surfactant in areas of motorized traffic and for soil adhesion, and covering of trucks containing loose material. Because of the relative isolation of the site and lack of nearby receptors, the three agencies felt that compliance with this ARAR was achieved by the above methods. In addition, both an industrial hygienist (IH) and a health physics technician (HPT) would be on site during RA, monitoring the workers for exposure to airborne matter using personal air monitor sampling pumps. Additional administrative controls would be employed on the basis of recommendations by the IH and HPT. The workers also were required by the Occupational Safety and Health Administration (OSHA) to participate in an Occupational Medical Program (OMP) to work on the RA site.

Upon completion of the combined Draft RD and RA Work Plan, it was submitted to IDHW and EPA for review as a primary document. Initially the EPA and IDHW performed a high-level review to identify any major issues early in the review process. These major concerns were identified to the DOE-ID WAG manager so that efforts to address them could begin early in the process. By the time 
formal comments from IDHW and EPA were transmitted at the end of their review period, all major issues were in the process of being resolved. The WAG managers continued to hold discussions during the comment resolution period and all comments had been resolved by the end of that time period. A Request for Proposal (RFP) to procure a contractor to construct the cap was issued at the same time the Draft Final RDRA Work Plan was transmitted to EPA and IDHW.

\subsubsection{Remedial Action}

Auditable Safety Analysis (ASA) - Because of the relatively low concentration of contaminants in the pond, the RA was classified as a Category 3 (per DOE Order 5480.23) requiring an ASA to be developed by the contractor for the job. The ASA was initiated once the preliminary information was prepared and finalized after the subcontractor provided their procedures for constructing the cap. Once the ASA had been reviewed by the contractor's independent review committee, the subcontractor was permitted to proceed with construction.

Explanation of Significant Differences - During the TS for the cap construction materials, only one type of clay was identified as meeting the specified design criteria. Unfortunately, the nearest available source for this unique clay was in eastern Wyoming and had to be transported to the INEL. This additional cost for transporting and purchasing the clay had not been considered in the original cost estimate proposed in the ROD and therefore, an ESD was written to inform the public of this variance. This cost discrepancy was identified during the development of the cost estimate included in the RD and RAWP.

Procurement - As stated earlier, the RFP for a fixed unit price, estimated quantity, total estimated price procurement was issued concurrently with the Draft Final RD and RAWP. However, the RFP was written such that the award of the contract was contingent on acceptance by the public of the ESD. The award was issued after the ESD public comment period was closed.

This contract allows payment to be made during construction on the basis of actual quantities expended or installed. The schedule of values is used to break down the work into a logical listing of work elements to manage the subcontractor effectively for measurement and payment purposes.

Two weeks following the award of the contract, the notice to proceed was issued. The subcontractor submitted for review and approval by the contractor the following items: their H\&S Plan, Quality Program Plan (QPP), construction schedule, and standard operating procedures.

Prefinal Inspection - Although several inspections were conducted by the tri-party WAG managers during the installation of the cap (scheduled to coincide with the quality hold points identified by the contractor), a formal prefinal inspection was conducted to ensure the cap construction met the RAOs identified in the ROD and was able to be maintained and monitored as specified in the O\&M Plan.

At completion of the cap construction but before demobilization, the WAG managers conducted the prefinal inspection of the UMTRA design-based cap. The prefinal inspection checklist had been prepared prior to the actual inspection and had been reviewed by all three agencies for content.

Because the prefinal inspection had been completed prior to the subcontractor demobilizing from the site, the subcontractor was able to perform the few items identified as outstanding during the prefinal inspection. The WAG managers concurred on how to resolve the outstanding items during the inspection and identified the corrective action measures for the contractor and subcontractor to implement. DOE-ID, because of their location at the INEL, reviewed and acknowledged the 
RD/RA Guidance

Rev. 1

$10 / 13 / 93$

completion of the outstanding items so that the subcontractor could be released from the job and provide notice of completion to EPA and IDHW.

RA Report - A final inspection of the cap was conducted by the tri-party WAG managers and the project site turned over to the operating contractor of the facility for maintenance and monitoring of the cap and groundwater in accordance with the O\&M Plan. The RA Report provided as-built drawings of the cap, a description of outstanding items from the prefinal inspection, an explanation of modifications to the RD and RAWP, certification that the remedy was functional, and a discussion of work performed to that point in time.

\subsubsection{Monitoring}

Monitoring, as identified in the O\&M Plan, was performed for the cap and groundwater and periodically evaluated for potential impacts to the site. However, this monitoring was based on best management practice and not on any actionable levels identified in the ROD. Monitoring reports were submitted as tech memos to the agencies based on a schedule agreed to in the RAWP.

O\&M Report - An O\&M Report was not required for this project because there were no RAOs identified in the ROD that would affect O\&M and require a decision point.

Five-Year Review - A 5-year review of the site was required for this remedy by EPA. During this review the agencies looked at the results of the past 5 years of monitoring and any new ARARs that would require a change in the remedy.

\subsection{Example B: Incineration Project}

\subsubsection{Situation}

This example is designed to illustrate implementation of a complex remedy utilizing proven remediation technologies for hazardous waste but not commonly employed on mixed-waste cleanup operations. To meet the CERCLA time-frame requirements, phasing is used to implement the remedy and an early planned procurement approach is utilized to expedite the RD/RA process.

This operable unit entails a trench that was used for disposal of hazardous and radioactive wastes from 1963 to 1967 . The trench was estimated to contain 220,000 cubic feet of waste with approximately 10 feet of overburden. Inventory records indicate the trench was used primarily for the disposal of nitrate salts contaminated with low levels of radionuclides. In the later years of pit operation, sludges contaminated with solvents, heavy metals, and transuranic radionuclides were disposed.

The RI focused on the trench as a source; groundwater and the vadose zone were addressed as separate operable units. During the RI, sampling of the trench contents indicated that the wastes had commingled and that equally high levels of radionuclides and organic solvents can be found throughout the trench. Fate and transport modeling indicated that solvents will reach the aquifer in 30 years. The Baseline Risk Assessment (BRA) showed that concentrations of these contaminants posed an unacceptable risk to the future use residential receptor starting at $\mathbf{3 0}$ years and continuing through 1000 years. 
Because of the risk posed by this trench, the agencies made a risk management decision to proceed with a proposed plan that calls for the preferred remedy to be incineration of the wastes with solidification of the ash. However, because this remediation technology had not been employed routinely on mixed wastes, the agencies decided a post-ROD TS was warranted to ensure that the mechanics of the system were achievable and that ARARs could be met. Based on transuranic content, some ash was stored onsite for future disposition, and the remaining low-level ash was returned to the trench, which was reconfigured to include a liner and cover. The agencies decided to take a high-risk approach to remedy implementation in this situation based on the risk reduction benefits and data needed to feed into an upcoming action. Considering the complexities of the remedy, the agencies determined that a contingent remedy involving chemical extraction and solidification would be implemented in the event that TS goals were not met.

Specific points addressed by this example that affected the RD/RA strategy of this project are listed below:

- $\quad$ Perform post-ROD TSs

- Plan for a contingent ROD

- Prepare a phased RD/RA SOW

- Phase the RD/RA to meet CERCLA requirements

- Comply with ARARs

- Prepare phased O\&M Plans

- Award performance based specifications subcontract to perform the TS and design, build, and operate the treatment facility

- Conduct a prefinal inspection after construction of the incinerator but before the trial burn

- Prepare an RA Report at the end of the shakedown phase

- Prepare an O\&M Report after 1 year of operation.

\subsubsection{Scoping}

FS Scoping Involvement - A scoping meeting for the FS was held with participation from DOE-ID and its RI/FS contractor, IDHW, and EPA. The purpose of the meeting was to identify FS objectives and arrive at a list of remedial alternatives for preliminary screening.

The remedial alternatives identified were

- Removal, treatment by incineration, solidification of the ash, and disposal

- In situ treatment

- Containment 
RD/RA Guidance

Rev. 1

$10 / 13 / 93$

- Removal, treatment by chemical extraction and solidification, and disposal

- No action.

The following RAOs were established:

- Average concentrations of transuranic isotopes in residuals (i.e., treated waste stream being returned to the trench) are to be less than 10 nanocuries per gram transuranic.

- Wastes and/or materials containing greater than 10 nanocuries will be treated to reduce the volume by greater than 90 percent (in addition to meeting the treatment standard above) before being returned to the trench or being placed in interim storage.

- For materials being treated and returned to the trench, all ARARs will be met.

The detailed evaluation of alternatives performed in the FS identified removal, incineration, solidification of the ash, and disposal as the preferred alternative.

The Environmental Assessment (EA) was prepared and reviewed concurrently with the proposed plan. In this manner, the requirements to meet NEPA were fulfilled prior to the signature of the ROD.

RD/RA Scoping - At completion of the FS and proposed plan, the agencies decided to begin the $\mathrm{RD} / \mathrm{RA}$ scoping process immediately to meet the schedule requirements of the FFA/CO. The scoping meeting covered discussions on development of the TS Work Plan and the treatability criteria, RD/RA SOW, procurement approach, and RD/RA strategy.

At the conclusion of the RD/RA scoping meeting, the agencies agreed that a TS would be conducted to determine the ability of the remedy to meet the ROD goals and ARARs. The TS involved incineration of surrogate material that simulated the waste in the operable unit and solidification of the residual ash to meet Resource Conservation and Recovery Act (RCRA) ARARs. The TS was conducted offsite by a qualified subcontractor to expedite the treatability process by avoiding the requirements for operations at DOE facilities.

Specific objectives of the TSs include:

- Achieve 90 percent volume reduction

- $\quad$ Meet RCRA ARARs to dispose of solidified ash in the trench

- Demonstrate capability of monitoring systems to detect releases

- Evaluate incinerator's capability to achieve a destruction and removal efficiency of at least 99.99 percent for each principal organic hazardous constituent (POHC).

RD/RA SOW - The agencies agreed that the effective implementation of this remedial action required phasing the design elements and construction. To best manage the work, two RD/RA SOWs were developed to address the two distinct phases. The first phase RD/RA SOW was produced early in conjunction with the ROD and was submitted prior to the 21-day timeframe dictated by the FFA/CO. This was necessary because elements of the RD/RA SOW needed to be agreed upon by all three agencies to effectively incorporate the elements and decisions into the procurement package 
being prepared for submittal to prospective bidders. The second phase RD/RA SOW was developed and submitted later in the process following the completion of the TS.

The first phase RD/RA SOW included the common elements that would be employed regardless of which treatment remedy was used, the preferred or the contingent remedy. This included the design and construction of the building covering the waste trench, the excavation plan of the waste, and the site preparation for the treatment facility and storage facility. The RD/RA SOW for the first phase included a discussion on the planning of the second phase of the remedial action and associated schedule. Phase I also included planning for the contingent remedy and identifying the performance criteria for the TS. The outcome of the TS was used to determine the direction for the second phase of the work and the associated second phase RD/RA SOW.

The TS was completed and successfully demonstrated that the preferred remedy could be implemented. Therefore, the contingent remedy identified in the ROD was disregarded. On the basis of the success of the TS in meeting the performance criteria, a second SOW was developed to address the completion of the remedial action. This second phase included the design and construction of the disposal cell, the transuranic disposal facility, and the treatment process including the incineration facility and solidification system. The second phase RD/RA SOW also incorporated information gained from the TS but did not affect the performance criteria already specified in the subcontract.

The deliverable documents associated with the two phases of the RD/RA SOW were as follows:

Phase I

- Treatability Study Report (primary)

- Remedial (Prefinal) Design - Building, Site Preparation (secondary)

Phase II

- Preliminary Design - Cell Construction (secondary)

- Preliminary Design - Treatment (secondary)

- Remedial Design/RA Work Plan (primary)

- Prefinal Inspection Report (secondary)

- RA Report (primary)

Procurement - To reduce costs and time in the procurement phase, the RD/RA contractor proposed using one procurement to perform all required tasks including the TS, the design, the remedial action, and the operation of the treatment process and disposal facility. The RFP was designed to entice the awarded subcontractor to successfully complete the TS to proceed with design, construction and operation of the treatment train. However, if the TS had failed to achieve the performance requirements as specified in the RFP, the subcontract would have been terminated at the completion of the building construction and site preparation.

Therefore, to meet the schedule requirements, the TS work plan and criteria were identified early to include them in the RFP. The phased approach to RD/RA also was developed early to incorporate it into the RFP and associated documents. 
Because of the complexities of the project, a source evaluation board (SEB) was organized to evaluate each proposal's attributes. During the SEB review of the proposals, prospective bidders were required to provide facility tours, perform demonstrations, and provide technical presentations to indicate their knowledge, capabilities, experience, and special qualifications demonstrating their ability to perform the remedial action. The award of the subcontract provided the best value (optimum technology at a reasonable price) for the Government.

Subcontract payments were broken up according to the various steps and elements of the project, i.e., the TS was a fixed price based on results of the treatability tests and the construction of the building was fixed price. As a result of the longevity of the design stage of the treatment and disposal systems, interim payments were provided at 30 percent, 60 percent, and 90 percent on the basis of the design completion verified through drawing and specification submittal and approval. During construction of the modular treatment units, payment was made on line items as delivered or completed and accepted as meeting the contract requirements. Payments during the treatment operation were fixed unit price based on actual quantities installed or expended.

To successfully accomplish this remedial action, the procurement offered an incentive in the form of a bonus payment to the subcontractor for meeting the treatability performance criteria and accomplishing the task within a defined milestone date.

The key to this procurement being successful was the sufficient characterization and consideration of uncertainties conducted during the process, and the cooperative integration between the DOE's RI/FS contractor and the RD/RA contractor in developing the performance criteria. Also, the performance specifications developed to manage the subcontractor were reasonable, practicable, and technically achievable.

\subsubsection{Phase I}

Remedial Design - The remedial design for Phase I of the remedial action involved the design of the building constructed over the trench, designed to meet DOE orders, ARARs, and performance requirements identified in the RFP. A preliminary design review meeting was conducted among the three agencies, the RD/RA contractor, and the subcontractor. Copies of the building design, site preparation layout, and excavation approach were reviewed to gain early consensus among the agencies.

To meet the CERCLA schedule requirements, the prefinal design was submitted as a secondary document to the agencies for review with the intent of addressing any outstanding resolution issues in the submittal of the RD/RA Work Plan identified in Phase II. Elements included in the prefinal design were as follows:

- $\quad$ Plans and specifications for the building and site preparation

- QAPjP

- H\&S Plan

- O\&M Plan including filter maintenance and monitoring plan

- $\quad$ ARARs compliance

- Excavation plan 
Safety Analysis - Because of the nature of the proposed work in Phase I, the RD/RA contractor through its performance of the preliminary hazard assessment determined that the work classified as less than a Category 3 hazard and an ASA was performed. The ASA was initiated concurrent with the prefinal design of the building in order to be completed and reviewed prior to the proposed construction start date.

Remedial Action - Once the ASA was approved by DOE, site preparation activities were initiated. Because of the large accumulation of snow at the site and frozen ground, the site preparation activities took longer than anticipated. However, the lag time caused by the weather provided the necessary time to obtain the long-lead item for the building structure, the high efficiency particulate air (HEPA) filtration system.

Prefinal Inspection - Although preliminary inspections were conducted earlier by the WAG managers, a formal prefinal inspection was conducted after construction of the incinerator but before the trial burn. The prefinal checklist was developed from two sources, the design documents and the periodic field inspection reports that had been conducted over the construction period of the project. The following were some of the elements included on the checklist:

\section{Containment Structure}

- Are closure points and penetrations fabricated in accordance with plans and specifications?

- Are entrance/egress points constructed/functioning to eliminate hazardous/radioactive releases? Are all such points equipped with an airlock which will not permit inner and outer doors to open at the same time? Is monitoring equipment installed and functional? Are monitors connected to all required alarms and control points (including any remote monitoring stations)? Are decontamination stations complete and functional?

- Are vents/air handlers properly installed with filters to eliminate uncontrolled releases? Is the entire facility operating at negative pressure? Are pressure monitors in place and operational? Are backup air handlers and emergency power in place and operational to ensure that negative pressure is maintained? What is the actual start-up time for a backup generator to come on line after air pressure falls outside of the specified level? Are filters accessible for change-out, with minimum risk of contaminant release?

- Are site layout and traffic controls established to minimize risk to containment structure integrity?

- Will the structure accommodate the expected types of activities (excavation/treatment) with an adequate margin of safety?

- Does all installed equipment conform with the project safety specifications, e.g., are all electrical devices explosion-proof and installed per the National Electric Code (NEC)?

- Is the overall integrity, workmanship, and completeness of the structure adequate?

\section{Excavation}

- Is all necessary equipment (including emergency equipment) onsite prior to proposed startup? 
- Is equipment of the type and capacity identified in the plans and specifications?

- Are all safety devices, including those that relate to potential environmental releases, in place and operational?

- Is the site laid out to minimize the risk of accidents/uncontrolled releases? Are controls in place to ensure that the containment structure will not be damaged?

- Are controls in place to limit access to the digging face and minimize exposure to excavated hazardous or radioactive waste?

A Prefinal Inspection Report was prepared that included the inspection checklist, a discussion of findings, corrective action plans needed to correct deficiencies, and an updated O\&M Plan.

\subsubsection{Phase II}

Remedial Design - On the basis of the successful outcome of the TS, the subcontractor developed the design for the various elements to implement the remedial action. These included the design of the disposal cell by retrofitting the trench, the transuranic waste disposal facility, and the treatment process. To accomplish the design as quickly as possible, the disposal cell design was initiated following submittal of the TS Report for agency review. A preliminary design for the disposal cell was submitted as a secondary document, and a review meeting with the agencies was conducted. This completed design package was then incorporated into the RD/RA Work Plan primary document submittal.

In addition to meeting the expedited process, the design for the treatment and disposal facility was initiated following the completion of the Phase II RD/RA SOW. Again, the preliminary design was submitted as a secondary document, and a review meeting with agencies on the design was conducted.

The subcontractor also was authorized to purchase long-lead procurement items. As the design developed, the treatment system was assembled offsite into modular units for subsequent ease of installation later at the site.

The trial burn plan was included for agency review as part of the RD/RA Work Plan. One of the ARARs identified in the ROD that was evaluated in the trial burn plan was 40 CFR 264.343, Subpart O. Compliance with this ARAR included the design of the incinerator for destruction and removal efficiency of 99.99 percent for each POHC in the waste stream, 99 percent removal efficiency of hydrochloric acid, and control of particulate matter emission to less than 180 milligrams per dry standard cubic meter. The regulations also required that fugitive emissions be controlled by keeping the combustion zone totally sealed, maintaining negative draft, or an equivalent alternative means of control. The agencies reached agreement in the Phase II SOW on how compliance with this ARAR would be measured including contaminant criteria, measurement frequency, location and contingent plans for non-compliance conditions.

Safety Analysis - On the basis of the chemical and radiological hazards expected for Phase II of the remedial action, a SAR as a category 2 was developed. To expedite the process of the SAR and its reviews, a Preliminary Safety Analysis Report (PSAR) was developed which bounded the requirements for the design. Then, a Final Safety Analysis Report (FSAR) was developed at completion of the design utilizing the procedures developed to establish the operational safety requirements. Although mobilization and assembly of the treatment facility components on-site was 
allowed to proceed prior to the FSAR being approved by DOE, shakedown operation of the facility was prevented from occurring for a couple of months until the FSAR review was completed.

Remedial Action - Several inspections were conducted by the agencies during the delivery and assembly of the treatment facility. The results of issues identified in these inspections were documented in the monthly report from DOE to EPA and IDHW.

Following assembly of the treatment system and the transuranic storage facility, the three agencies conducted the prefinal inspection. A checklist had been prepared prior to the inspection and agreed upon by all three parties. Corrective actions were identified for outstanding items noted during the inspection and were discussed with the RD/RA contractor and subcontractor to schedule resolution of corrective actions.

Prior to initiating the trial burn, the incinerator and solidification process systems were operated using "clean" material to assess their functional capabilities. The shakedown period lasted for 1 month.

Once the data had been produced on the trial burn, and the incinerator met the performance requirements identified in the Trial Burn Plan, remedial operations were allowed to begin. The incinerator was designed and met the operational parameters for an average 10,000 pounds per hour, therefore, the waste was consumed through the treatment process in 1 year.

RA Report - The RA Report documented the results of the trial burn and shakedown and updated planning for the O\&M phase of the project. It also included an O\&M Plan update to address longterm maintenance of the trench. A final inspection was performed during the operations to evaluate the systems performance in accordance with the specifications. The results of the final inspection were included in the RA Report.

\subsubsection{Operation and Maintenance}

O\&M Report - Following completion of the remedial action, approximately 1 year, the O\&M Report was prepared. The requirement for the O\&M Report was criteria contained in the ROD which stipulated that groundwater monitoring be conducted for a period of 1 year. At the end of this time period, there would be a formal review to discuss the results of the monitoring. The O\&M Report included a description of the O\&M, the results of site monitoring, verification of compliance with the performance standards, and identification of future O\&M requirements, i.e., the disposal facilities. 


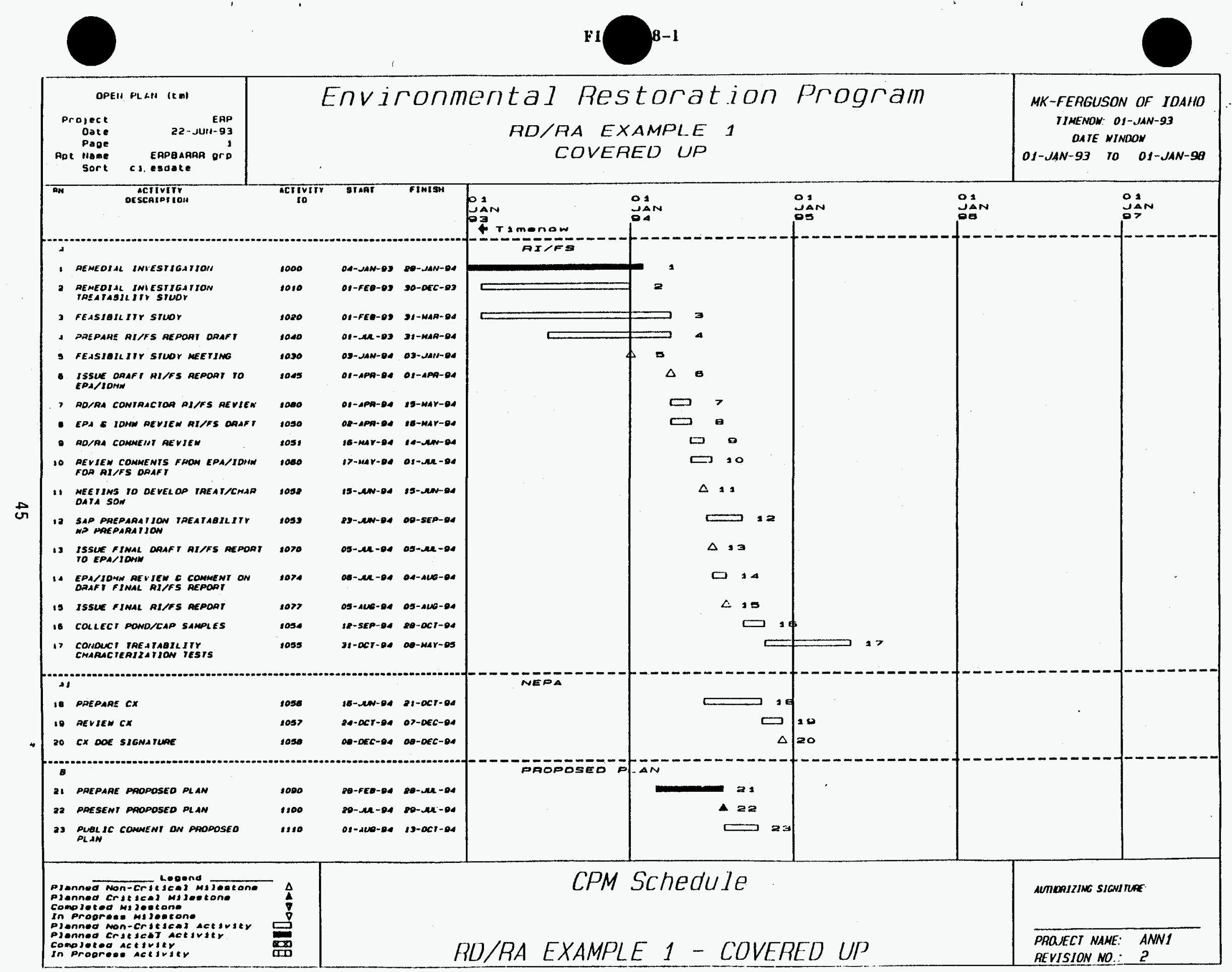


Flgure 8-1

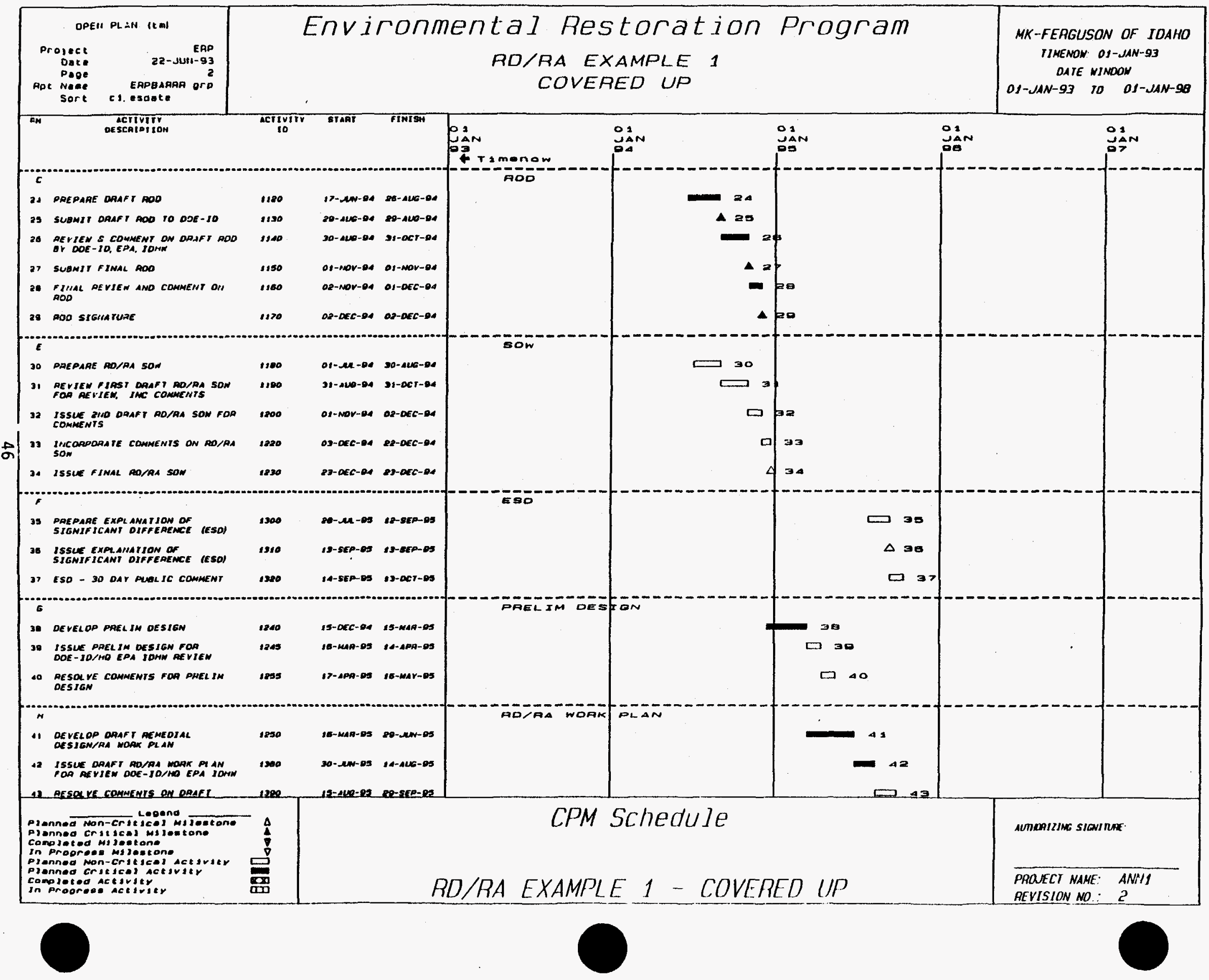




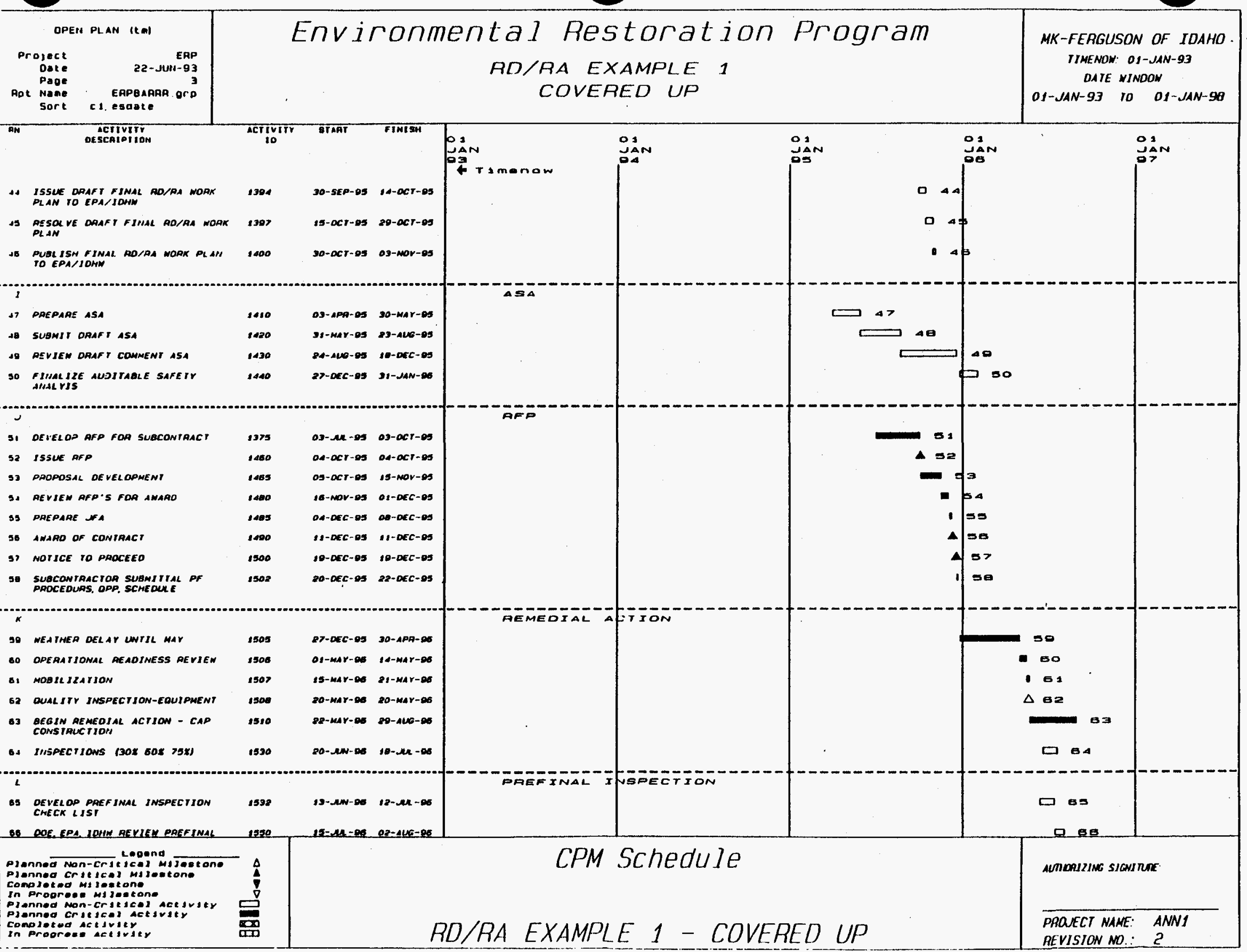


FIgure 8-1

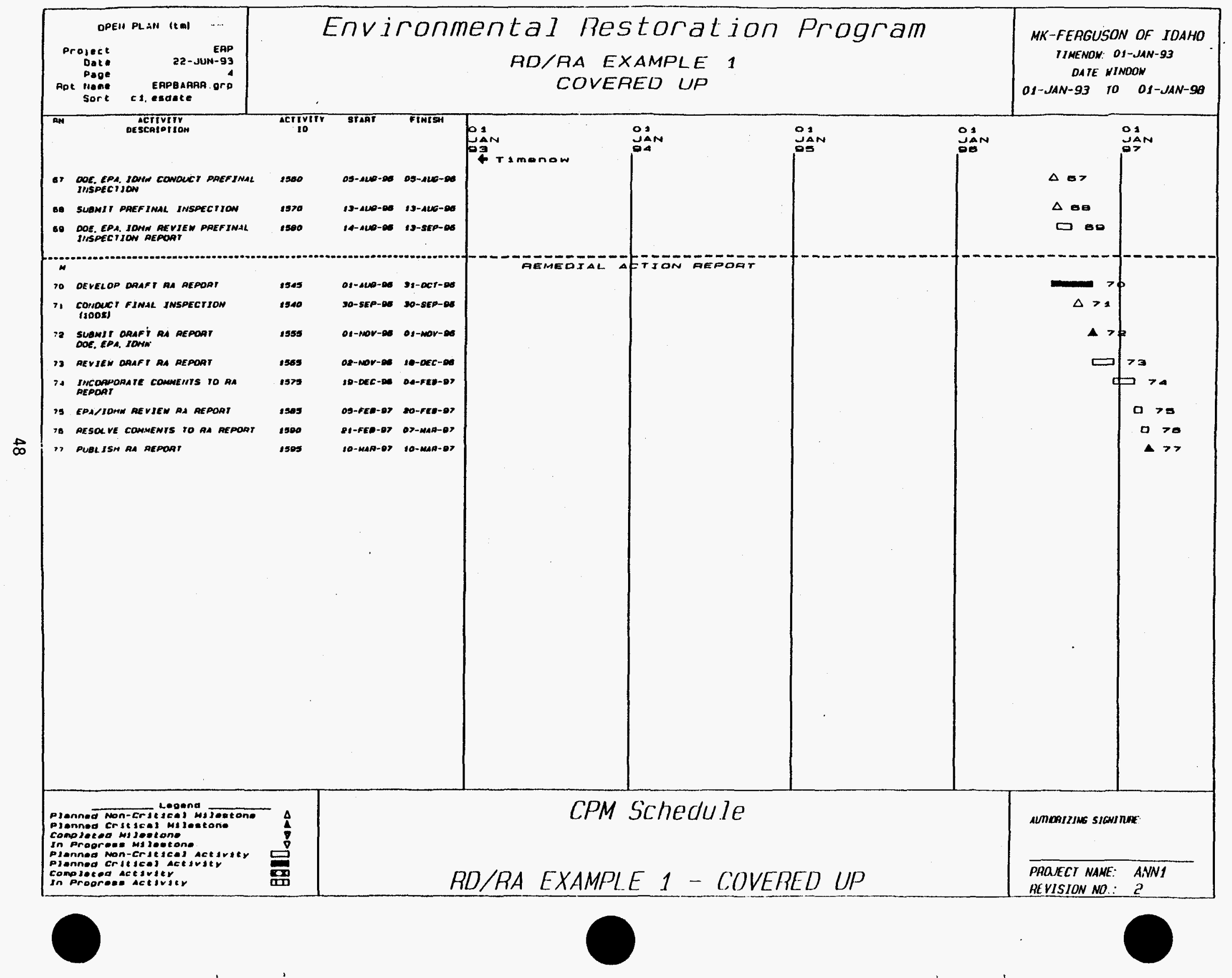




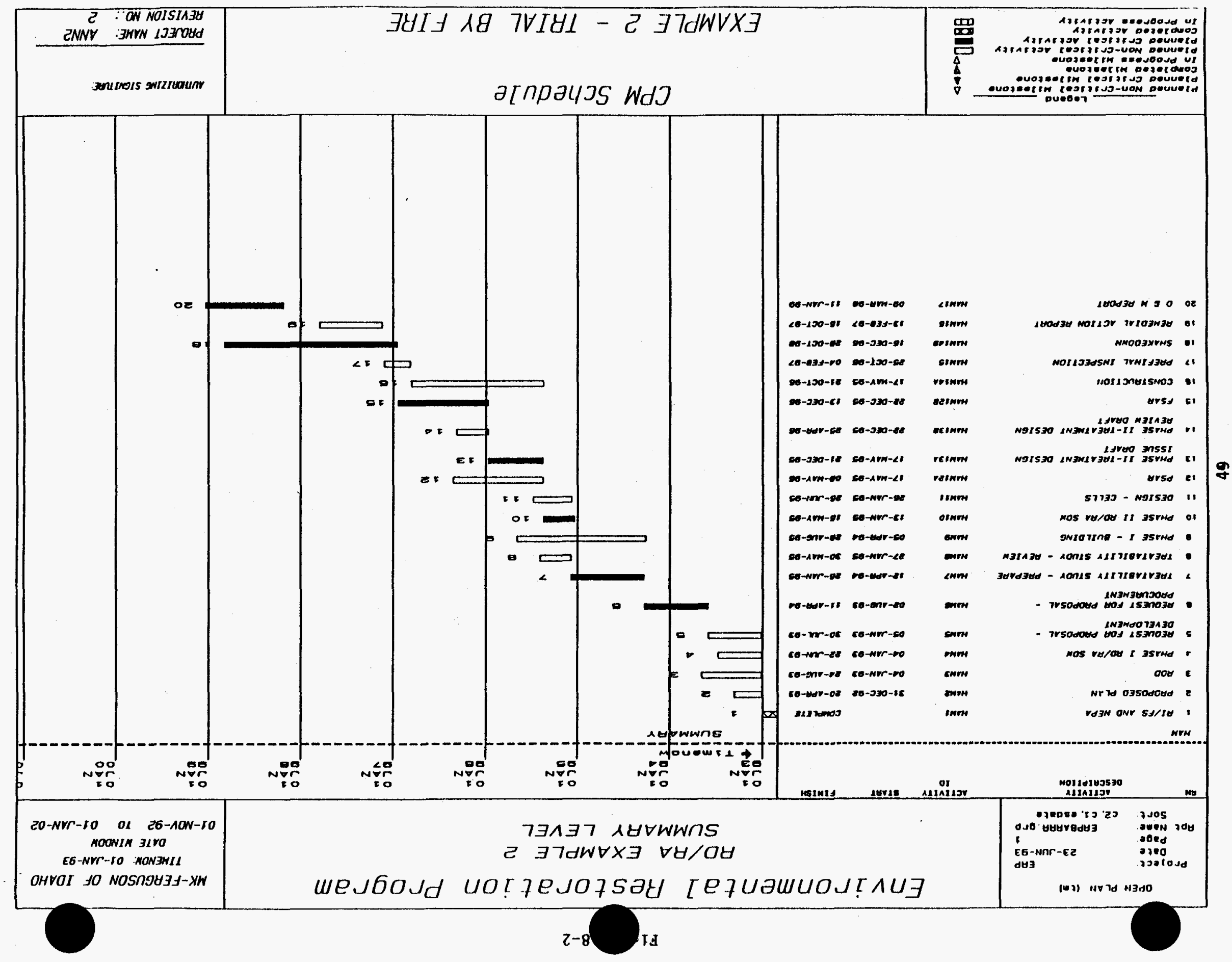




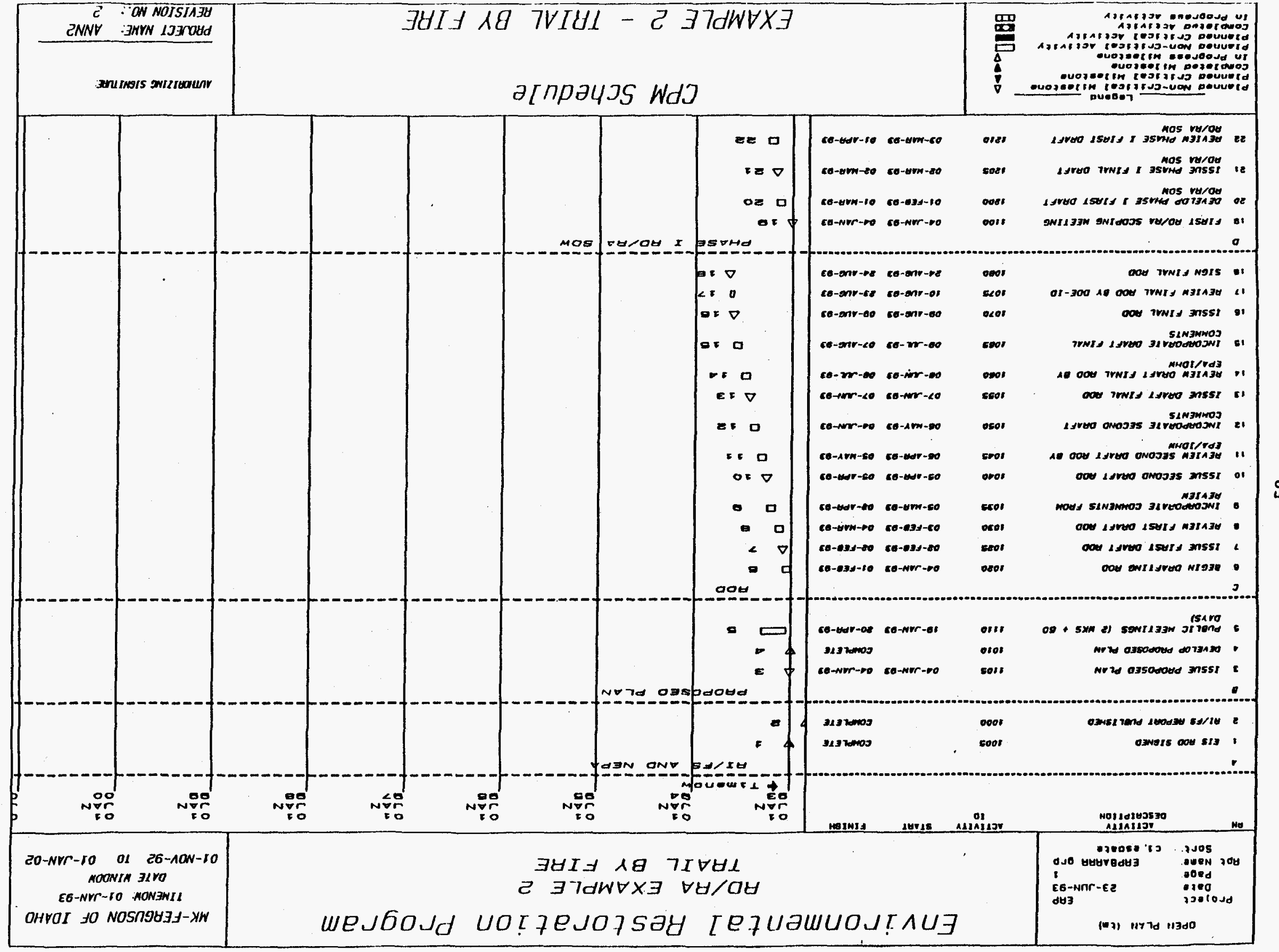




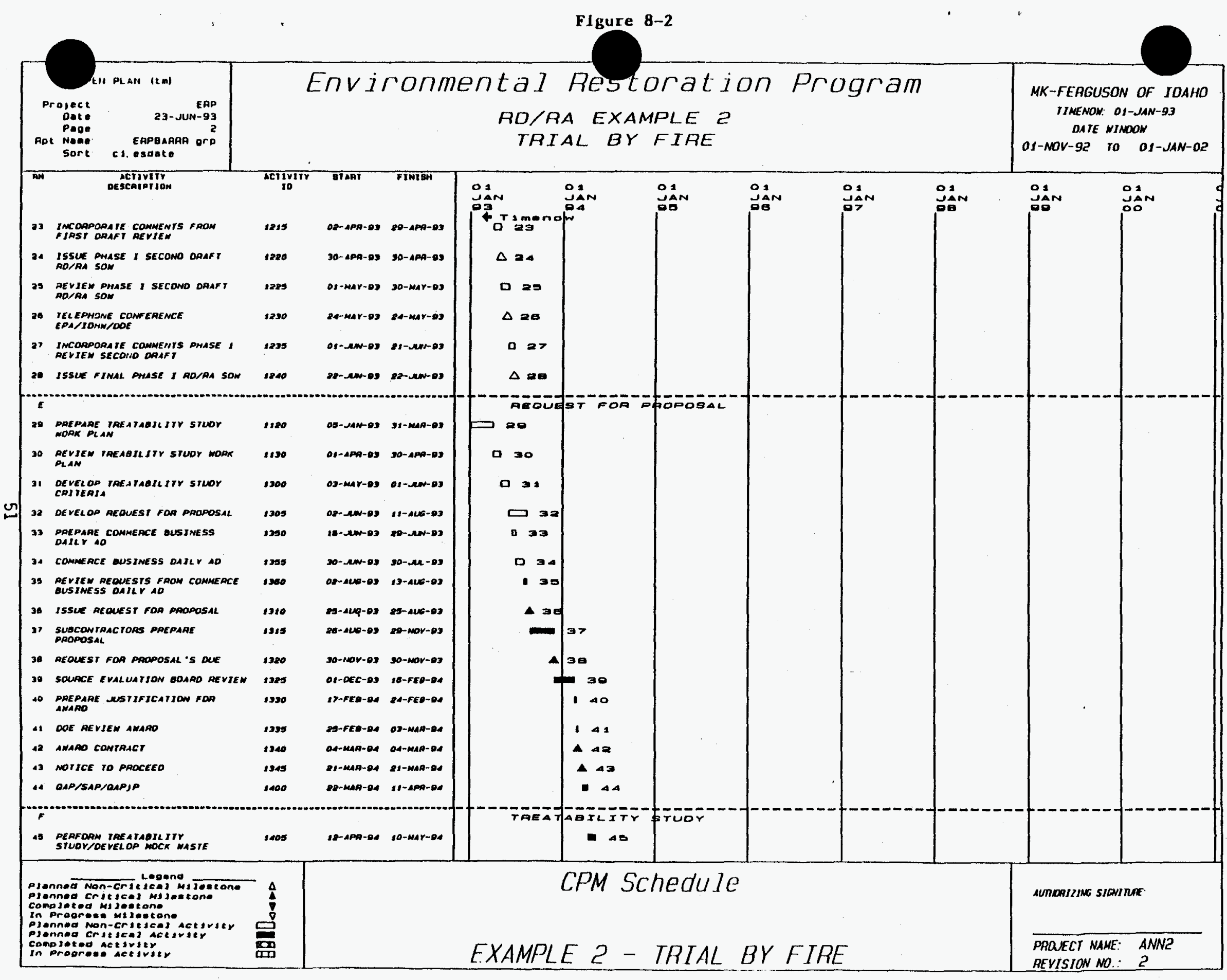




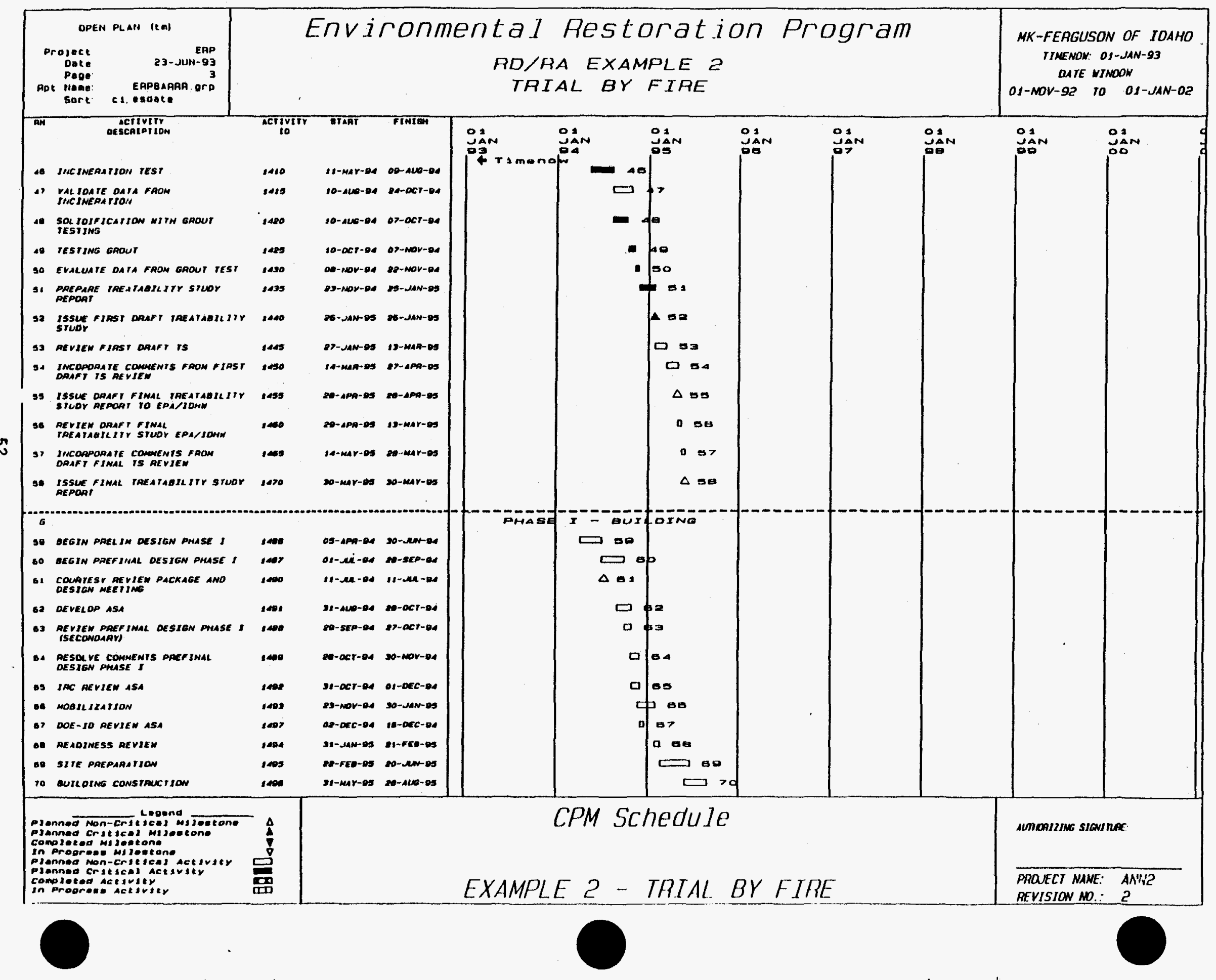




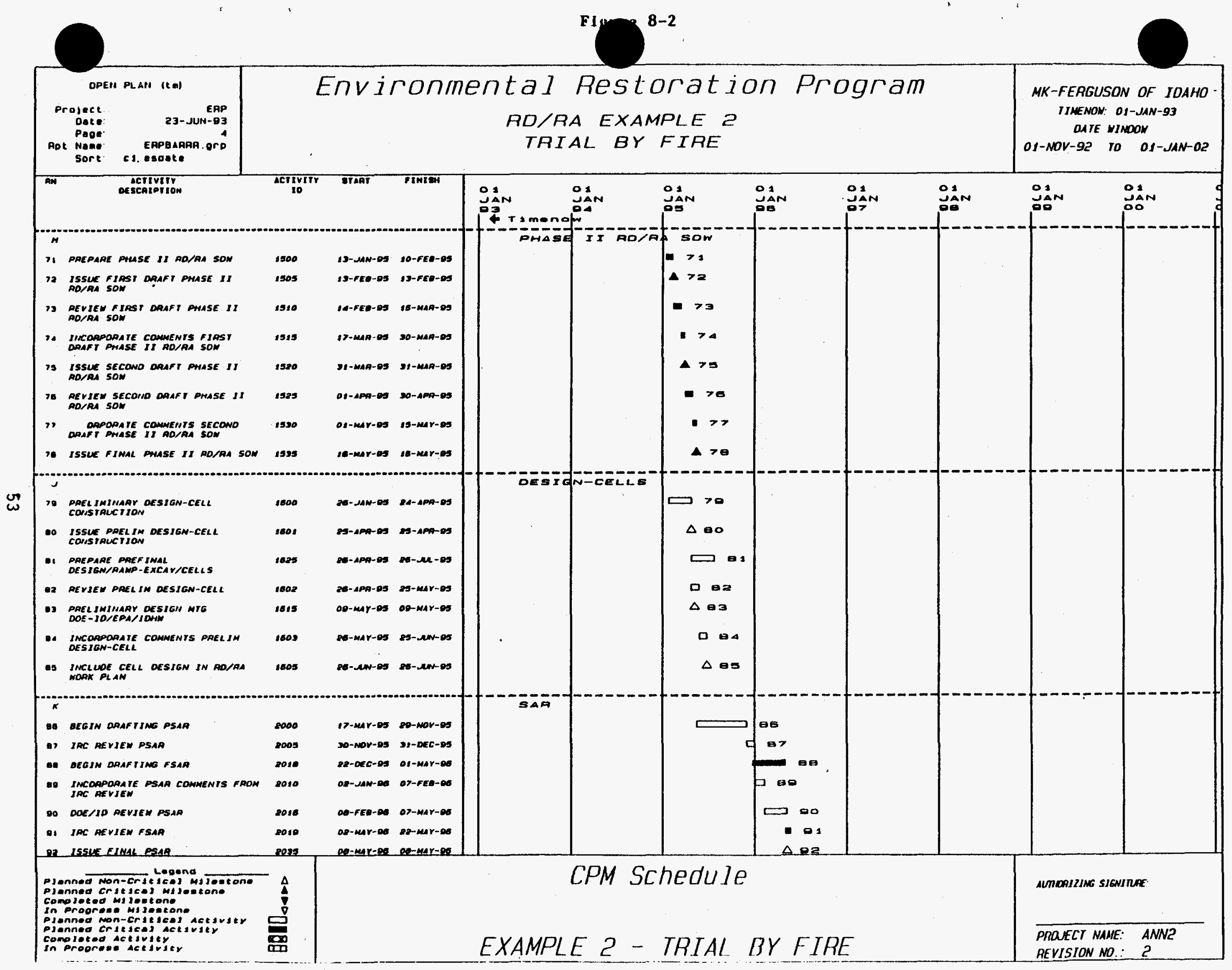


E1gure 8-2

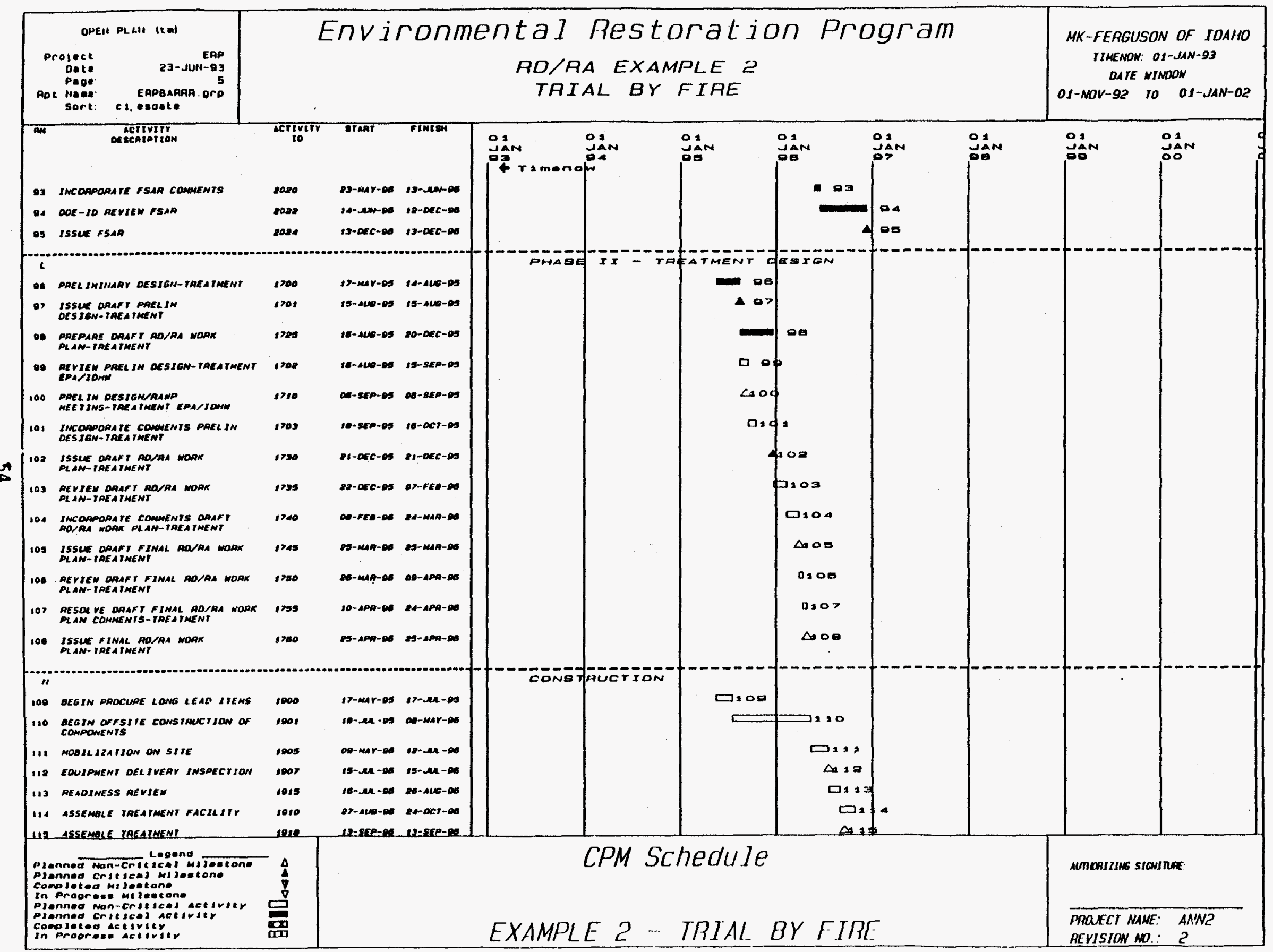




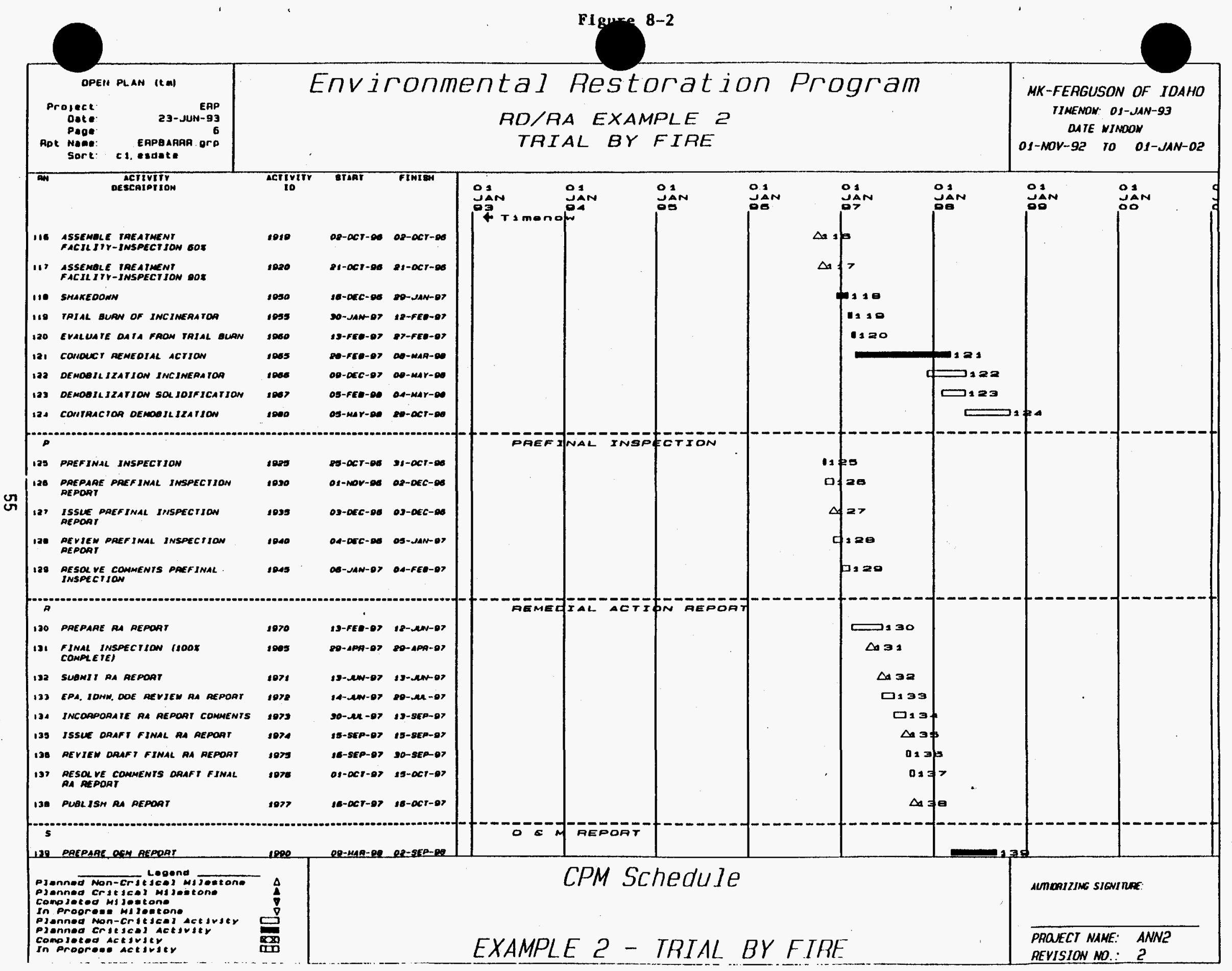


Figure 8-2

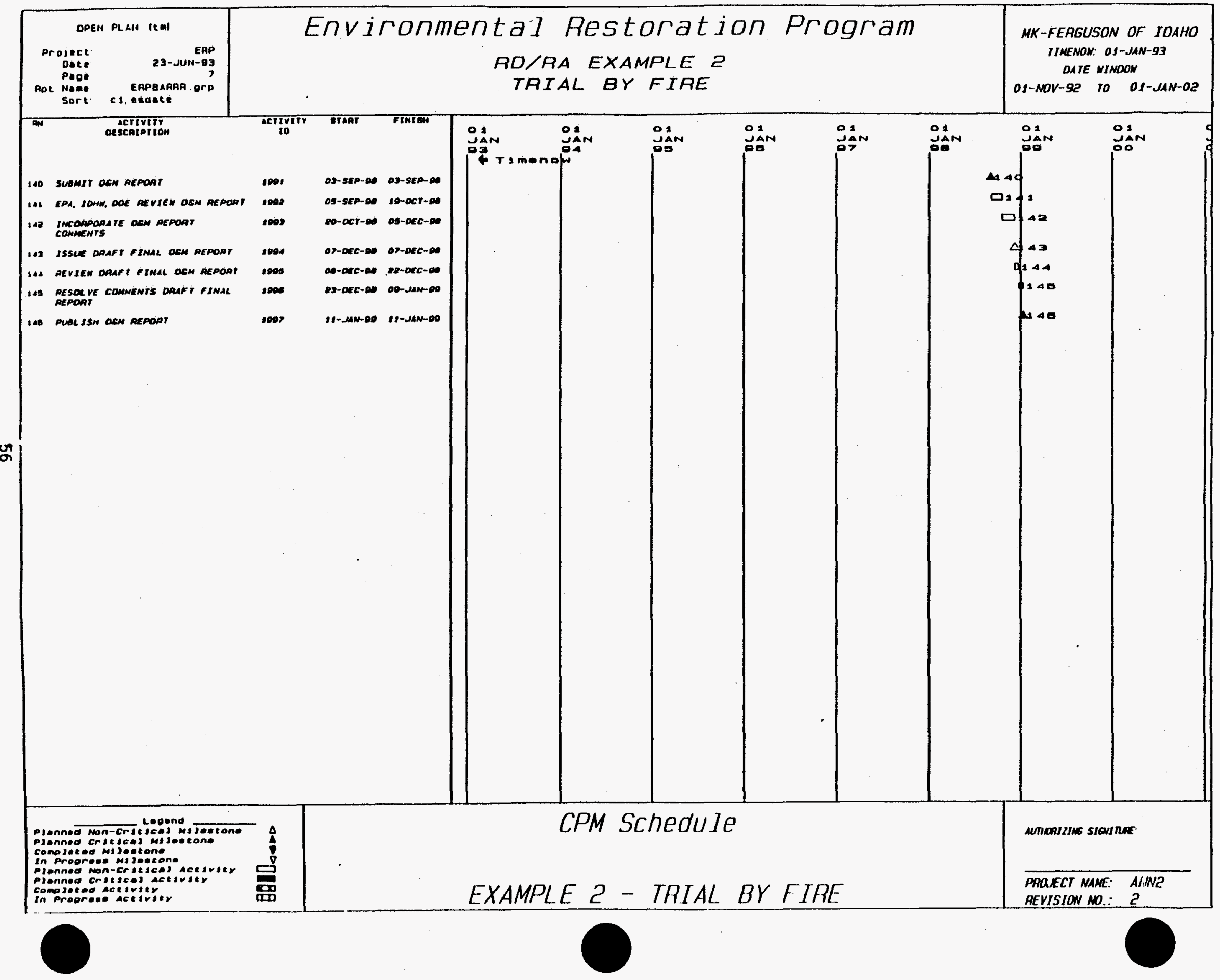




\subsection{References}

OSWER Directive 9355.5-01, 1990 Guidance on Oversight of PRP Performed RD/RA, Office of Solid Waste and Emergency Response, U.S. Department of Commerce, National Technical Information Service, Springfield, VA, February 1990.

OSWER Directive 9355.0.4A, 1986 Superfund Remedial Design and Remedial Action Guidance, Office of Solid Waste and Emergency Response, U.S. Environmental Protection Agency, Washington, DC, June 1986.

OSWER Directive 9355.3-02, 1989 Interim Final Guidance on Preparing Superfund Decision Documents: The Proposed Plan, The Record of Decision, Explanation of Significant Differences, The Record of Decision Amendment, Office of Solid Waste and Emergency Response, U.S. Environmental Protection Agency, Washington, D.C., June 1989.

40 CFR Part 300, 1990 National Oil and Hazardous Substances Pollution Contingency Plan; Final Rule, U.S. Environmental Protection Agency, March 8, 1990.

Environmental Restoration and Waste Management, 1991, "Managing for Safety and Quality Manual," Idaho National Engineering Laboratory, U.S. Department of Energy, Idaho Operations Office, Revision 2.

Longest II, H. L., U.S. Environmental Protection Agency, 1990, to Director, Waste Management Division Regions I, IV, V, VIII; Director, Emergency and Remedial Response Division Region II; Director, Hazardous Waste Management Division Regions III, VI, and IX; Director Hazardous Waste Division Region X, U.S. Environmental Protection Agency, Subject: "Guidance on Expediting Remedial Design and Remedial Action," June 1990.

Moylan, J. E., 1991 Data Gaps In Remedial Design, U.S. Army Corp of Engineers, Technology Innovation Office, Office of Solid Waste and Emergency Response and the U.S. Environmental Protection Agency, Washington, D.C., July 1991, pp. 1-5.

ADN-088-06-29-120, 1991 Federal Facility Agreement and Consent Order, The State of Idaho, Department of Health and Welfare; The U.S. Environmental Protection Agency; and the U.S. Department of Energy, for the Idaho National Engineering Laboratory, December 1991. 


\title{
Appendix A
}

\author{
Excerpts from the INEL FFA/CO Action Plan
}

Relevant to the RD/RA Process

\subsection{Post-ROD Process}

A general process and documentation are necessary to implement RODs at the INEL. Post-ROD activities include the RD and RA phases. The RD/RA process will be streamlined, to the extent possible, to meet the CERCLA requirement to commence substantial continuous physical on-site remedial action within 15 months of issuance of a ROD.

\subsection{RD/RA Scoping Process}

Part 12.2 of the Agreement states that U.S. DOE will, within 21 days of issuance of the ROD, propose target dates and deadlines for completion of post-ROD documents. This requirement will be met for the RD phase through the submittal of an RD/RA SOW will establish deadlines for submittal of two primary documents required by Part VIII of the Agreement, the RD and the RA Work Plan. The RD/RA SOW establishes the overall strategy for managing the RD/RA and, therefore, applies to all phases and remedial work elements. The RD/RA SOW will include, at a minimum, the following:

- Strategy for RD/RA and rationale for remedial work element breakout

- Recommended RD/RA approach including:

- critical path schedule for the RD/RA process through RA work element commencement

- funding needs and funding availability for RD/RA

- brief description of the scope of each remedial work element

- $\quad$ plans to expedite RD/RA

- Description of issues that remain to be resolved or that require further analysis

- Identification of elements of the Community Relations Plan that will be implemented during RD/RA

Because it is not possible to define a single set of secondary documents that will be useful in all cases, the RD/RA SOW will establish the secondary documents associated with the RD phase and the target submittal dates for each ROD. Comments received on secondary RD documents will be incorporated into the following primary remedial design document, recognizing that RD secondary documents represent incremental steps toward completing the Remedial Design.

For complex remedies, the Project Managers may determine that RD/RA will be best accomplished by dividing the RD and the RA processes into smaller, more manageable remedial work elements. A remedial work element is a portion of a project that has been broken out through phasing. The criteria for phasing may be the availability of existing information, type of waste, type of medial involved, technology requirements, and/or funding availability. Although the Agreement identifies 
the Remedial Design and the RA Work Plan as separate primary documents, the Project Managers may choose to combine these documents into a single primary document. In this instance, elements of the RA Work Plan will be incorporated into the Remedial Design.

To streamline the RD/RA process, the RD/RA SOW is not defined as a primary or secondary document in the Agreement. The lead and support agencies will have $\mathbf{3 0}$ days after submittal to invoke dispute resolution regarding its content. However, all three Project Managers intend to participate in the development of the RD/RA SOW. Given the 21-day timeframe for submittal of the RD/RA SOW, it will be a brief document (10 to 15 pages, mostly figures and tables).

\subsection{Remedial Design Process}

In most cases, the Remedial Design phase will be initiated with the development of the RD Work Plan, a secondary document. For simple remedies, a separate RD Work Plan may not be necessary and the typical elements of the RD Work Plan could be incorporated into the RD/RA SOW. For complex remedies, a separate RD Work Plan may be developed for each identified work element. The RD Work Plan will include:

- Scope of preliminary and/or draft design documents

- Cost estimate for the RD phase

- Requirements for correlations between plans and specifications

- Identification of substantive permit requirements (see Part VII C of the Agreement)

- Identification and schedules for the preparation of other design elements (e.g., Additional Required Studies, Operation and Maintenance Plan, Quality Assurance Project Plan, Site Health and Safety Plan)

- Design approval procedures and requirements

Given the critical nature of the $\mathrm{RD}$, it will be necessary to provide the agencies with early design documents to ensure that consensus is maintained. This will be accomplished through the submittal of secondary design documents. In general, at least one secondary design document, the Preliminary Design, will be submitted. The Preliminary Design will typically represent $30 \%$ completion of plans and specifications. If available, preliminary results of any additional required studies may be included.

The Remedial Design will include:

- Plans and specifications for remedial action including design and analysis and construction drawings and specifications

- Cost estimate for remedial action

- O\&M Plan

- QAPjP

- Site H\&S Plan 
- Results of additional required studies, if any.

The Draft RD (prefinal Design) will include all aspects of the design and be essentially complete. It will be considered representative of approximately $90 \%$ design completion. The final $10 \%$ of the design will include the resolution of comments on the Draft RD and preparation of reproducible construction drawings and specifications ready for bid advertisement. These changes and additions will be included in the Draft Final RD, which is $100 \%$ design.

\subsection{Remedial Action Process}

The RA Work Plan will incorporate, by reference, pertinent aspects of the RD Work Plan. It will

- Specify any relevant changes in the content of the RD Work Plan arising from the design effort

- Update and expand upon schedules in the RD Work Plan by including dates for the submittal of primary and secondary documents for that remedial work element

- Update and expand upon the cost estimate for RA in the RD and

- Identify additional RA secondary documents.

The remedial action process includes the preparation of at least one primary and one secondary document. The Prefinal Inspection Report will be a secondary document that will include:

- Outstanding construction requirements

- Actions required to resolve items

- Completion date and

- Date of final inspection.

The prefinal inspection will be conducted by the Project Managers, at a minimum, and possibly by an independent fourth party. DOE will prepare the Prefinal Inspection Report. Although DOE will respond to comments received, the Prefinal Inspection Report will not be revised but, rather, will be finalized in the context of the primary RA Report. To the extent possible, RA Reports for individual work elements will be consolidated into a singe RA Report.

The RA Report will be prepared at the completion of remedial action and will include:

- A brief description of outstanding items from the Prefinal Inspection Report

- Synopsis of work defined in RA Work Plan and certification that this work was performed

- Explanation of any modifications to the RA Work Plan

- Certification that the remedy is operational and functional, and

- Documentation necessary to support deletion of the site from the NPL, as discussed in Part XXV of the Agreement. 
RD/RA Guidance

Rev. 1

$10 / 13 / 93$

2.14 Operation and Maintenance

At the completion of O\&M activities, the DOE-ID will prepare and submit an O\&M Report to the EPA and IDHW. To the extent possible, O\&M Reports for individual work elements will be consolidated into a single O\&M Report. This primary document will include the following elements:

- Description of O\&M activities performed

- Results of site monitoring, verifying that the remedy meets the performance criteria and

- Explanation of additional O\&M (including monitoring) to be undertaken at the site. 


\section{Appendix B}

\section{List of Applicable U.S. Department of Energy Orders}

Below is a listing of documents that relate to the implementation of the Remedial Design and Remedial Action Process. These documents provide project management systems and requirements pertinent to the RD/RA guidance outlined in the INEL FFA/CO.

DOE Order $4700.1(06 / 02 / 92)$

DOE-ID $4700.1(11 / 25 / 88)$

DOE Order 1324.5A (04/30/92)

DOE Order $5400.1(06 / 29 / 90)$

DOE-ID $5400.1(08 / 12 / 91)$

DOE Order $5400.4(10 / 06 / 89)$

DOE-ID $5400.4(07 / 09 / 91)$

DOE Order $5400.5(06 / 05 / 90)$

DOE-ID $5400.5(10 / 07 / 91)$

DOE Order 5480.1B (03/27/90)

DOE-ID 5480.1B $(08 / 12 / 91)$

DOE Order $5480.4(09 / 20 / 91)$

DOE-ID $5480.4(08 / 12 / 91)$

DOE Order $5480.9(11 / 18 / 87)$

DOE-ID $5480.9(09 / 23 / 91)$

DOE Order $5480.11(06 / 17 / 92)$

DOE-ID $5480.11(08 / 27 / 91)$
Project Management System: Establishes the principles and requirements that govern the development, approval, and execution of the DOE Project Management System.

Records Management Program: Establishes guidelines for creation, maintenance, use, and disposition of records.

General Environmental Protection Program: Specifically defines environmental protection requirements, authorities and responsibilities for DOE operations.

CERCLA Requirements: Establishes policies and procedures for implementation of CERCLA requirements, as set forth in the National Oil and Hazardous Substances Pollution Contingency Plan, to all DOE elements and contractors.

Radiation Protection of the Public and the Environment: Establishes standards and requirements for operations of the DOE and contractors with respect to protection of the public and the environment from undue risk from radiation.

Environmental Safety and Health Program for DOE Operations: Establishes the Environmental Safety and Health Program for DOE Operations, and applies to all elements, contractors, and subcontractors.

Environmental Protection, Safety, and Health Protection Standards: Specifies the mandatory environmental protection, safety, and health standards applicable to facility design, construction, operation, modification, and decommissioning.

Construction Safety and Health Program: Establishes guidance for development of procedures and requirements that provide for worker safety and protection during construction activities. Also establishes definition of contractor.

Radiation Protection for Occupational Workers: Establishes radiation protection standards and requirements for workers at DOE facilities. 
DOE Order $5480.19(05 / 18 / 92)$

DOE-ID $5480.19(09 / 23 / 91)$

DOE Order $5480.22(09 / 15 / 92)$

DOE Order $5480.23(04 / 30 / 92)$

DOE Order 5481.1B (05/19/87)

DOE-ID 5481.1B (10/18/91)

DOE Order $5700.6 \mathrm{C}(08 / 21 / 91)$

DOE-ID 5700.6D (08/06/92)

DOE Order 5820.2A (09/26/88)

DOE Order 6430.1A (04/06/89)

DOE-ID 6430.1A (07/20/89)

ERWM Managing for Safety and Quality Manual $(06 / 91)$
Conduct of Operations for DOE Facilities: Provides guidelines and requirements for use in development of directives, plans and/or procedures related to the conduct of operations at DOE facilities.

Technical Safety Requirements: Establishes DOE's nuclear facility technical safety requirements.

Nuclear Safety Analysis Reports: Establishes the requirements to obtain an approved SAR and authorization to operate a nuclear facility.

Safety Analysis and Review System: Requires safety analyses on all hazards identified for activities or facilities being proposed.

Quality Assurance: Sets forth the principles for achieving, assessing, and managing quality assurance.

Radioactive Waste Management: Establishes policies, guidelines, and minimum requirements by which DOE will manage its radioactive and mixed waste and contaminated facilities.

General Design Criteria: Establishes the responsibilities and authorities for the development and maintenance of general design criteria, for use in the acquisition of DOE facilities.

Provides policy statements and procedures that define project management requirements for the Environmental Restoration Program. 


\section{EPA Engineering Issue}

\section{DATA GAPS IN REMEDIAL DESIGN}

John E. Moylan

The Regional Superfund Engineering Forum is a group of EPA professionals, representing EPA's Regional Superfund Offices, committed to the identification and resolution of engineering issues impacting the remediation of Superfund sites. The Forum is supported by and advises the Superfund Technical Support Project.

This paper was prepared by the U.S. Army Corps of Engineers (US ACE), Kansas City District, Geotechnical Branch in cooperation with the EPA Engineering Forum. Engineering Forum review and comments were coordinated by Ken Erickson (Region IX), Forum Co-chair. For further information contact John Moylan at FTS 867-3455 or Ken Erickson, FTS 484-2324.

\section{Introduction}

As the number of Superfund sites in the phases of Remedial Design (RD) and Remedial Action (RA) has grown, we have become increasingly aware of the adverse effects of inadequate or insufficient design data. This paper is intended for use by RPMs as a checklist or reminder to consider certain aspects of RD/RA data needs as early as possible in the life of a Superfund site. Most of the items have been gleaned from the collective memory of EPA and USACE personnel who have learned some of the lessons the hard way.

The items addressed include:

- types of data where quality or quantity is most often found to be inadequate or have the greatest effect on successful RD and RA;

\section{U.S. Army Corps of Engineers \\ Kansas City District Geotechnical Branch}


examples of why these data are needed;

- data needs for particular remediation features;

Many design problems causing schedule slippage or cost overruns in either RD or RA can be attributed to site characterization data that are not sufficient for purposed of design. (No attempt is made in this paper to address potential inadequacies in interpretation of the site characterization data.) These data gaps affect not only highly technological treatment processes but also the more mundane aspects of remediation such as caps and liners.

Technical work during the RI/FS phase has typically been considered the province of scientists whereas engineers are given the functional lead during RD/RA. The engineers have not always been requested to provide significant input during RI/FS. Similarly, the scientists have often not been made available during RD/RA. Consequently, some RODs or settlement agreements have dictated remedies that are only marginally appropriate or not effective at all, much more costly than anticipated, or virtually impossible to implement.

The RPM should consider that a broad-spectrum technical assistance team is a key aspect to successful management of the site from beginning to end. Under ideal circumstances, this team should consist of members from organizations other than the contractors used by Superfund. The starting point is the Regional Engineering Forum representative and other Regional technical specialists, such as the Technical Support Sections formed by some Regions or experiences RPMs, who can participate in the peer review process. Other resources include the Technical Support Centers (under the auspices of the OSWER Technology Innovation office Technical Support Project), U.S. Army Corps of Engineers, U.S. Bureau of Reclamation, U.S. Bureau of Mines, state agencies, and so forth.

It should be noted that typically design engineers are accustomed to working from a clearly defined problem. Unfortunately, most subsurface and ground water contamination sites lack the degree of site characterization needed to clearly define the design at the beginning of the RD phase. Therefore, it is important that the scientific disciplines be available throughout out the entire RD/RA period to further define site conditions and provide interpretations for the engineer. This will help assure an expeditious and satisfactory implementation of the design.

A few examples of problems associated with incomplete site characterization data follow:

1. Soils properties and handling characteristics are often poorly evaluated or even ignored when considering various remediation technologies which require materials excavation and processing. 
2. Volatile emissions during excavation and handling of contaminated soils are often not anticipated.

3. Lace of information on temporal and spatial variations in contaminant loading in ground water remediation decisions can lead to inefficient designs.

4. No pre-ROD consideration of availability of utilities resulting in underestimation of costs or schedule.

5. Poor understanding of the permeability of slurry wall key layer leading to unacceptable leakage.

6. Ground water treatment processes which focus on the contaminant of interest but ignore total ground water chemistry, especially the anions and cations present, will impact the effectiveness of the treatment process.

7. Solvent extraction of explosives from soil is feasible, however, the unrecognized instability of the residue can be disastrous.

8. Cap designs which utilize the cost-effectiveness of geosynthetics but require slopes on which geosynthetics are not stable or caps which require the use of low permeability clays but don't evaluate the availability of suitable clay borrow material can be impractical to construct or very costly.

9. Excavation limits may be defined based on chemical analysis of bore hole samples and not account for contaminant migration along secondary pathways, e.g., root holes. Trenching and careful inspection and sampling may alleviate this problem.

10. The presence of debris or boulders may not be recognized or fully appreciated during the analysis of remedial alternatives if bore holes along are used to investigate the limits of waste.

The term geochemical is used rather than the more narrow chemical term in order to emphasize the importance of understanding the chemical process operating in the geological environment in order to implement effective remediations. The importance of quality analytical chemistry is already well understood and appreciated, however, our understanding of ongoing chemical processes needs improvement. The following paragraphs identify some commonly overlooked data requirements and include examples of problems resulting from the data gaps.

Site Data needs are often overlooked in the pre-ROD/consent degree phase and even well into design. Unforeseen cost increases, time delays, and contract modifications can do result. Some common data needs include:

1. Topographic Surveys - The need should be readily apparent, however, this aspect is often overlooked. In some instances, available general topographic mapping is 
used without verification. Consequently during RA, excavation of fill overruns or underruns or impossible site drainage are discovered which require contract modification. Property boundary surveys and adequate horizontal and vertical controls are also included in this category.

2. Utility Availability - Water, gas, power, and sewer services required for remedy implementation must be identified. In addition, leaking industrial sewer lines might be contamination sources and previously unidentified utility lines crossing a remediation site can cause contract shutdown pending their relocation or protection.

3. Borrow Availability - In most cases, site remediation which includes earthwork, e.g., liners, caps, slurry walls, etc., require the utilization of earth materials to effect the remediation. When those materials are not available from required onsite excavation, they must be obtained elsewhere and are referred to as borrow. In some areas suitable borrow is scarce. The costs of trucking suitable material from a distance borrow pit will add significant cost and transportation problems if not recognized. As an example, a 5-acre cap with an average thickness of 3 feet of soil, requires almost 25,000 cubic yards or approximately 1,400 truckloads of suitable earth borrow material. The availability of admixtures such as fly ash, cement, and lime for stabilization should also be considered in this category.

4. Transportation Network - The proximity of suitable roadways and/or rail lines is important to remedies requiring the transportation of heavy equipment and earth materials into the site or contaminated or treated wastes from the site. Local opposition to frequent heavy truck traffic and damage to streets and roads, especially through residential areas, must be anticipated.

Geochemical Data collection can often be improved to more confidently select effective remedies and better effect quality RD and RA. Some examples include:

1. Multiple Sampling Rounds - In too many cases, remediation decisions are made which are based on single or poorly timed, multiple ground water sampling rounds. Time allowed for RD often doesn't provide for seasonal sampling. As a result, chemical loading may exceed treatment plant capability, the plant may be over-designed, or the operating plan is not optimized to accommodate variations in loading.

2. Anion/Cation Analysis - These analyses are inexpensive, yet if they are overlook in ROD preparation, the designed treatment train may be either more expensive than anticipated or ineffective if not detected during $\mathrm{RD}$. Eh, $\mathrm{pH}$, and TOC are other chemical parameters that must be considered for effective RD.

In addition, cautions should be exercised when unusually high metals analyses are obtained from turbid ground water samples. If these analyses are used for treatment plant design, the design and cost estimates can be unrealistic. Total chemistry also 
impacts well design. Anion and cation precipitates will prematurely clog injection wells if not recognized and treated.

Geotechnical Data must be gathered for many types of remedies, both for purposes directly related to the remedial process and for design auxiliary to the actual remedial process, such as building foundation design or excavations.

1. Soil Moisture Content - The natural moisture content of site soils, especially finegrained soils, is valuable information both in the pre-ROD and RD phases. As examples, the moisture content of contaminated soil that will receive thermal treatment affects fuel consumption and the moisture content of a fine-grained foundation soil can be an indicator of the soils strength and consolidation characteristics.

2. Atterberg Limits - These parameters define the plasticity of fine-grained soils, give the geotechnical designer an early indication of the strength of that soil, especially when evaluated with moisture content, and can be an indicator of contaminated soil handling and processing characteristics. The test is relatively inexpensive but the results can be very useful.

3. Soil Strength Parameters - Generally not needed prior to the RD phase. Some design features requiring soil strength testing include structure or building foundations, significant excavations, dredging, and slurry wall trenches. Blow counts from Standard Penetration Tests can be used as an early indication of soil strength.

4. Gradations - Some representative gradations or particle size distribution analysis done in the RI/FS phase can be very helpful in estimating approximate permeability and for designing efficient monitoring wells. Gradations are required for the design of such things as collection drains and withdrawal wells and in evaluating soils handling and processing characteristics.

5. Excavatability - While there is no one test or set of tests to define this design parameter, evaluations and judgments should be made in the pre-ROD phase concerning excavatability when excavations of any kind are required in the remedy. Excavatability includes such factors as whether the material can be machine excavated, the necessity for blasting, the existence of boulders or cobbles, the need for dewatering, etc. None of the excavatability factors should be minimized since all of them can greatly impact the final cost of remediation.

6. Landfill Subsidence - remediations often include capping an existing landfill and perhaps incorporating a gas collection and venting system. Many such landfills are still subsiding with attendant surface disruptions capable of adversely impacting the effectiveness of the cap and vent system. Carefully surveyed settlement data collected throughout the RI/FS phase are invaluable for remedy selection and to support design. Settlement data collection should continue 
through RD and RA and into the operations and maintenance phase if displacements are continuing and significant.

Hydrogeological Data are routinely collected both during the RI/FS and RD phases. However, several aspects will be discussed which are sometimes slighted but can be very important to selection an an effective remedy and to proper design and implementation.

1. Multiple Water Levels - In order to understand the hydrogeological character of the site in sufficient detail to select an effective remedy, it is important that enough water levels be obtained to define both the vertical and horizontal flow directions seasonally and as they respond to both natural and manmade recharge and discharge. For example at a ground water contamination site in the Plains States, the regional flow is severely distorted locally by irrigations pumping during several months of the year.

2. Detailed Stratigraphy - In too many cases, stratigraphic detail has not been well developed due to poor sample recovery often coupled with too infrequent sampling intervals, lack of geophysical logs, improper sampler selection, field geologists poorly trained in logging methods, or combinations of he above. Even relatively minor variations in lithology have a strong influence on contaminant migration and plume development. This is an important factor during pre-ROD, $\mathrm{RD}, \mathrm{RA}$, and even into the operation and maintenance phase of both ground water and vadose zone remediation.

Secondary Porosity Features - Joints, defoliation planes, bedding planes, root holes, etc., often strongly influence the overall gross permeability of bedrock materials and fine-grained souls, especially clays. In too many cases these features are not targeted during site exploration or if they are, the vertical features are difficult to intercept and analyze. Careful consideration of these features is warranted during the RI/FS phase and remedy selection for problems such as contaminated bedrock aquifers, multiple stacked aquifers, and slurry walls keyed into an impermeable layer. For sites such as these, additional characterization will also be needed during RD.

The various types of site characterization data discussed in this paper are not needed or at least not to the same degree for all feature of site remediation. The following remediation features were considered:

1. Withdrawal \& injection wells

2. Internal drains

3. Slurry walls

4. Slurry wall key layer

5. Caps

6. Chemical Stabilization

7. Ground water treatment Landfills 
9. Thermal treatment

10. Soil washing

11. Excavations

12. Dredging

13. Vapor extraction

Table 1 presents a summary of site characterization data determined to be useful or needed for remediation. The table also suggests in which phase or phases of the remediation process it is advantageous to acquire the data. 


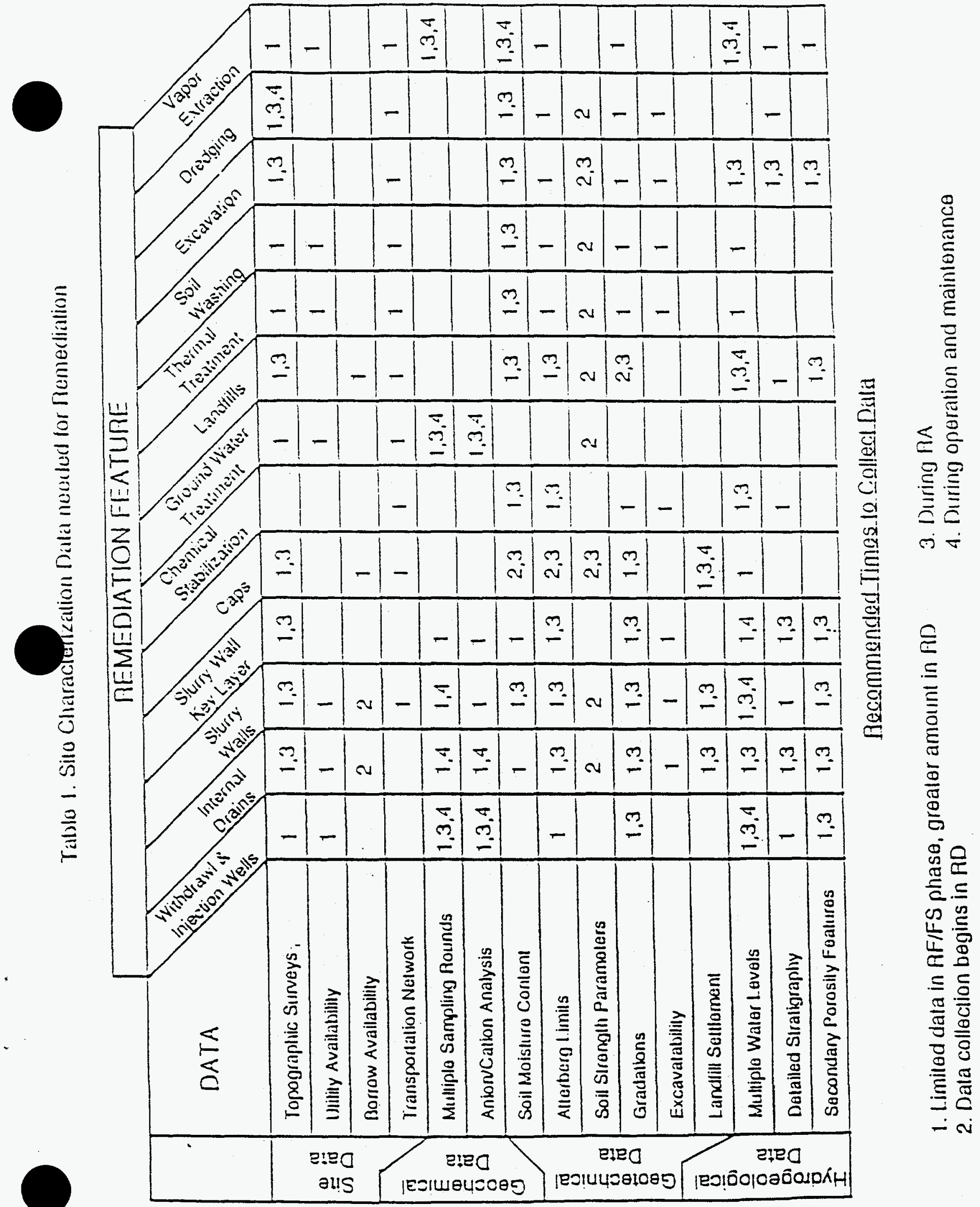




\section{Comments for RD/RA Guidance Document, rev 0, 6/25/93 (DOE)}

\section{8/06/93}

\begin{tabular}{|c|c|c|c|c|}
\hline ITEM & SECTION & PAGE & COMMENTS & RESOLUTION \\
\hline 1 & General & & $\begin{array}{l}\text { This guidance reiterates the philosophies of team work and cooperation } \\
\text { that we have been trying to foster all along during development of the } \\
\text { FFA/CO. As far as real guidance though, it could have been more } \\
\text { concise and clear on what it will look and smell like when l've done a } \\
\text { good job of following the guidance. }\end{array}$ & $\begin{array}{l}\text { Comment noted, but the guidance is not intended to be a } \\
\text { cookbook and the level of detail is reflected by that fact. }\end{array}$ \\
\hline 2 & General & & $\begin{array}{l}\text { There is a stated philosophy that only key issues should be reviewed by } \\
\text { EPA and IDHW, yet there seems to be a trend to establish several new } \\
\text { deliverables such as issue resolution plans and an RD/RA strategy. I } \\
\text { believe there should be more emphasis on WAG manager communication } \\
\text { and we should be very careful about establishing new deliverables and } \\
\text { reviews which are the biggest time consumers on most schedules. }\end{array}$ & $\begin{array}{l}\text { The guidance does not establish any new deliverables, but } \\
\text { emphasizes the need for documentation of communication in } \\
\text { existing deliverables. Where possible it will be clarified that the } \\
\text { plans mentioned are intended to be part of an existing } \\
\text { document. }\end{array}$ \\
\hline 3 & General & & $\begin{array}{l}\text { There are a number of editorial things that need to be corrected. A } \\
\text { technical editor should be used before it the document goes final. For } \\
\text { example, memoranda is plural for memorandum and acronyms aren't } \\
\text { always written out at the first usage. }\end{array}$ & The guidance has been tech edited prior to being issued. \\
\hline 4 & General & & $\begin{array}{l}\text { Unless EPA and IDHW will have a role in ensuring DOE compliance with } \\
\text { its own requirements, discussion of applicable DOE Orders and } \\
\text { requirements should be minimized. }\end{array}$ & $\begin{array}{l}\text { Comment noted, however the RD/AA committee felt the level of } \\
\text { the discussion currently in the guidance was appropriate. }\end{array}$ \\
\hline 5 & General & & A discussion of site close-out following cleanup should be presented. & $\begin{array}{l}\text { This comment will be incorporated in future revisions after } \\
\text { some experience on what this entails at the INEL is gained. }\end{array}$ \\
\hline 6 & General & & $\begin{array}{l}\text { Present more discussion regarding characterization sampling during the } \\
\text { RD Stage. For example, suppose a Track } 2 \text { investigation demonstrates } \\
\text { the need for an interim or removal action and there is not sufficient } \\
\text { information to design the action. }\end{array}$ & $\begin{array}{l}\text { The inclusion of a Sampling and Analysis Plan (SAPI in the } \\
\text { RD/RAWP will be included in Section } 4.3 \text {. }\end{array}$ \\
\hline 7 & General & & $\begin{array}{l}\text { More detail is needed regarding the transition during finalization of the } \\
\text { ROD and development of the RD/RA SOW and RD Work Plan. }\end{array}$ & $\begin{array}{l}\text { Comment will be incorporated by expanding discussion in } \\
\text { Section } 2.2 \text {. }\end{array}$ \\
\hline 8 & General & & $\begin{array}{l}\text { Other than the examples, the document does not discuss the types of } \\
\text { contracting possibilities, how contracting fits into the process, and the } \\
\text { effects it may have on cost and schedule. Explain when development of } \\
\text { the RFP fits into the schedule, what impacts may the contracting process } \\
\text { have on the schedule and when does the mechanism for doing the work } \\
\text { need to be determined in the process. Identify the mechanism for } \\
\text { keeping all three parties involved and outline their responsibilities for } \\
\text { these matters. }\end{array}$ & $\begin{array}{l}\text { To some degree this information is contained in the referenced } \\
\text { EPA guidance. The RD/RA committee agreed that this } \\
\text { information will be incorporated in the next revision to the } \\
\text { document. In the interest of timeliness, however, it has not } \\
\text { been included in this edition of the guidance. }\end{array}$ \\
\hline
\end{tabular}




\begin{tabular}{|c|c|c|c|c|}
\hline ITEM & SECTION & PAGE & COMMENTS & RESOLUTION \\
\hline 9 & $\begin{array}{l}\text { General - } \\
\text { examples }\end{array}$ & & $\begin{array}{l}\text { The examples are positive to an extreme. Instead of stating this is how it } \\
\text { was done in the example land all is a perfect world), it would possibly be } \\
\text { more beneficial to point out key areas where deficiencies have occurred } \\
\text { to date and show other options to help things progress more smoothly. } \\
\text { A single Munchkin-Land example of the DOE WAG manager keeping her } \\
\text { wonderful and attentive counterparts informed is sulficient to get the } \\
\text { point across. }\end{array}$ & $\begin{array}{l}\text { The introduction to the examples will be modified to state that } \\
\text { the examples are idealized. A training session will be given on } \\
\text { the guidance and should include a lessons learned section to } \\
\text { help point out past problems. }\end{array}$ \\
\hline 10 & $\begin{array}{l}\text { General - } \\
\text { examples }\end{array}$ & & $\begin{array}{l}\text { In general many things are stated as being done differently from the way } \\
\text { they have been done previously. Hopefully this would be a big } \\
\text { improvement, however, additional detail is needed regarding the means } \\
\text { for accomplishing these things. Examples of items requiring additional } \\
\text { discussion of their implementation include NEPA EAs, RD/RA scoping at } \\
\text { the RI/FS stage, and SARs. }\end{array}$ & $\begin{array}{l}\text { Examples of these items have been included in the two } \\
\text { examples in Section } 8.0 \text {. Because these items are extremely } \\
\text { project specific they would need to be worked on a case-by-case } \\
\text { basis and so have not been included in the guidance. Additional } \\
\text { text will be added on RD/RA scoping at the RI/FS stage. }\end{array}$ \\
\hline 11 & 2.2 & 3 & $\begin{array}{l}\text { Please explain what is meant by "involvement of the RD/RA contractor in } \\
\text { planning for the RI/FS or interim action". This section and further } \\
\text { descriptions in section } 2.4 \text {. might be interpreted by some as a conflict of } \\
\text { interest by the RD/RA contractor. A more definitive explanation is } \\
\text { needed for what the involvement is and what is allowed without crossing } \\
\text { the line into a conflict of interest. }\end{array}$ & $\begin{array}{l}\text { Text will be expanded to include more specilic verbiage on } \\
\text { RD/RA contractor involvement at the RI/FS stage. }\end{array}$ \\
\hline 12 & 2.2 & 3 & $\begin{array}{l}\text { It is unclear as to exactly when the RD/RA contractor is expected to } \\
\text { become involved in the CERCLA process. Is it possible to provide the } \\
\text { level of support as noted in the fifth sentence at such an early stage in } \\
\text { the RI/FS process? Provide more specific guidance on coordination } \\
\text { between the pre- and the post-ROD contractors. }\end{array}$ & See above resolution. \\
\hline 13 & Figure $2-1$ & 4 & $\begin{array}{l}\text { In the Remedial Design/Procurement Phase, delete the second block from } \\
\text { the top, "Primary Design Review Stage". The Preliminary Remedial } \\
\text { Design is a secondary document, even the footnote denotes that and } \\
\text { therefore would not be subject to a primary review. Delete the } \\
\text { connecting lines between "Primary Design Review Stage and } \\
\text { "Construction Subcontract Procurement." Typically construction is not } \\
\text { procured with a preliminary design. }\end{array}$ & $\begin{array}{l}\text { The figure has been revised to reflect this comment and } \\
\text { comments from EPA and IDHW. }\end{array}$ \\
\hline 14 & Figure 2-1 & 4 & $\begin{array}{l}\text { In the Remedial Action Phase, add, where appropriate, "shakedown" } \\
\text { since that is defined in section } 1.2 \text { and "proof of remedy". }\end{array}$ & $\begin{array}{l}\text { Comment noted, but this is too much detail for the intent of the } \\
\text { figure. }\end{array}$ \\
\hline 15 & 2.2 & 5 & $\begin{array}{l}\text { In the second paragraph, insert "procurement documents" after design } \\
\text { documents. }\end{array}$ & Comment incorporated. \\
\hline
\end{tabular}




\begin{tabular}{|c|c|c|c|c|}
\hline ITEM & SECTION & PAGE & COMMENTS & RESOLUTION \\
\hline 16 & 2.3 & 5 & $\begin{array}{l}\text { Add to the second sentence of the first paragraph of this section that a } \\
\text { team approach is also key to the success of the RD/RA process. }\end{array}$ & Comment incorporated. \\
\hline 17 & 2.3 & 5 & $\begin{array}{l}\text { Elaborate on the subject of the last paragraph on this page. Explain the } \\
\text { meaning of "dilute the accountability" and provide an example. }\end{array}$ & Paragraph deleted because it was beyond scope of document. \\
\hline 18 & 2.4 & 6 & $\begin{array}{l}\text { For sensitive readers, in the second sentence of item " } 1 \text {." clarify that } \\
\text { adequate consideration of constructability and implementability, design } \\
\text { data needs, and dependence on definition of RAOs is a shortcoming of } \\
\text { many feasibility studies prepared under CERCLA and not specifically } \\
\text { feasibility studies prepared at INEL. }\end{array}$ & Comment incorporated. \\
\hline 19 & 2.4 & 6 & $\begin{array}{l}\text { In the last paragraph on this page, provide more discussion on how plans } \\
\text { for issue resolution should be incorporated in RD/RA planning documents. } \\
\text { Identify the "RD/RA planning documents", other than the RD/RA SOW, } \\
\text { that are cited in the last sentence on this page. Emphasize that it is } \\
\text { preferable for the WAG Managers to handle as many issues as possible } \\
\text { informally through teamwork and communication and that plans in formal } \\
\text { documents are a last resort. }\end{array}$ & $\begin{array}{l}\text { Text has been revised. WAG managers should handle as many } \\
\text { issues as possible through teamwork, but the primary document } \\
\text { still remains their key to invoke a dispute. }\end{array}$ \\
\hline 20 & 2.5 & 7 & $\begin{array}{l}\text { A better approach to the discussion in the second paragraph would be to } \\
\text { identify items that are considered applicable and to allow those that think } \\
\text { something in addition is applicable to argue their case. II it is necessary } \\
\text { to justify why an element is "not applicable" the likely result will be that } \\
\text { everything will be classified as "applicable" because someone will } \\
\text { probably disagree with the justilication of its inapplicability. }\end{array}$ & Paragraph deleted as it was redundant. \\
\hline 21 & 2.5 & 7 & $\begin{array}{l}\text { The tech memos discussed in the third paragraph on this page should be } \\
\text { used sparingly and only to resolve large key issues that should not wait } \\
\text { for a primary or secondary document. Even though tech memos are not } \\
\text { primary or secondary, if they are a document on a schedule they require } \\
\text { significant time and resource commitments both in development and } \\
\text { review. Much more emphasis should be put on WAG manager } \\
\text { communication to reduce the need for documents to resolve issues. }\end{array}$ & $\begin{array}{l}\text { The discussion will be revised to clarify the intent of tech } \\
\text { memos as informational only and not for resolving issues. It will } \\
\text { also be emphasized that tech memos will be used only when } \\
\text { there is too much information or the information is too complex } \\
\text { to handle through informal communication by the WAG } \\
\text { managers. }\end{array}$ \\
\hline
\end{tabular}




\begin{tabular}{|c|c|c|c|c|}
\hline ITEM & SECTION & PAGE & COMMENTS & RESOLUTION \\
\hline 22 & 2.5 & 7 & $\begin{array}{l}\text { Clarify the first sentence of the first bullet. Indicate that agency time } \\
\text { constraints and limited resource availability do not allow for special } \\
\text { interest area reviews on the RD/RA docurnents. Indicate that special } \\
\text { interest reviews impede the overall cost effectiveness and efficiency of } \\
\text { the program. State explicitly that reviews should focus on factors that } \\
\text { affect the design and implementation of a remedy and that reviewers } \\
\text { should not expend resources commenting on differences in interpretation } \\
\text { or presentation that do not affect the integrity of the RD/RA process. }\end{array}$ & Comment incorporated. \\
\hline 23 & 2.5 & 7 & $\begin{array}{l}\text { Delete "etc" from the second sentence of the first bullet. The fact that } \\
\text { the list presented is not all inclusive is indicated by "such as" and "etc" is } \\
\text { redundant. }\end{array}$ & Comment incorporated. \\
\hline 24 & 2.5 & 8 & $\begin{array}{l}\text { In the last bullet, explain what "Design and/or Operational Readiness } \\
\text { Quality Review meetings" entail and when they occur. Identify criteria } \\
\text { that EPA and IDHW measure during an Operational Readiness Quality } \\
\text { Review. Explain the difference between this meeting and the one } \\
\text { describe in Section } 4.5 .1 \text {, the tri-party design review meeting on the } \\
\text { Preliminary Design or the Prefinal Inspection. If these meetings are the } \\
\text { same, can this bullet be deleted. Delete the quotation marks in this bullet } \\
\text { unless a source can be cited. }\end{array}$ & Text deleted as it is already covered in Section 4.5.1. \\
\hline 25 & 2.6 & 8 & $\begin{array}{l}\text { Make it clear in this section that, except in emergency situations, only } \\
\text { DOE should be giving direction to its contractors. Emphasize that, } \\
\text { similarly to document reviews, field oversight should focus on key critical } \\
\text { issues. In the third paragraph of this section, rather than stating that } \\
\text { visits will be coordinated "where appropriate", state that visits will be } \\
\text { coordinated unless it is inappropriate and then provide examples of where } \\
\text { coordination might be inappropriate. }\end{array}$ & Comment incorporated. \\
\hline 26 & 2.7 & 9 & $\begin{array}{l}\text { Many reviewers were unfamiliar with the paradigms suggested. A } \\
\text { Description and explanation of these paradigms in an appendix would be } \\
\text { useful as would references for them. Also, if appropriate, a training } \\
\text { program in these paradigms should be initiated. Suggest the use of the } \\
\text { word "models" rather than "paradigms" because its meaning is } \\
\text { essentially the same and it is more widely understood by plain folks } \\
\text { implementing the RD/RA process and living in the hills of ldaho. }\end{array}$ & $\begin{array}{l}\text { The term models will be used instead of paradigms, but an } \\
\text { appendix on these concepts will not be included. If program } \\
\text { personnel are not familiar with these concepts than they need to } \\
\text { solve this problem outside the realm of this guidance. }\end{array}$ \\
\hline 27 & 2.7 & 9 & Change "effect" to "alfect" in the fourth bullet under item "3.". & Comment incorporated. \\
\hline
\end{tabular}




\begin{tabular}{|c|c|c|c|c|}
\hline ITEM & SECTION & PAGE & COMMENTS & RESOLUTION \\
\hline 28 & 2.7 & 9 & $\begin{array}{l}\text { In the fourth paragraph, recommend changing the second sentence to } \\
\text { read "Planning for emergency events will be consistent with the facility } \\
\text { emergency response plan and will be documented in the emergency } \\
\text { response procedures included in the RA Work Plan or O\&M Plan". This } \\
\text { change reflects direction that has been provided by the operating } \\
\text { facilities during the development of emergency documentation for the } \\
\text { interim actions currently underway. }\end{array}$ & Comment incorporated. \\
\hline 29 & 2.7 & 10 & Change "effect" to "affect" in item "5.". & Comment incorporated. \\
\hline 30 & 3.1 & 11 & $\begin{array}{l}\text { The approach to RD/RA SOW and RD Work Plan development presented } \\
\text { in the second paragraph needs to be re-evaluated. The paragraph states } \\
\text { that, as standard practice, an RD Work Plan is not necessary. The } \\
\text { second sentence goes on to state, however, under those circumstances } \\
\text { where you need more information, an RD Work Plan can be produced to } \\
\text { satisfy this need, but, it should be completed at the same time as the } \\
\text { RD/RA SOW as a combined document. Given the flexibility of the } \\
\text { approach outlined in the guidance, it appears that any required } \\
\text { information, if it is available, could be presented in an "RD/RA SOW" } \\
\text { rather than an "RD/RA SOW and RD Work Plan". Arguably, the only } \\
\text { reason to have an RD Work Plan would be because sulficient information } \\
\text { to completely plan the RD effort is not available when the SOW is } \\
\text { developed. In other words, all RD/RA SOWs should, in essence, be } \\
\text { combined RD/RA SOWS and RD Work Plans unless, due to an inability to } \\
\text { completely plan the RD effort during the development of the SOW, it is } \\
\text { necessary to write a separate RD Work Plan. II all the design phase } \\
\text { planning cannot be completed and presented in the RD/RA SOW an RD } \\
\text { Work Plan should be submitted as a separate document later or, perhaps, } \\
\text { submitted as part of a conceptual design document. }\end{array}$ & Section 3.1 will be revised to incorporate this comment. \\
\hline 31 & 3.1 & 11 & $\begin{array}{l}\text { In the second sentence of the third paragraph, clarify who receives the } \\
\text { RD/RA SOW from DOE-ID. }\end{array}$ & Comment incorporated. \\
\hline 32 & 3.3 & 11 & $\begin{array}{l}\text { Identify in the text, by example if necessary, the significant elements that } \\
\text { are extracted from the RD Work Plan and presented in the modified } \\
\text { RD/RA SOW. }\end{array}$ & $\begin{array}{l}\text { The FFA/CO Action Plan text is included in Appendix } A \text { and the } \\
\text { elements can be found there. }\end{array}$ \\
\hline
\end{tabular}

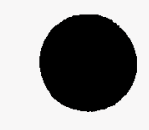




\begin{tabular}{|c|c|c|c|c|}
\hline ITEM & SECTION & PAGE & COMMENTS & RESOLUTION \\
\hline 33 & 3.3 & 11 & $\begin{array}{l}\text { Following the last sentence on this page elaborate on situations where } \\
\text { some elements of the RD/RA SOW presented in the guidance might not } \\
\text { be applicable. Providing examples may be the easiest way to define } \\
\text { these situations. }\end{array}$ & $\begin{array}{l}\text { Text changed to "The emphasis placed on elements of the } \\
\text { RD/RA SOW identified in this section will vary based on the } \\
\text { specifics of a project. For example, the RD/RA SOW for a } \\
\text { simple, straight forward project may contain little or no } \\
\text { discussion of some of the elements identified. In contrast a } \\
\text { complex project may warrant detailed discussion of each } \\
\text { element in turn." }\end{array}$ \\
\hline 34 & 3.3.4 & 12 & $\begin{array}{l}\text { Emphasize that every elfort should be made by the WAG Managers to } \\
\text { resolve issues informally through teamwork and cooperation and that } \\
\text { formal documentation of unresolved issues should be used only as a last } \\
\text { resort. }\end{array}$ & $\begin{array}{l}\text { An effort has been made to emphasize teamwork and } \\
\text { cooperation throughout the document. The second sentence } \\
\text { has been revised to clarify that the plan to resolve issues is an } \\
\text { integral part of the RD/RA SOW. }\end{array}$ \\
\hline 35 & 3.3.5 & 13 & $\begin{array}{l}\text { In the third paragraph, clarify whether an article in the INEL Reporter } \\
\text { represents an adequate "Fact Sheet". }\end{array}$ & $\begin{array}{l}\text { An article in the INEL Reporter would meet the requirement } \\
\text { cited. The text has been clarified to read, "An article in the INEL } \\
\text { Reporter could serve this purpose, however, in some cases a } \\
\text { more detailed presentation in a fact sheet dedicated to the } \\
\text { project may be warranted." }\end{array}$ \\
\hline 36 & 3.3.6 & 13 & $\begin{array}{l}\text { With regard to the second bullet, elaborate on what constitutes } \\
\text { compliance with ARARs. Recognizing that it is project dependent, } \\
\text { elaborate on what level of detail is appropriate. It is also important to } \\
\text { recognize that it may not be possible to spell out in great detail what } \\
\text { constitutes compliance with ARARs in the SOW. It may be more } \\
\text { appropriate to provide a detailed discussion of ARAR compliance in the } \\
\text { Remedial Design. }\end{array}$ & $\begin{array}{l}\text { Additional discussion of compliance with ARARs has been } \\
\text { added. }\end{array}$ \\
\hline 37 & 3.3 .6 & 13 & $\begin{array}{l}\text { With regard to the third bullet, any DOE specific permits should also be } \\
\text { included so that it is clear what is required and where they fit in the } \\
\text { project. }\end{array}$ & Comment incorporated. \\
\hline 38 & 3.3 .8 & 13 & $\begin{array}{l}\text { Elaborate on the level of detail required to identify the referenced } \\
\text { measurement methods. }\end{array}$ & $\begin{array}{l}\text { Comment incorporated. A sentence has been added to state } \\
\text { that measurement methods will be identified as precisely as } \\
\text { possible, but given the early stage of projects, it may only be } \\
\text { possible to identify them conceptually. }\end{array}$ \\
\hline 39 & 3.3 .9 & $\begin{array}{l}13 \\
8 \\
14\end{array}$ & $\begin{array}{l}\text { Identify weather as a bounding assumption. It affects both cost and } \\
\text { schedule in the design and implementation. There is a need to balance } \\
\text { weather related cost and scheduling problems with a let the schedule fall } \\
\text { were it falls approach. }\end{array}$ & Comment incorporated. \\
\hline
\end{tabular}




\begin{tabular}{|c|c|c|c|c|}
\hline ITEM & SECTION & PAGE & COMMENTS & RESOLUTION \\
\hline 40 & 3.3 .9 & 14 & $\begin{array}{l}\text { In the sixth bullet add SARs with NEPA in parenthesis. NEPA bounding } \\
\text { requirements are apparent prior to beginning RD/RA, however, SAR } \\
\text { requirements are not. Explain how the potential for SAR requirements to } \\
\text { differ from requirements outlined in final CERCLA documents can be } \\
\text { addressed. Identify the mechanism for and level of involvement for the } \\
\text { IDHW and EPA in changes resulting from SAR requirements. }\end{array}$ & $\begin{array}{l}\text { Comment noted, but this level of detail is not appropriate to the } \\
\text { intent of the guidance. SARs have been added to parenthesis. }\end{array}$ \\
\hline 41 & 3.3 .10 & 14 & $\begin{array}{l}\text { Rather than identifying specific design criteria at the SOW stage which is } \\
\text { the initial step in the RD/RA process, general design criteria be } \\
\text { developed. These criteria should be fine tuned through the design } \\
\text { process and become more specific with each stage of the design process } \\
\text { le.g. the Preliminary Design, the Prefinal Designl. Insert "general" after } \\
\text { "Development of the ..." in the first sentence. In the second sentence, } \\
\text { add "as identified in the ROD." after "Operational parameters". In the } \\
\text { third sentence, delete "conceptual". Delete the last sentence that } \\
\text { requires specificity and completeness. }\end{array}$ & Comment incorporated. \\
\hline 42 & 3.3.11 & 14 & $\begin{array}{l}\text { Elaborate on plans to deal with changed conditions. Provide a general } \\
\text { plan for dealing with changed conditions that the WAG Managers can } \\
\text { adapt and implement as appropriate on their projects. }\end{array}$ & Comment incorporated. \\
\hline 43 & 3.3.13 & 14 & $\begin{array}{l}\text { Clarify this paragraph. Explain what is being correlated with what and } \\
\text { why it is being correlated. }\end{array}$ & Comment incorporated. \\
\hline 44 & 3.3 .14 & 14 & $\begin{array}{l}\text { In the second paragraph in this section identify the items being referred } \\
\text { to by "etc" and delete "etc". }\end{array}$ & Comment incorporated. \\
\hline 45 & 3.4 & 15 & $\begin{array}{l}\text { As commented earlier, submittal of the RD Work Plan in combination with } \\
\text { the RD/RA SOW may not be the best approach. If the design is } \\
\text { extremely complex, it would be more appropriate to take additional time } \\
\text { to fully develop the RD Work Plan elements rather than meeting the early } \\
\text { deliverable date of the RD/RA SOW. }\end{array}$ & Section revised to reflect comment. \\
\hline 46 & 3.5 .1 & 15 & $\begin{array}{l}\text { The discussions of phasing are not clearly developed and presented in } \\
\text { this section. Portions appear to conflict with what is intended. }\end{array}$ & Comment incorporated. \\
\hline
\end{tabular}




\begin{tabular}{|c|c|c|c|c|}
\hline ITEM & SECTION & PAGE & COMMENTS & RESOLUTION \\
\hline 47 & 3.5 .1 .1 & 15 & $\begin{array}{l}\text { Please explain why an SOW should be developed for a contingent } \\
\text { remedy. It is not appropriate to expend the resources at this preliminary } \\
\text { stage developing a plan of action for a contingent remedy. "This } \\
\text { approach is based on the assumption that no ESD would be needed to } \\
\text { implement the contingent action because the contingent action } \\
\text { established in the ROD is fully planned." According to OSWER 9355.3- } \\
\text { 02, "Interim Final Guidance on Preparing Superfund Decision } \\
\text { Documents," the use of contingent remedies should be limited. Explain } \\
\text { why a new SOW cannot be developed for the contingent remedy at the } \\
\text { time the preferred alternative is deemed unworkable. In this way the } \\
\text { work proceeds based on the assumption that the prelerred alternative is } \\
\text { indeed workable, feasible, and technically achievable. }\end{array}$ & $\begin{array}{l}\text { Comment incorporated. The guidance has been revised to state } \\
\text { that a SOW for a contingent remedy should not be written until } \\
\text { the remedy is triggered. }\end{array}$ \\
\hline 48 & 3.5 .1 .1 & 15 & $\begin{array}{l}\text { In the second paragraph, explain what happens when there is not a } \\
\text { common element between the preferred and the contingent remedy as in } \\
\text { the case of the Warm Waste Pond Record of Decision. Will future RODs } \\
\text { be written such that a common element will exist between the two } \\
\text { remedies? }\end{array}$ & $\begin{array}{l}\text { This section has been revised and the inconsistency cited has } \\
\text { been eliminated. }\end{array}$ \\
\hline 49 & 3.5 .1 .1 & 15 & $\begin{array}{l}\text { Clarify the fourth sentence of the second paragraph, regarding the } \\
\text { meaning of "after the decision process". Is this "decision process" the } \\
\text { ROD? Is the Phase I SOW developed and approved prior to the ROD? }\end{array}$ & This section has been revised. \\
\hline 50 & 3.5 .2 & 16 & $\begin{array}{l}\text { Clarify the second sentence of the second paragraph regarding the } \\
\text { preparation of an RD/RA SOW preparation schedule. In the real world, } \\
\text { where last minute ROD changes are the rule, a schedule may change } \\
\text { faster than it can be updated. Starting SOW preparation early is a good } \\
\text { idea, but, the guidance must emphasize that the schedule for SOW } \\
\text { development should be general, informal and dynamic. }\end{array}$ & Comment incorporated. \\
\hline 51 & 3.5 .2 & 16 & $\begin{array}{l}\text { The phrasing of the last sentence of the second sentence implies the } \\
\text { development of a deliverable. Emphasize that the "strategy" is informal } \\
\text { and dynamic and that it is built on teamwork and communication and not } \\
\text { documentation. }\end{array}$ & Comment incorporated. \\
\hline 52 & 3.5 .2 & 16 & $\begin{array}{l}\text { In the last paragraph, elaborate on what a Phase I SOW is and when it is } \\
\text { employed. Indicate whether it finalized prior to the ROD. Clarify the } \\
\text { meaning of the second sentence in the last paragraph. Elaborate on the } \\
\text { content of a Phase II SOW. Explain the meaning of a "plan for a plan". }\end{array}$ & Discussion deleted based on other comments. \\
\hline 53 & 3.5 .2 & 16 & $\begin{array}{l}\text { Clarify the discussion of "phase I" and "phase "I" of the RD/RA SOW. } \\
\text { The idea is not sufficiently developed. }\end{array}$ & Discussion deleted based on other comments. \\
\hline
\end{tabular}




\begin{tabular}{|c|c|c|c|c|}
\hline ITEM & SECTION & PAGE & COMMENTS & RESOLUTION \\
\hline 54 & 4.1 & 17 & $\begin{array}{l}\text { In the second sentence of the last paragraph, clarify that it is up to the } \\
\text { WAG managers to decide how the RD and RAWP are configured and that } \\
\text { decision is documented in the RD/RA SOW. Provide examples to show } \\
\text { that they can be presented as separate documents, separate volumes, or } \\
\text { integrated into one document as one large submittal. Emphasize that this } \\
\text { configuration is at the disgression of the WAG Managers. }\end{array}$ & $\begin{array}{l}\text { Discussion has been expanded to clarify issues. In the interest } \\
\text { of brevity, examples were not included. }\end{array}$ \\
\hline 55 & 4.3 .1 & 18 & $\begin{array}{l}\text { In the second sentence of the first paragraph modify the phrasing to say } \\
\text { "may include" rather than "will typically include". Depending on how the } \\
\text { sOW schedule is developed, there may not be enough time available to } \\
\text { provide all of these elements in a preliminary design. Clarify that the } \\
\text { WAG Managers must identify and agree upon the critical components for } \\
\text { presentation in the preliminary design meeting and in the preliminary } \\
\text { design document. Emphasize that the list presented is simply a list of } \\
\text { things that might be considered for incorporation in the preliminary } \\
\text { design, but, all items are negotiable depending on schedules, complexity } \\
\text { of the project and other factors. }\end{array}$ & Comment incorporated. \\
\hline 56 & 4.3 .1 & 18 & $\begin{array}{l}\text { Add to the list of bullets "design criteria". Also add the word "drawings" } \\
\text { following "General Arrangements" in the second bullet. }\end{array}$ & Comment incorporated. \\
\hline 57 & 4.3 .2 & 18 & $\begin{array}{l}\text { In the first sentence of the first paragraph modify the phrasing to say } \\
\text { "may include" rather than "will typically include". Clarify that the WAG } \\
\text { Managers must identify and agree upon the critical components for } \\
\text { presentation in the Remedial Design. Emphasize that the list presented is } \\
\text { simply a list of things that might be considered for incorporation in the } \\
\text { design, but, all items are negotiable depending on schedules, complexity } \\
\text { of the project and other factors. }\end{array}$ & Comment incorporated. \\
\hline 58 & 4.3.2 & 18 & $\begin{array}{l}\text { Add to the list of bullets "design criteria". Also add the word "drawings" } \\
\text { following "General Arrangements" in the fourth bullet. }\end{array}$ & Comment incorporated. \\
\hline 59 & 4.3.2 & 18 & $\begin{array}{l}\text { Clarify the meaning of "permitting considerations" as identified in the } \\
\text { fourth bullet of this section and provide examples. Also provide a } \\
\text { discussion of ARARs presentation and the content of that presentation. }\end{array}$ & The discussion of ARARs has been revised and expanded. \\
\hline
\end{tabular}




\begin{tabular}{|c|c|c|c|c|}
\hline ITEM & SECTION & PAGE & COMMENTS & RESOLUTION \\
\hline 60 & 4.4 & 19 & $\begin{array}{l}\text { In the fourth sentence of the first paragraph modily the phrasing to say } \\
\text { "may include" rather than "will typically include". Clarify that the WAG } \\
\text { Managers must identify and agree upon the critical components for } \\
\text { presentation in the Remedial Action Work Plan. Emphasize that the list } \\
\text { presented is simply a list of things that might be considered for } \\
\text { incorporation in the work plan, but, all items are negogitiable depending on } \\
\text { schedules, complexity of the project and other factors. }\end{array}$ & Comment incorporated. \\
\hline 61 & 4.4 & 19 & $\begin{array}{l}\text { Provide additional discussion of "construction inspection hold points" } \\
\text { Explain how those points are identified and set. Clarify that those points } \\
\text { are dynamic and may tloat in time depending on the complexity of } \\
\text { various construction tasks, weather delays and other factors. }\end{array}$ & $\begin{array}{l}\text { Comment noted, but this is too much detail for the intent of } \\
\text { these bullets. }\end{array}$ \\
\hline 62 & 4.4 & 19 & $\begin{array}{l}\text { Replace "plan" in the seventh bullet with "procedures". The facility } \\
\text { landlords are responsible for "Emergency Plans" while the RD/RA } \\
\text { contractor would be responsible for "emergency procedures" that } \\
\text { complement the plan. }\end{array}$ & Comment incorporated. \\
\hline 63 & 4.5.1 & 20 & Delete "etc" from the third sentence of the first paragraph of this section. & Comment incorporated. \\
\hline 64 & 5.3.1 & 21 & $\begin{array}{l}\text { In the first sentence of this section, replace "startup test programs" with } \\
\text { "startup test procedures". }\end{array}$ & Comment incorporated. \\
\hline 65 & 5.4 .1 & 22 & $\begin{array}{l}\text { In the last bullet suggest including "The completed Prefinal Inspection } \\
\text { Checklist with signatures, dates, and compliance action may be included } \\
\text { as an appendix to the RA Report." }\end{array}$ & Comment incorporated. \\
\hline 66 & 7.3.1 & 26 & Clarily the meaning of the term "off normal". & The term off-normal has been replaced by "unexpected". \\
\hline 67 & 7.4.1 & 27 & $\begin{array}{l}\text { Provide more information regarding when the O\&M report is developed. } \\
\text { Clarify whether it is developed during the O\&M phase or during D\&D. } \\
\text { Elaborate on the types of action levels that might triger the preparation } \\
\text { of an O\&M report and indicate where those action levels would be } \\
\text { identified. Indicate that it might not always be appropriate to develop an } \\
\text { O\&M report and provide examples of situations where an O\&M report } \\
\text { may not be necessary fi.e. cappingl. Emphasize that the timing, content } \\
\text { and need for an O\&M report will be decided by the WAG Managers and } \\
\text { documented in the RD/RA SOW. }\end{array}$ & Comment incorporated. \\
\hline
\end{tabular}




\begin{tabular}{|l|l|l|l|l|l|}
\hline ITEM & SECTION & PAGE & \multicolumn{1}{|c|}{ COMMENTS } & RESOLUTION \\
\hline 68 & 8.2 .1 & 28 & $\begin{array}{l}\text { Clarify which contractor organization lassessment or RD/RA) is } \\
\text { responsible for the activities identified in the third bullet. Clarify whether } \\
\text { these activities are conducted before or after the Record of Decision is } \\
\text { signed. Explain how these treatability studies influence organizational } \\
\text { interfaces and information exchanges. }\end{array}$ & $\begin{array}{l}\text { Comment incorporated later in the example because it was too } \\
\text { much detail to include in the bullet. }\end{array}$ \\
\hline 69 & 8.2 .3 & 31 & $\begin{array}{l}\text { For this relatively simple and straight forward project, explain in the } \\
\text { discussion on compliance with ARARs how the information on ARARs } \\
\text { implementation differs from that which should have been provided in the } \\
\text { RD/RA SOW. }\end{array}$ & Comment incorporated. \\
\hline 70 & 8.2 .3 & 31 & $\begin{array}{l}\text { The last sentence of the third paragraph is not completely accurate. } \\
\text { OSHA's regulations require annual medical surveillance under 1910.120. } \\
\text { Although the OMP meets the 1910.120 requirements, it is a DOE } \\
\text { requirement. Suggest revising to separate the DOE requirements trom } \\
\text { OSHA requirements as follows "The workers were also required to be } \\
\text { under an Occupational Medical Program in order to work on the remedial } \\
\text { action." }\end{array}$ & Comment incorporated. \\
\hline & & & & \\
\hline
\end{tabular}




\section{IDHW COMAENTS ON \\ REMEDIAL DESIGN REMEDIAL ACTION GUIDANCE DOCUMENT}

1) Section 1.1

page 1,

The document is tied to the existing INEL FFA/CO. Per chance the Keystone Agreement causes the agreement to be renegotiated would this guidance remain in effect?

Response: This comment is not within my power to answer.

2) Section 1.2, Definition of Terms

page 2,

Please expand and clarify the definitions of: Remedial Action, Remedial Design, Operation and Maintenance, Shakedown and Project closeout. Please do not define these items in terms of each other.

Please also define the following: Oversight, Title 1, Title 2 and Title 3 .

Response: comment noted and portions incorporated to the extent practicable. Title I, II, and III have been added.

3) Section 2.1 First Bullet page 3,

Please clarify "agreement" (first bullet item) with more specificity (e.g., ROD, FFA/CO).

Response: Comment incorporated.

4) Section 2.2, Remedial Action/Remedial Design Process pages 4 and 5 ,

Please expand and clarify the purpose of the RD/RA contractor during the FS scoping process.

Response: Comment incorporated.

5) Section 2.3, WAG Manager Roles and Responsibilities page 5,

Please clarify on what is meant by "... does not dilute the accountability of DOE-ID contractors performing the work." "Diminish" may be more appropriate.

Response: Paragraph has been deleted because it was beyond scope of document. 
6) Section 2.4, Project Scoping page 6 ,

First bullet, these issues should be discussed and clarified during the Record of Decision process.

Response: While this comment is true, it is still something to be looked at during project scoping.

7) Section 2.4, Project scoping

page 7 , first paragraph,

Recommend that scope and comment should be agreed to, in part, but document format can be left during this phase of project scoping.

Response: Comment incorporated.

8) Section 2.5, Document Reviews page 7 ,

Please rephrase first bullet item to clarify the last sentence. For the first bullet refer back to the definitions of Oversight (Section 1.2 , page 1, Definition of Terms). It should be up to each agency and their WAG Manager to determine what is of priority importance to review.

Response: Comment incorporated.

9) Section 2.7, Disposition of Changed Conditions page 9 , item 1,

Please clarify what is meant by Uncertainty Management. Also, please provide DOE-ID's "SAFER" model and SACM in appendices to this document.

Response: Comment noted, and uncertainty management will be defined. The models will be provided to IDHW in lieu of putting them in Appendices to this document.

10) Section 2.7, Disposition of Changed Conditions page 9, item 3, second bullet,

Please change $+/-150 \%$ variance of estimate provided in the ROD to $+50 \%,-30 \%$ of ROD estimate.

Response: Comment incorporated.

11) Section 2.7, Disposition of Changed Conditions page 9 , item 3 , third bullet 
Suggest the following: "Changes that require modifications to all documents ( i.e., primary documents, secondary documents, etc.), and..." rather than primary documents exclusively.

Response: Comment incorporated.

12) Section 3.1, Purpose

page 11,

The statement is made that if all of the design phase planning cannot be incorporated into the RD/RA SOW, the RD Work Plan should be submitted as a combined document with the RD/RA SOW. This may work in some instances, but may cause problems in meeting the 21 day post ROD requirement when the sow is delayed until the RD Work Plan is completed. Suggest that for complex sites, the RD Work Plan may need to be submitted as a separate document.

Response: Comment incorporated.

13) Section 3.2 Background page 11,

If the RD/RA SOW and RD/RA Workplan are not a secondary document, but subject to dispute resolution are they then, by default a primary document?

Response: The RD/RA SOW retains its unique designation and the RD Work Plan is still a secondary document.

14) Section 3.3.3, Plans to Expedite RD/RA

page 12,

Shortening the review periods may not be the only factor in expediting the RD/RA process. Document quality will have a direct bearing on the timeliness and effectiveness of the review process (e.g., first drafts need to be a better quality).

Response: This goes without saying.

15) Section 3.3.12 RD Cost Estimate page 14,

Please address whether the cost estimate in the ROD includes the RD costs. Because the RD cost estimate will be satisfied through section 28 , it is assumed that no cost estimate figures will be included in the RD Work Plan, please clarify. Also, please clarify what is meant by this paragraph; section 28 only speaks of DOE legal requirement to obtain adequate funds to implement the FFA/CO. 
Response: The original text from the earlier version of the guidance will be put back into this section. The cost estimate in the ROD should include RD costs, but this section pertains to the RD/RA SOW and not to the ROD. Early involvement by the RD/RA contractor should ensure that the costs in the ROD reflect the actual work planned.

16) Section 4.3.1, Preliminary Design

page 18, second bullet,

Please clarify "General arrangements" by possibly adding "of equipment and apparatus" to indicate that layout drawings showing placement and arrangement of treatment equipment, etc. should be included.

Response: Comment incorporated.

17) Section 4.4, Elements of Remedial Action Work Plan page 19, third bullet,

Please add, "including rationale for the various tasks".

Response: Comment incorporated.

18) Section 4.4, Elements of Remedial Action Work Plan page 20 , third bullet,

As above please add, "including rationale for the selection of each measurement point".

Response: Comment incorporated.

19) Section 4.5.1 Logistics

page 20 ,

Please clarify why final design submittals are omitted in the first paragraph.

Response: Per FFA/CO direction the final design is called the draft final design. The draft final design automatically becomes the final design unless an issue causes one of the agencies to invoke dispute resolution.

20) Section 5.1, Purpose, Prefinal Inspection Report

page 21,

The statement is made that the "Project Managers" perform the prefinal inspection; this should be the WAG Managers?

Also, at the end of the paragraph that the report is signed by the FFA/CO Project Managers; this should also be the WAG Managers? Furthermore, it is suggested that signing (if realiy necessary) of the report does not mean that the 
"remediation will be considered complete", but rather, means that the objectives of the ROD have been met. This distinction is necessary, as remediation may not be complete if the action is an interim action and it is later decided (as a result of an RI/FS) that further remediation is necessary.

Response: "Or their designees" has been added to text. It was decided by the RD/RA committee in the seattle meetings in May that the PMs would not sign the report, so the text will be changed to reflect this, and phrasing will be changed to "objectives of the ROD have been met."

21) Section 5.3.1, Inspection Checklist page 21,

The document needs to clarify by who and when the inspection checklist is prepared.

Response: Comment noted, but this information is already included in Section 5.4.1.

22 Section 6.3.3, Certification that the Remedy is operational and Functional

page 24,

Please further clarify how DOE-ID will certify that the remedy is achieving or has achieved the requirements of the ROD (i.e., does it require the involvement of an independent third party? If so, provide an example of when third party involvement would be necessary as opposed to a situation that wouldn't.) How is "certification" actually achieved?

Response: Discussion has been expanded to incorporate comment.

23) Section 6.3.5, Results of Final Inspection page 25 ,

Normally, when a RA Report is provided it is due 60 days following the final inspection. If no final inspection is necessary, then when would the RA report be due? This seems important since the $R A$ report is considered a primary document.

Response: Text will be clarified to state that there will always be a final inspection and it will be done 60 days before the RA Report.

24) Section 6.4.1 Logistics, Remedial Action Report process page 25, 
The statement that the RA Report may be used at the completion of simple projects implies that more than one RA Report may be submitted for a single overall project. Since the RA Report is a primary document, it is suggested that calling the reports for multiple simple projects something other that a RA Report in order to avoid confusion.

Response: The intent was not to imply more than one RA Report. This has been clarified.

25) Section 7.3.3, Verification that the Remedy Meets Performance Criteria

page 26,

Please define how DOE-ID verifies that the remedial action is in compliance with the RAO's specified in the ROD. Some suggestions or ideas may be helpful here.

Response: Comment incorporated.

26) Section 7.4.1, Logistics, Operation and Maintenance Report Process

page 27,

Last paragraph states that "during the review of the report, the agencies will use information provided in the report to make a major decision concerning remedy implementation." Please clarify what "major decision" is being made, or provide examples.

Response: Comment incorporated. 


\section{U.S. ENVIRONMENTAL PROTECTION AGENCY \\ REGION 10, SEATTLE, WASHINGTON}

COMMENTS ON THE REMEDIAL DESIGN/REMEDIAL ACTION GUIDANCE DOCUMENT FOR THE IDAHO NATIONAL ENGINEERING LABORATORY, REVISION 0

1. Section 2.2 , page 3

Given the confusion often associated with the definition of RA start, it would be useful to describe the flexibility associated with determining $R A$ start and to provide several examples of work and/or contractual start activities.

Response: This information was incorporated in a earlier version. It was deleted by consensus of the RD/RA committee at the seattle meetings in May.

2. Figure 2-1

For clarification, it would be useful to identify parallel activities, such as the SAR, that have the potential to impact the overall RD/RA process.

Response: The figure has been revised but, by agreement of the RD/RA committee, it does not include anything but FFA/Co documents.

3. Section 2.4 , page 6 , Item 1

Presumptive remedies for sites with similar characteristics, such as types of contaminants, types of disposal practices, or how environmental media are affected, should be included as part of the feasibility study discussion.

Reference materials for presumptive remedies include the following:

- Presumptive Remedies: site Characterization for Volatile Organic Compounds in Soils, Publication 9355.4-04FS, February 1993.

- Streamlining the RI/FS for CERCLA Municipal Landfill sites, Publication 9355.3-11FS, September 1990

Response: Comment incorporated.

4. Section 2.5 , page 7 
For clarity, the time frame for document reviews should be identified, as well as how response to comments will be addressed regarding secondary documents and technical memorandums (e.g., errata sheet, letter, or reissue).

Response: Document reviews are specified in the FFA/CO and the tech memo discussion has been revised.

5. Section 2.7 , page 9, Item 1 and page 10 , Item 6

The necessity for and scope of contingency planning (as distinguished from changes that fall within the normal scope of changes occurring during the RD/RA engineering process) should be clarified.

Response: The level of detail requested is not appropriate for the guidance document.

6. Section 2.7 , page 10 , Item 6

It should be stated that DOE will be responsible for expeditiously identifying all non-CERCLA activities that have the potential to adversely impact CERCLA activities.

Response: Comment incorporated.

7. Section 3.3 .12 , page 14

Section 28 of the FFA/CO would not provide the level of detail appropriate for an RD cost estimate within the context of a specific action. Therefore, preliminary cost estimates should be included in the RD/RA SOW.

Response: Comment incorporated.

8. Section 6.3 .6 , page 25

A discussion of the D\&D Program should be included. This may include a description of the decommissioning modes and the requirements and schedules associated with each.

Response: The discussion of D\&D activities is beyond the scope of this guidance, but this section will be revised to clarify that the D\&D being discussed is only for the RA.

9. Section 6.3 .7 , page 25

Technical requirements to determine completion of Superfund sites and the subsequent procedural requirements for deleting sites from the NPL should be discussed. Refer to attached OSWER Guidance 9320.2-2, 9320.2-3A,-3B, and -3C, and memorandum dated November 14,1989 for guidance. 
In particular, the discussion should address the relationships of sites within WAGs and WAGS within INEL, and the necessity for building and preserving a meaningful data base to eventually support the delisting of INEL.

Response: Comment not incorporated based on discussions at the Seattle meetings in May. It was agreed that delisting of the INEL is far enough in the future that any discussion on this topic would be highly speculative.

10. Section 6.3 .8 , page 25

Implementation of five-year reviews and the issues associated with implementation should be discussed. Refer to attached OSWER Directive (9355.7-02) for guidance.

Response: comment not incorporated based on discussions at the seattle meetings in May. It was agreed that five year reviews of any of the remedial action sites is far enough in the future that any discussion on this topic would be highly speculative.

11. Section 7.3 .3 , page 26

Verification that the remedy achieved performance should involve all parties, as opposed to solely DOE-ID. Moreover, the basis for verification should be established and agreed to by all parties prior to o\&M.

Verification should include the approach for determining success (e.g. trend analysis), and should be closely coordinated with long-term O\&M monitoring requirements.

Response: comment partially incorporated. The guidance says that DOE-ID "documents" the verification, not that they are the only party involved. See the discussion for performance standards and certifications. 